MARIA CLÁUDIA SANTIAGO HAMPSHIRE

O MODELO DO SISTEMA VIÁVEL NA CONCEPÇÃO

DA ARQUITETURA DE SISTEMAS DE INFORMAÇÃO:

APLICAÇÃO NO CONTEXTO DE INCIDENTES

EM INSTALAÇÃO DE PESQUISA NA ÁREA NUCLEAR

São Paulo

2008 
MARIA CLÁUDIA SANTIAGO HAMPSHIRE

O MODELO DO SISTEMA VIÁVEL NA CONCEPÇÃO

DA ARQUITETURA DE SISTEMAS DE INFORMAÇÃO: APLICAÇÃO NO CONTEXTO DE INCIDENTES EM INSTALAÇÃO DE PESQUISA NA ÁREA NUCLEAR

Dissertação apresentada à Escola

Politécnica da Universidade de São Paulo para obtenção do título de Mestre em Engenharia.

São Paulo 


\section{O MODELO DO SISTEMA VIÁVEL NA CONCEPÇÃO \\ DA ARQUITETURA DE SISTEMAS DE INFORMAÇÃO: \\ APLICAÇÃO NO CONTEXTO DE INCIDENTES \\ EM INSTALAÇÃO DE PESQUISA NA ÁREA NUCLEAR}

Dissertação apresentada à Escola

Politécnica da Universidade de São Paulo para obtenção do título de Mestre em Engenharia.

Área de Concentração: Departamento de Engenharia Naval e Oceânica.

Orientador: Prof. Dr. Mardel Bongiovanni de Conti. 
Este exemplar foi revisado e alterado em relação à versão original, sob responsabilidade única do autor e com a anuência de seu orientador.

São Paulo, de dezembro de 2008.

Assinatura do autor

Assinatura do orientador

\section{FICHA CATALOGRÁFICA}

Hampshire, Maria Cláudia Santiago

O Modelo do sistema viável na concepçāo da arquitetura de sistemas de informaçāo: aplicaçāo no contexto de incidentes em instalaçāo de pesquisa na área Nuclear / M.C.S. Hampshire. -ed.rev. -- São Paulo, 2008.

p.

Dissertaçāo (Mestrado) - Escola Politécnica da Universidade de São Paulo. Departamento de Engenharia Naval e Oceânica.

1. Tecnologia da informaçāo 2.Sistemas de informaçāo (Arquitetura) 3.Segurança nuclear I.Universidade de Sāo Paulo. Escola Politécnica. Departamento de Engenharia Naval e Oceânica II.t. 


\section{DEDICATÓRIA}

Para meus pais,

meus irmãos Kiko e Aninha, e meus amores Paulinho, Leo e Paulinha. 


\section{AGRADECIMENTO}

Ao Prof. Dr. Mardel Bongiovanni de Conti, meu orientador, pela competência profissional, paciência e atenção a mim dedicada, e que, muito além de suas funções acadêmicas, se mostrou um companheiro e grande amigo.

À minha família que, durante todo o período de desenvolvimento deste trabalho, me deu apoio incondicional e amor.

Aos meus amigos queridos, que sempre me deram carinho, apoio e incentivo para a realização deste empreendimento. 


\section{EPÍGRAFE}

Não devemos nos acostumar com a lógica de um mundo em que os meios e os fins se divorciaram.

Da mesma forma, não podemos sucumbir ao sistema de poder que divorcia a mão humana do fruto de seu trabalho, que obriga o perpétuo desencontro da palavra e do ato, que esvazia a realidade de sua memória e faz cada pessoa competidora e inimiga das demais. Já é hora de voltarmos os olhos para as coisas de real valor.

O formalismo dominante deve abrir espaço para a justiça.

A ética deve permear toda conduta, diariamente. Seremos compatriotas e contemporâneos de todos os que tenham aspiração de justiça e de beleza, tenham nascido onde tenham nascido e tenham vivido quando tenham vivido, sem que importem nem um pouco as fronteiras do mapa ou do tempo.

Caminhando nesse sentido, e somente assim, é que a ciência cumprirá com responsabilidade

o papel destinado a ela pela sociedade, e agirá como verdadeiro instrumento de mudança, descortinando a quem tiver os olhos abertos, o esplêndido leque de outra realidade possível.

Mário José D. S. Santiago, meu querido irmão (2008). 


\section{RESUMO}

O trabalho apresenta um estudo com a finalidade de verificar a aplicabilidade do Modelo do Sistema Viável (VSM - Viable System Model) no projeto de uma arquitetura robusta de um Sistema de Informação voltado à área naval nuclear.

A ênfase do estudo está em avaliar uma modelagem alternativa para a especificação da arquitetura do Sistema de Informação, incorporando o conjunto de funcionalidades especificadas pelo VSM, com o objetivo de fortalecer esta arquitetura.

A estratégia desta pesquisa baseia-se em uma revisão bibliográfica relacionada ao VSM, aos Sistemas de Informação e a sua arquitetura, e às influências destes elementos na sobrevivência das organizações diante das mudanças constantes no ambiente.

É apresentado um estudo de caso onde são mostrados os elementos teóricos do VSM e da arquitetura de SI aplicados na elaboração da arquitetura de um SI. O Sistema escolhido para esta aplicação é o Sistema de informação de incidentes nucleares (SIN) nas instalações onde são feitas pesquisas e desenvolvimento de tecnologia nuclear a ser aplicada na propulsão de um submarino.

Palavras chave

Modelo do Sistema Viável (VSM), Cibernética Organizacional, Tecnologia da Informação (TI), Sistemas de informação (SI), Arquitetura de Sistemas de Informação, Sistema de Qualidade e Segurança Nuclear. 


\begin{abstract}
The present work presents a study aiming to verify the applicability of the Viable System Model (VSM) in a robust architecture for an Information System targeting nuclear naval area.

The emphasis of the study is in assessing an alternative modeling for the Information System (IS) architecture specification, incorporating a set of functionalities defined by the VSM, with the purpose of strengthening this architecture.

The strategy of this research is based on a bibliographic revision on VSM, Information System and its architecture, and the influence of those elements in the survival of the organizations in a ever changing environment.

It is presented one case study where it is showed the theoretical elements of the VSM and IS architecture applied on the development of a IS architecture. The selected system for this application is the IS for nuclear incidents (SIN) on the installations dedicated to research and development on nuclear technology applied to submarine propulsion system.
\end{abstract}

Keywords:

Viable System Model (VSM), Cybernetic Organization, Information Technology, Information Systems, Information System Architecture, Nuclear Safety and Quality System. 


\section{LISTA DE FIGURAS}

Figura 1 - O contexto do presente estudo está inserido no cenário do projeto 8

Figura 2: Os cinco elementos a serem considerados na Arquitetura de Sistemas......9 Figura 3 - VSM: Representação das cinco funcionalidades necessárias e suficientes

Figura 4 - Contexto deste trabalho: SI de incidentes nucleares + aplicação dos conceitos do VSM = verificação da aplicabilidade do VSM na definição de uma arquitetura de $\mathrm{SI}$

Figura 5 - Classificação das pesquisas acadêmicas. Fonte Vergara (2007). .22

Figura 6 - As quatro fases do controle. Fonte: (CHIAVENATO, 2004). 30

Figura 7 - Lei da variedade Requerida. Fonte: Adaptação (ASHBY, 1970). .33

Figura 8 - Modelo esquemático de um sistema geral de comunicação 35

Figura 9 - Visão das funcionalidades do VSM baseada no diagrama original de Beer

Figura 10 - Dimensões recursivas de um sistema viável .43

Figura 11 - Esquema geral de um Sistema de Informação - Fonte: (LAUDON \& LAUDON, 2002). .44

Figura 12 - Hierarquia da engenharia de Sistemas - Fonte: (PRESSMAN, 2002)....45 Figura 13 - O domínio dos Sistemas de Informação. Fonte: adaptação de (LAUDON \& LAUDON, 2002) 46

Figura 14 - Relação de recursividade ente recursos de TI e re-planejamento do negócio organizacional. Fonte: (DAVENPORT \& SHORT, 1990). 48

Figura 15: Arquitetura integrada. Fonte: Scheer,1992. .49

Figura 16 - Visão de arquitetura integrada - Organização, dados, controle e função.

Figura 17 - Visões de uma arquitetura de sistema de informação simplificada .50

Figura 18 - Modelo proposto por Davenport: 5 passos para o re-planejamento de uma organização 52

Figura 19 - Modelo seqüencial linear. Fonte: (PRESSMAN, 2002) ….....................53

Figura 20 - Modelo incremental. Fonte: (PRESSMAN, 2002) . .................................54

Figura 21 - Típico modelo de espiral. Fonte (PRESSMAN, 2002) ..........................54

Figura 22 - Sistema de gestão de radioproteção e da segurança, representado como 
um Sistema Viável, onde o sistema o SIN é uma das suas unidades organizacionais.

Figura 23 - Esboço da organização como sistemas aninhados sob o ponto de vista do sistema de interesse 60

Figura 24 - Interação do SI de incidentes nucleares com o meio ambiente - Fase 1. .66

Figura 25 - Legenda dos símbolos utilizados. .66

Figura 26 - O SI interage com o meio externo através de objetos construídos para fazer a interface ente eles.

Figura 27 - Primeiro cenário: SI de incidentes nucleares contido no Sistema de gestão de radioproteção e da segurança 69

Figura 28 - SIN faz parte do Sistema de gestão de radioproteção e da segurança .70

Figura 29 - Nível de recursão imediatamente superior .71

Figura 30 - Níveis de recursão paralelos. .73

Figura 31 - Nível de recursão imediatamente Inferior. .74

Figura 32 - Segundo cenário - SI de incidentes nucleares visto como um sistema viável 


\section{LISTA DE QUADROS}

Quadro 1 - Aspectos e características do SIN relativos à organização onde está inserido.

Quadro 2 - Aspectos e características do SIN relativos ao negócio onde está inserido

Quadro 3 - Aspectos e características do SIN relativos aos SI onde está inserido ...63

Quadro 4 - Aspectos e características do SIN relativos a TI onde está inserido .64

Quadro 5 - Aspectos e características do SIN relativos aos usuários .65

Quadro 6 - Interface entre o SIN e o SGA .75

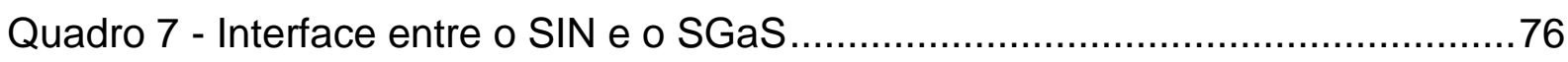

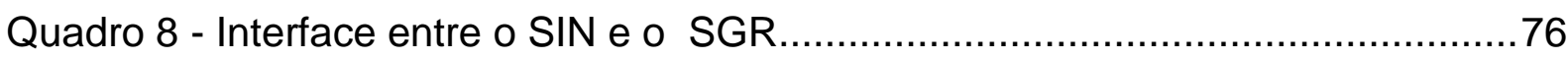

Quadro 9 - Interface entre o SIN e o Sistema SGeS..........................................77

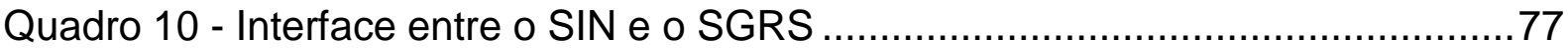

Quadro 11 - Interface entre o SIN e o Sistema de radioproteção e segurança (SRG) .82

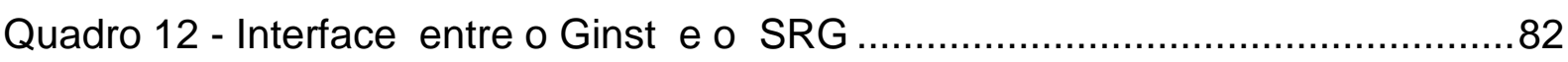

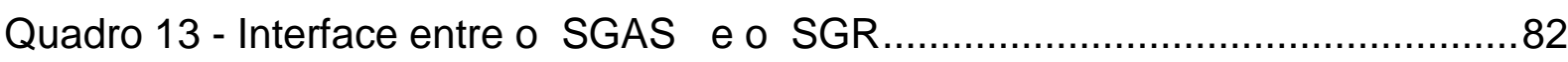

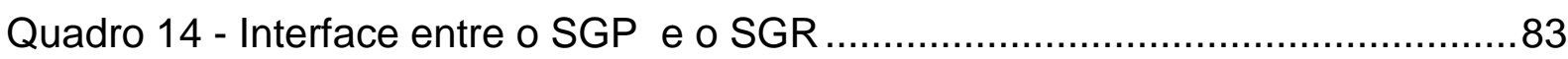

Quadro 15 - Interface entre o GN e as outras unidades organizacionais ................83

Quadro 16 - Interface entre o SIN e as outras unidades organizacionais ..................83

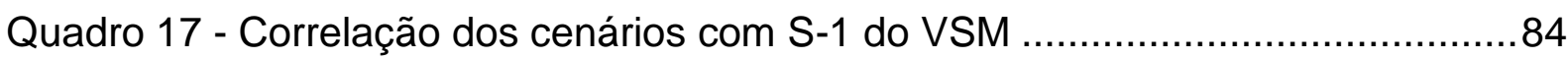

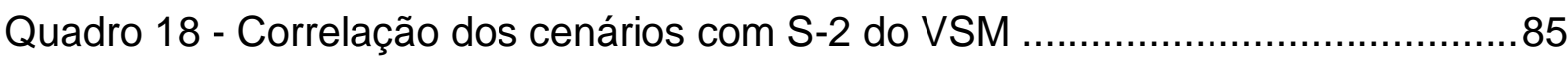

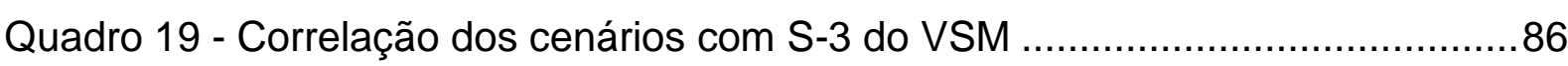

Quadro 20 - Correlação dos cenários com S-4 do VSM ......................................87

Quadro 21 - Correlação dos cenários com S-5 do VSM .......................................89

Quadro 22 - Resumo dos resultados numa visão por funcionalidades do VSM .......94

Quadro 23 - Resumo dos resultados numa visão por aplicação da recursividade ...95 


\section{LISTA DE ABREVIATURAS E SIGLAS}

$\mathrm{BI} \quad$ Business Intelligence

MB Marinha do Brasil

MCT Ministério da Ciência e Tecnologia

PWR Reator Experimental de Água Pressurizada (Pressurized Water Reator)

SI Sistema de Informação

SIN SI de incidentes nucleares

SNA Submarino Nuclear de Ataque

TGS Teoria Geral dos Sistemas

TI Tecnologia da Informação

UML Unified Modeling Language

VSM Viable System Model (Modelo de Sistema Viável) 


\section{SUMÁRIO}

1. Introdução 1

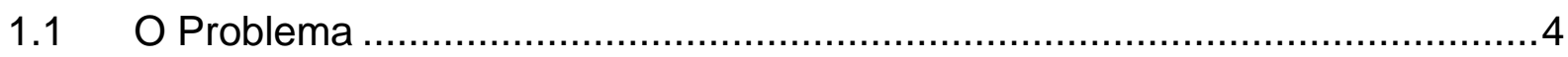

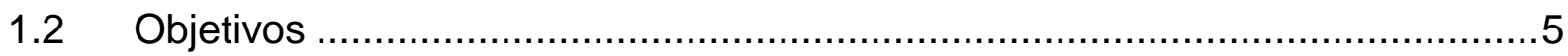

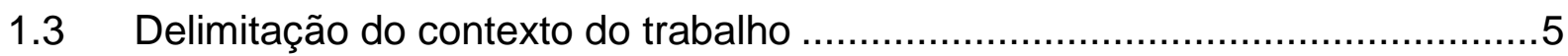

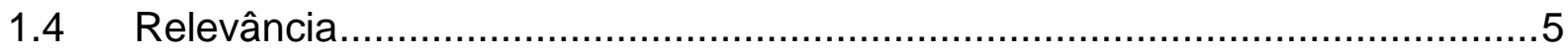

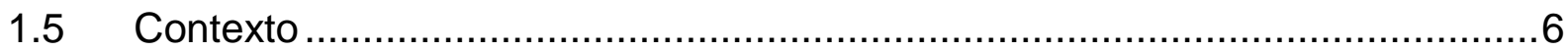

1.5.1 Projeto de pesquisa e desenvolvimento de tecnologia naval nuclear.............6

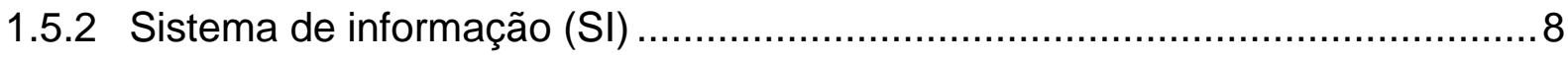

1.5.3 Modelo do Sistema Viável (Viable System Model - VSM) ...........................9

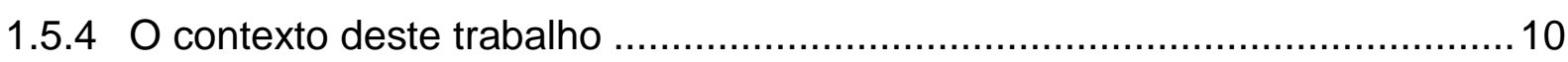

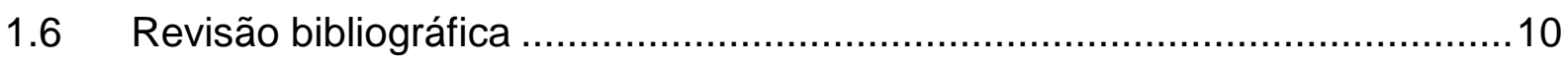

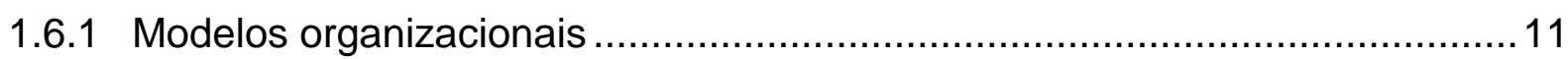

1.6.2 Cibernética e o modelo de sistema viável - VSM .................................... 13

1.6.3 Tecnologia da Informação no contexto organizacional...............................16

1.6.4 Arquitetura de Sistemas de Informação (SI) ......................................... 18

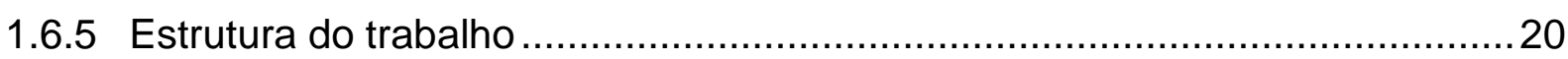

2. Metodolgia 22

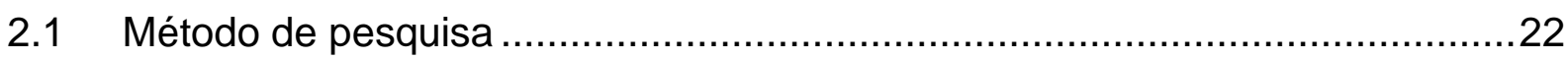

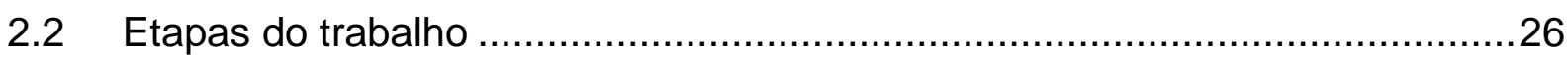

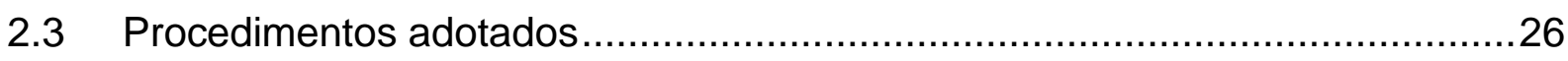

$\begin{array}{ll}3 . & \text { Fundamentos } \\ & 28\end{array}$

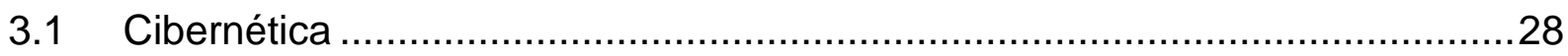

3.1.1 Sistemas, complexidade e conceito de "caixa-preta" ...............................28

3.1.2 Controle, auto-regulação, homeostase e a lei da variedade requerida ..........29

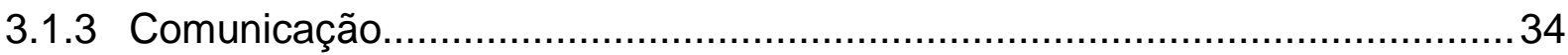

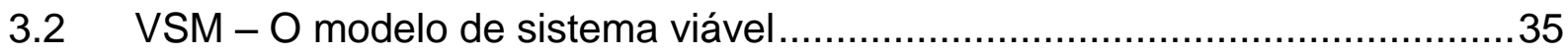

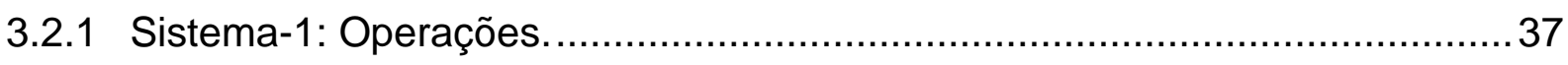

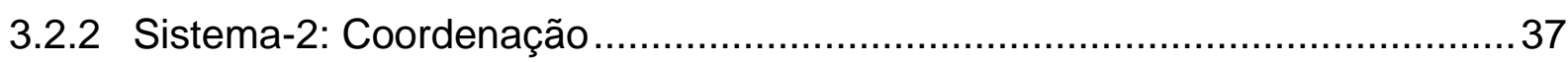




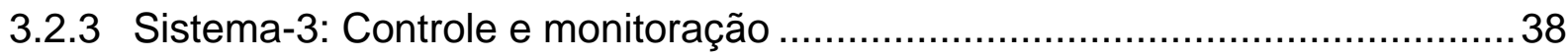

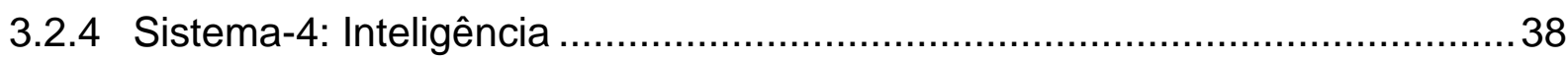

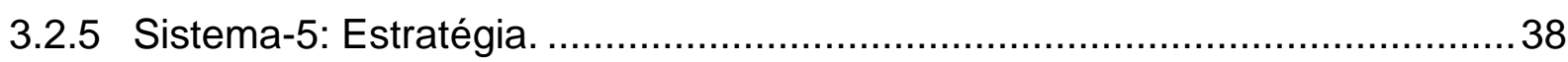

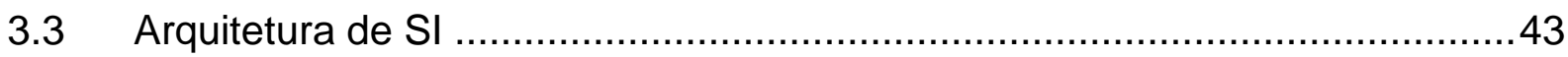

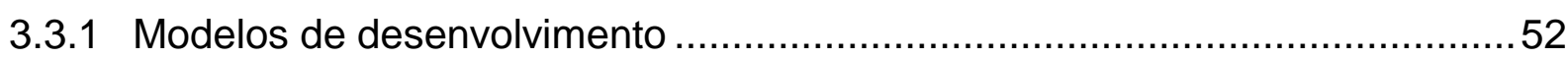

4. Estudo de caso 58

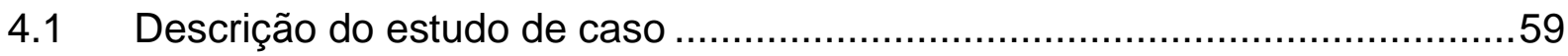

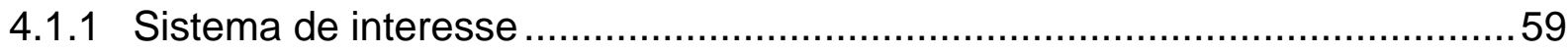

4.1.2 Atividades de levantamento de informações para a modelagem ...................59

4.1.3 Instrumentos utilizados para a modelagem …….......................................59

4.1.4 Recursividade utilizada para identificar o foco .........................................59

4.1.5 Mapeamento entre os componentes da arquitetura de SI e os elementos do

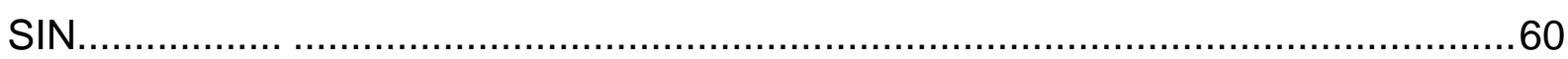

4.1.6 Caixa preta utilizada para detalhar os processos .........................................65

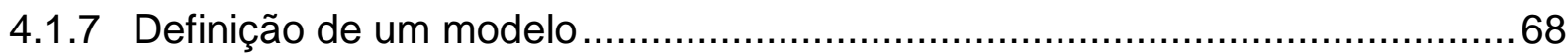

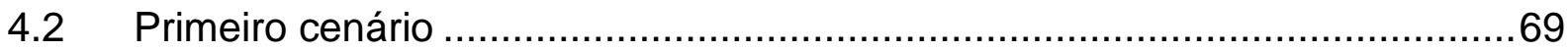

4.2.1 Descrição constitutiva das partes ....................................................... 70

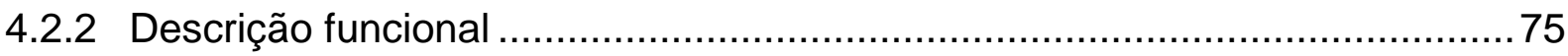

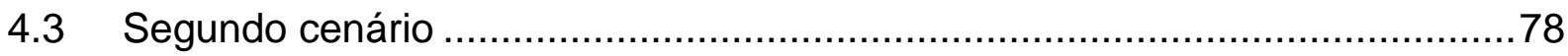

4.3.1 Descrição constitutiva das partes do SI de incidentes.................................78

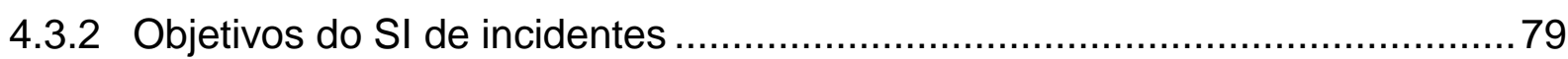

4.3.3 Definição de incidentes no contexto deste trabalho ......................................79

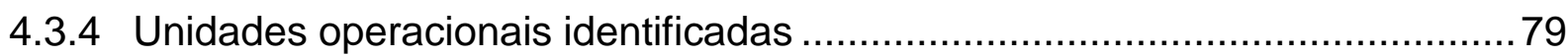

4.3.5 Descrição funcional: Interface entre as unidades operacionais e o sistema

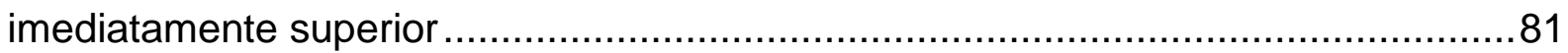

4.3.6 Descrição funcional: Interface entre as unidades operacionais.....................83

4.4 Correlação de níveis do sistema de interesse e o VSM ................................84

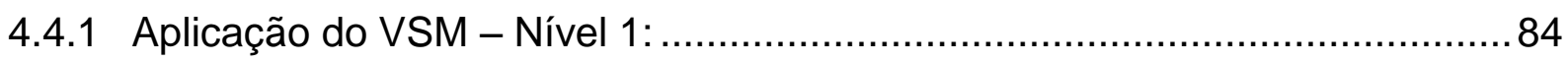

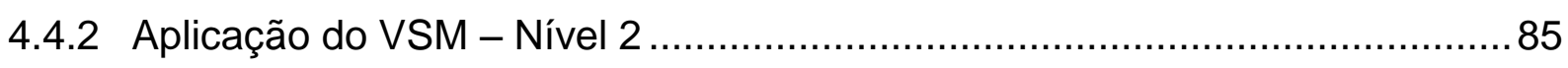

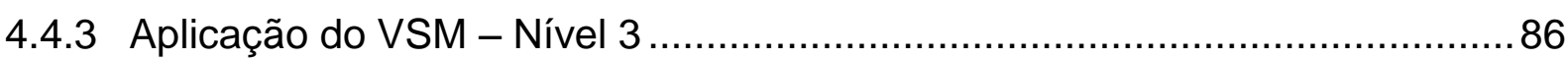

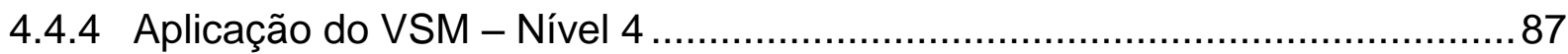

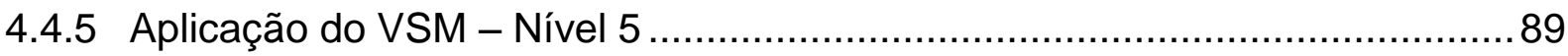


5. Resultados.

Erro! Indicador não definido.

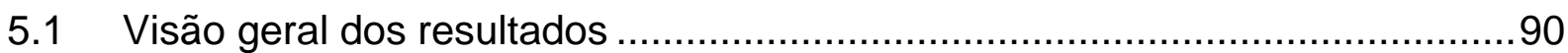

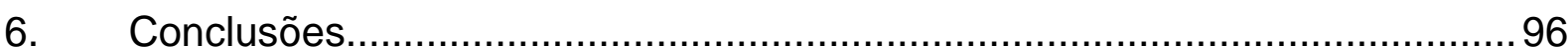

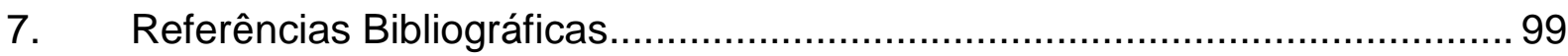




\section{INTRODUÇÃO}

O princípio do século XXI tem se caracterizado pela globalização e a emergência da sociedade do conhecimento. Ao contrário das antigas inovações, que tinham uma tendência a conceder uma vantagem competitiva duradoura ao inovador, muitas tecnologias da era da informação são igualmente acessíveis a todos os competidores. A diferença entre os competidores não é quem possui a tecnologia, mas aquele que a emprega melhor (JANTZEN, 2001).

Neste contexto de globalização e competição em mercados complexos, as organizações, para se manterem, são obrigadas a efetuarem mudanças de objetivos, missão, valores ou processos. Muitas vezes é exigida a ampliação de seus produtos e serviços, além da redefinição da sua estrutura política e administrativa (CURVELLO, 1996).

No panorama atual, onde o meio ambiente experimenta uma complexidade crescente, a inteligência organizacional no sentido de previsão, adaptabilidade e aprendizagem é fator que torna-se cada vez mais crítico para que as organizações sobrevivam e se desenvolvam. "A cibernética fornece modelos eficazes para vencer este desafio chave" (SCHWANINGER M. , 1998).

O ritmo acelerado das mudanças no ambiente impulsiona as mudanças nos processos de gerenciamento de projetos uma vez que, para se manter na dianteira, é necessário aperfeiçoar a eficácia dos sistemas existentes, além de procurar soluções para os novos problemas e estratégias para diferenciá-las das demais (BATTAGLIA, 1999).

O cenário de transição provocado pela alta competitividade do mercado exige das organizações respostas mais rápidas. É mandatória a necessidade de se obter informação, seja para avaliar a posição em relação à concorrência, seja para se manterem competitivas, que é condição elementar para a sobrevivência das organizações modernas. 
As organizações têm buscado apoio em Sistemas de Informação (SI) que passaram a ser ferramenta estratégica para o planejamento, coordenação e controle interno, além do acompanhamento do mercado em relação aos concorrentes, aos aspectos econômicos, legais, políticos e culturais em nível global(REINHARD, 1996).

Esta nova realidade tem determinado cada vez mais a aplicação de recursos em Tecnologia da Informação (TI). Estes investimentos incluem o SI e a infra-estrutura que lhe fornece suporte: o hardware, a infra-estrutura de redes, os recursos humanos qualificados e os mecanismos de segurança ${ }^{1}$ (LAUDON \& LAUDON, 2002).

Os investimentos em $\mathrm{TI}$ devem ser acompanhados das mudanças necessárias nas características organizacionais. A transformação organizacional decorrente do uso da $\mathrm{TI}$ deve ser ponderada quanto aos benefícios desejados e quanto aos custos decorrentes das mudanças organizacionais necessárias para a utilização da tecnologia. Os benefícios do uso da $\mathrm{TI}$ são marginais se forem simplesmente impostos nas condições organizacionais já existentes, especialmente estratégia, estruturas, processos e cultura (VENKATRAMAN, 1994).

É inegável o impacto organizacional causado pela TI. Uma vez que a coordenação de tarefas e de processos, além da fluidez de informações, é determinante para a estrutura da organização, e que esta é formada por pessoas, fica clara a natureza interativa do processo de mudança (ZANELA, MACADAR, \& SOARES, 1999).

As organizações públicas também passam por efetivas modificações em sua estrutura organizacional devido às exigências de serviços de qualidade, eficiência e também pelos moldes impostos pelo neoliberalismo. Os SI que normalmente

\footnotetext{
${ }^{1}$ Mecanismos de segurança devem ser entendidos de duas formas: segurança da informação e segurança de funcionamento do próprio sistema. Segurança da informação pode ser definida como uma área do conhecimento dedicada à proteção de ativos da informação contra acessos não autorizados, alterações indevidas ou sua indisponibilidade (Semola, 2003) e (NBR ISO/IEC 17799, 2001). Segurança de funcionamento de sistemas é a capacidade de um sistema cumprir com sucesso sua missão para o qual foi concebido, sem que ocorram eventos com conseqüências indesejáveis tanto para os componentes do próprio sistema, como para o ambiente onde o sistema interage(Leveson, 1995),(Herrmann, 1999) e (GUIMARAES, 2003).
} 
atendem ao mercado com pouca customização não se adequam às exigências e peculiaridades do setor público. Alguns fatores inerentes ao setor público também devem ser levados em conta, tais como: rotatividade de pessoal, o que implica em ausência de continuidade e responsabilidade, desmotivação dos recursos humanos, defasagem tecnológica, a falta de recursos, entre outros. Segundo Ortolani (1997), na organização pública somente é possível fazer o que está previsto na legislação; na organização privada, é permitido fazer tudo o que não é proibido pela legislação.

Para a construção de um SI que atenda às necessidades únicas de cada organização, é necessário levantar os requisitos, analisar os problemas da organização e verificar seu relacionamento com o SI existente, avaliar as necessidades de informação das pessoas, bem como da empresa como um todo, selecionar a tecnologia apropriada e, por fim, re-planejar os processos do negócio e as tarefas. Construído desta forma, o novo SI representa um processo de mudança organizacional planejada (LAUDON \& LAUDON, 2002).

O insucesso de sistemas baseados em TI pode ser motivado por ações tomadas com base na aplicação dos conhecimentos sobre dados e não baseados na integração entre conhecimento e informação. Outro aspecto limitador no uso de Tl é a cultura organizacional, tanto em seus aspectos formais como informais, que movimentam as organizações (TAIT, BARCIA, \& PACHECO, 2001).

A organização envolve aspectos diversos como recursos humanos, negócios, metas. Seus gestores têm que levar em conta todos estes aspectos para empreenderem projetos de SI, caso contrário, estes projetos podem não obter sucesso. 


\subsection{O Problema}

Manter uma gestão eficiente requer o desenvolvimento de um SI alinhado com os objetivos organizacionais (LAUDON \& LAUDON, 2002).

No entanto, apesar de existirem muitas técnicas para o levantamento correto dos requisitos e a sua transformação em um SI eficiente, muitas vezes estes projetos têm se transformado em um sucesso de tecnologia de software, mas não têm sido do mesmo modo eficazes como ferramentas de gestão, por motivos inerentes à administração da organização, uma vez que ela está sujeita à perturbações do ambiente e o SI não consegue se adaptar a estas alterações (LAUDON \& LAUDON , 2002; PRESSMAN, 2002).

ENSSLIN et al. (1996) ressalta problemas em projetos de $\mathrm{Tl}$ e atribui o insucesso a três aspectos: ênfase excessiva na técnica e não focar em problemas organizacionais; identificação errônea dos requisitos do usuário; e, falhas inerentes ao próprio projeto de desenvolvimento e implantação do SI.

O problema está na lacuna entre os modelos do SI e da organização.

Explora-se neste trabalho a perspectiva de aplicação de um modelo baseado na cibernética organizacional, o Modelo de Sistema Viável (VSM - Viable System Model), como uma ferramenta auxiliar no processo de elaboração de uma arquitetura de SI.

O modelo original concebido por Beer constitui-se em um conjunto de cinco sistemas e suas inter-relações, que são condições necessárias e suficientes para que o sistema seja viável (BEER, 1994).

Na situação de aplicação do VSM no estudo de caso, busca-se o entendimento do SI de incidentes em instalações de pesquisa na área nuclear e da conjuntura em que ele está inserido. 
A concepção de um SI visa atender às expectativas do requisitante. Para tal, são usadas ferramentas para caracterizar seus objetivos, seus limites e suas interações. Além disto, o $\mathrm{SI}$ deve integrar-se aos objetivos organizacionais e possuir flexibilidade razoável para acompanhar situações de mudança.

Para concretizar este entendimento do SI e do ambiente em que está inserido, a pesquisa se baseia na exploração da ampla aplicação dos princípios da cibernética organizacional. Assim, além do próprio VSM, são aplicados os conceitos de identidade, recursividade, adaptação, auto-regulação e homeostase.

\subsection{Objetivos}

O objetivo desta pesquisa é verificar a aplicabilidade do Modelo do Sistema Viável (VSM - Viable System Model) no projeto da arquitetura de um SI voltado à área naval nuclear, e identificar possíveis contribuições do uso dos seus conceitos, como ferramenta complementar, no auxílio à estruturação do pensamento do engenheiro de sistemas nesta tarefa.

\subsection{Delimitação do contexto do trabalho}

A pesquisa visa explorar o VSM, uma ferramenta para gestão administrativa, em uma aplicação não usual, ou seja, na concepção da arquitetura de SI. O estudo de caso visa verificar esta possibilidade.

A proposta desta pesquisa se limita a explorar o uso do VSM e seus conceitos como uma ferramenta adicional para o engenheiro de SI sob um enfoque diferente do convencional.

Não é intenção deste estudo propor nova metodologia, nem mesmo especificar detalhadamente a arquitetura do SI de incidentes.

\subsection{Relevância}


A motivação para a exploração do VSM no contexto de projetos de SI baseia-se em dois motivos normalmente apontados como causas de insucesso: o foco de se considerar somente a tecnologia, sem levar em consideração aspectos organizacionais, e o não entendimento dos requisitos.

A alternativa para minimizar as origens destes problemas é encarar a sua concepção sob uma nova perspectiva. O VSM possui características onde são identificados naturalmente aspectos organizacionais e os relacionamentos entre as partes envolvidas. Assim, ele favorece uma abordagem organizacional e um melhor entendimento do contexto.

A relevância deste trabalho encontra-se justamente neste aspecto, pois a aplicação deste modelo favorece a determinação da identidade do SI, explicita os fluxos de informação e possibilita a identificação dos pontos responsáveis por sua capacidade de adaptação, regulação e estabilidade.

\subsection{Contexto}

\subsubsection{Projeto de pesquisa e desenvolvimento de tecnologia naval nuclear}

O Programa Nuclear Brasileiro (PNB), vinculado ao Ministério da Ciência e Tecnologia (MCT), possui três seguimentos: o de pesquisa e desenvolvimento, 0 industrial e o de regulamentação e fiscalização do setor nuclear.

No final da década de 70, o governo brasileiro passou a conduzir o Programa de Desenvolvimento de Tecnologia Nuclear (PDTN), sem associação a nenhum outro país, cujos órgãos responsáveis são o Instituto de Pesquisas Energéticas e Nucleares (IPEN) e os institutos militares de pesquisa.

O projeto de pesquisa e desenvolvimento de tecnologia naval nuclear, que visa 
capacitar no domínio dos processos tecnológicos, industriais e operacionais, está ligado a este programa. O objetivo deste projeto é a construção de um submarino² nuclear de ataque (SNA) com propulsão nuclear.

Este projeto é composto por três subprojetos:

"ciclo do combustível" - visa o domínio do ciclo do combustível nuclear nas fases necessárias para atender o abastecimento dos reatores de interesse. No ciclo do combustível nuclear, a fase de maior complexidade tecnológica está no "enriquecimento", ou seja, na obtenção do Urânio com maior concentração do seu isótopo 235 , de modo a permitir sua utilização nos elementos combustíveis de um reator nuclear.

"laboratório de geração de energia núcleo-elétrica" - visa capacitar para projetar, implantar, comissionar, operar e manter instalações nucleares aplicáveis à propulsão naval.

"infra-estrutura" - visa prover todas as facilidades para o desenvolvimento dos projetos anteriores, tais como: água, energia, captação e tratamento de esgoto e efluentes industriais, comunicações, sistemas viários, sistemas de segurança e prédios das unidades de apoio.

O projeto exige uma infra-estrutura de instalações industriais de terra, como instalações de testes, laboratórios de validação experimental e algumas oficinas especiais para dar apoio à pesquisa e ao desenvolvimento desta tecnologia navalnuclear.

Suas características exigem um alto nível de gestão de qualidade e de segurança nuclear, que envolve uma estrutura organizacional para dar apoio às necessidades de segurança industrial, ambiental e normativa. Foi detectada por esta estrutura a necessidade de um SI de incidentes nucleares. A aplicação deste estudo se encontra neste contexto (Figura 1).

${ }^{2}$ Um submarino nuclear de ataque (SNA) é um submarino para uso militar que possui um reator de água pressurizada, que é a fonte de energia de sua instalação propulsora nuclear, e neste caso, o termo nuclear não se refere ao sistema de armas do submarino e sim, ao seu sistema de geração de energia; o termo ataque refere-se à sua capacidade de efetuar ataques com torpedos ou com mísseis a navios de superfície ou a outros submarinos(GUIMARÃES, 1999). 


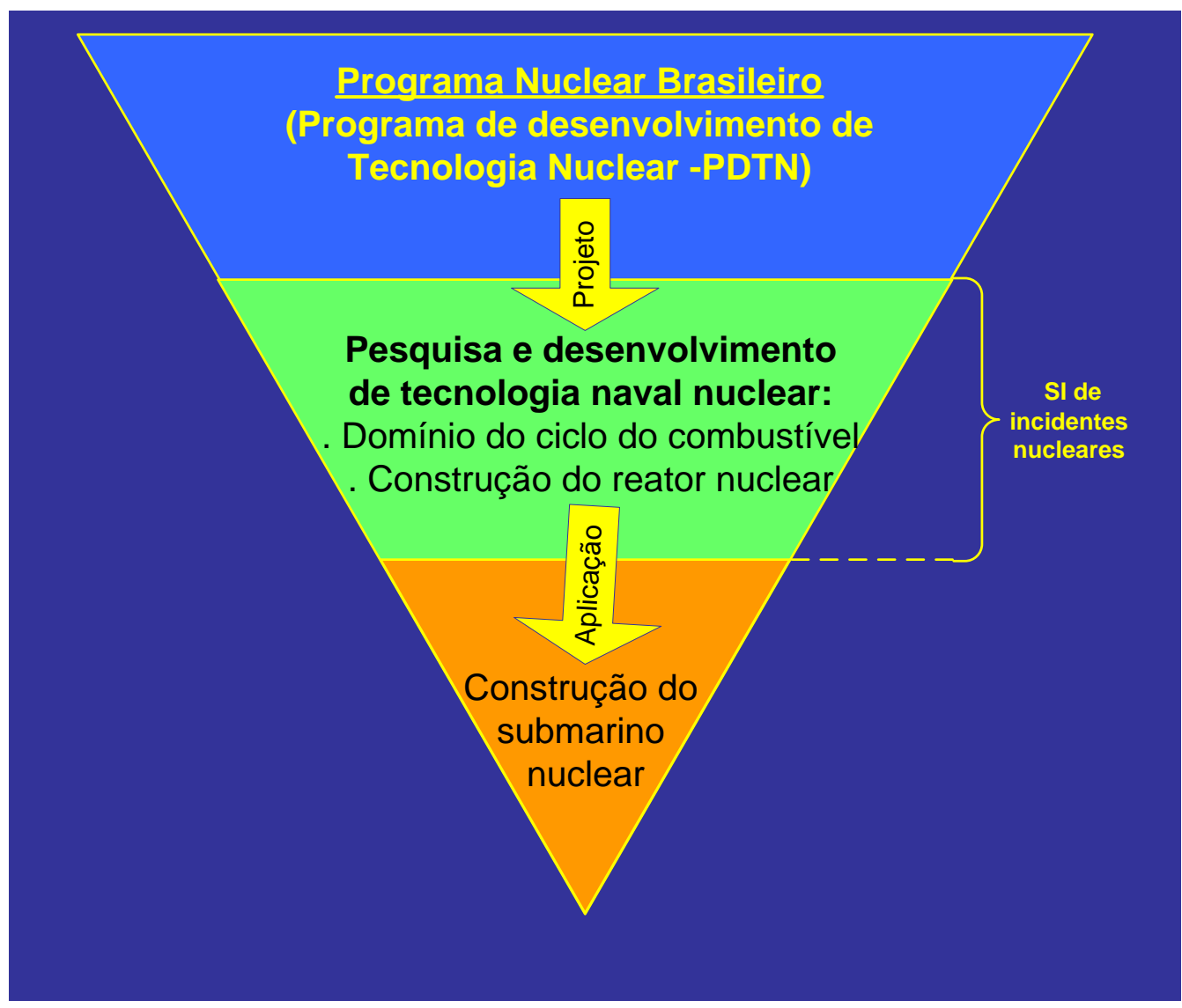

Figura 1 - 0 contexto do presente estudo está inserido no cenário do projeto de pesquisa e desenvolvimento de tecnologia naval nuclear

\subsubsection{Sistema de informação (SI)}

Diante do volume crescente de informações e da quantidade e complexidade dos SI, é necessário estabelecer uma arquitetura para definir e controlar as interfaces e a integração de todos os componentes de um SI (ZACHMAN, 1987).

Para o contexto desta pesquisa, o modelo de arquitetura de SI considera a integração entre três componentes básicos a saber: SI propriamente dito, TI, e a organização, sendo também incluídos outros dois componentes, negócios e usuários. O modelo é chamado de arquitetura de SI simplificado (Figura 2). Sua proposta é que os cinco níveis são integrados e tratados no mesmo patamar de importância (TAIT, BARCIA, \& PACHECO, 2001). Os conceitos de TI, SI e arquitetura de SI são tratados no capítulo 3, no âmbito do contexto organizacional. 


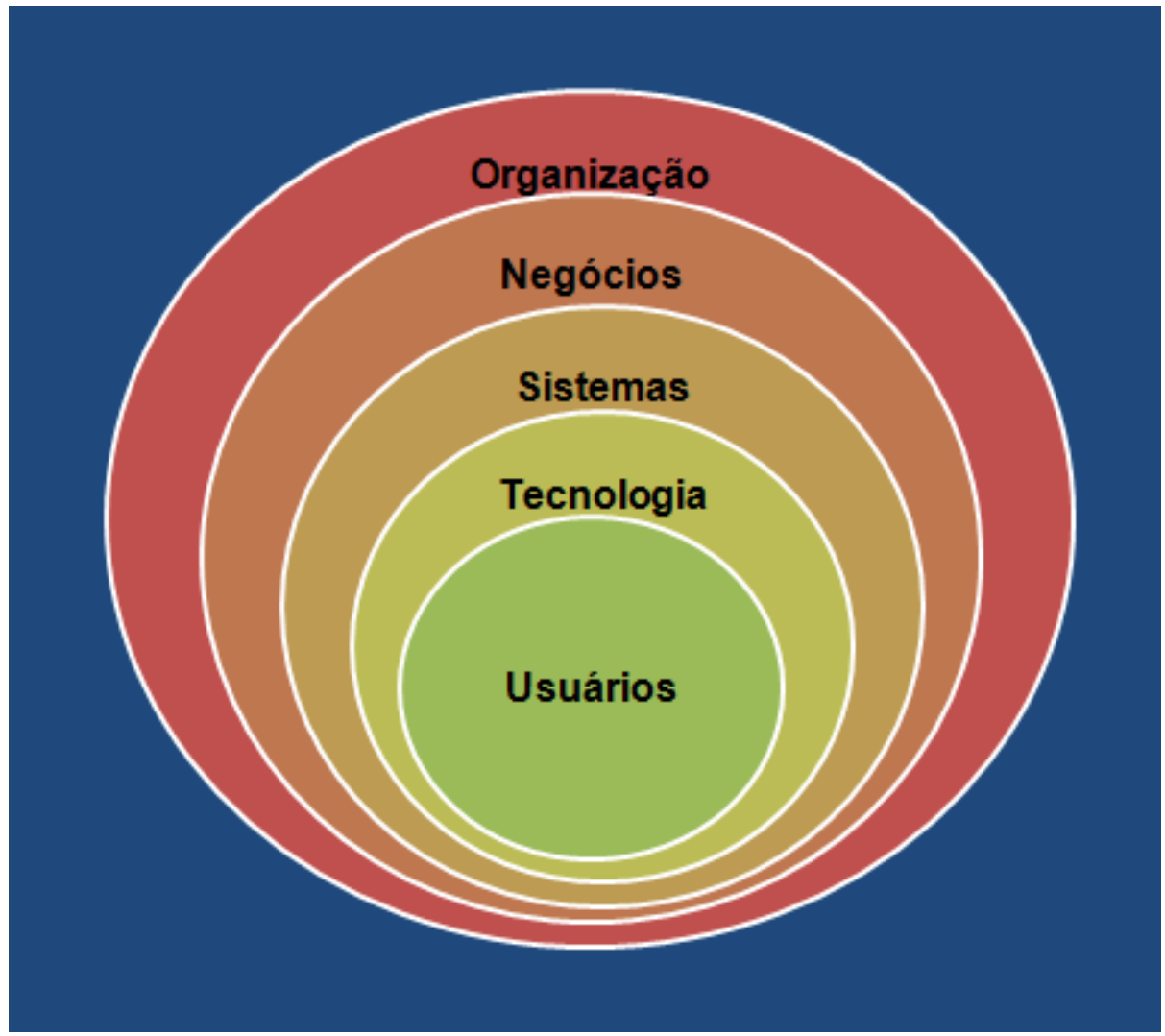

Figura 2: Os cinco elementos a serem considerados na Arquitetura de Sistemas de Informação (ASI). Fonte: (Tait, 2000).

\subsubsection{Modelo do Sistema Viável (Viable System Model - VSM)}

Pesquisadores têm procurado o entendimento do funcionamento das organizações e o desenvolvimento de modelos que possam aumentar sua eficiência.

Beer, em 1985, apresentou em seu livro "Diagnosing the System" um modelo baseado nos princípios da Cibernética, que ele chamou de Modelo dos Sistemas Viáveis (VSM). O desenvolvimento deste modelo foi documentado. Este modelo conceitual especifica o conjunto de cinco funcionalidades que um sistema organizacional deve possuir para sobreviver e se manter íntegro (Figura 3). Ele tem sido aplicado amplamente e tem obtido sucesso como ferramenta para o entendimento das organizações, re-planejamento (quando apropriado) e tem dado suporte às mudanças organizacionais (ESPEJO \& GILL, 1997). Os fundamentos deste modelo são explorados no capítulo 3. Este capítulo apresenta publicações que introduzem maneiras de pensar e seu impacto sobre o cenário relacionado com o 
contexto.

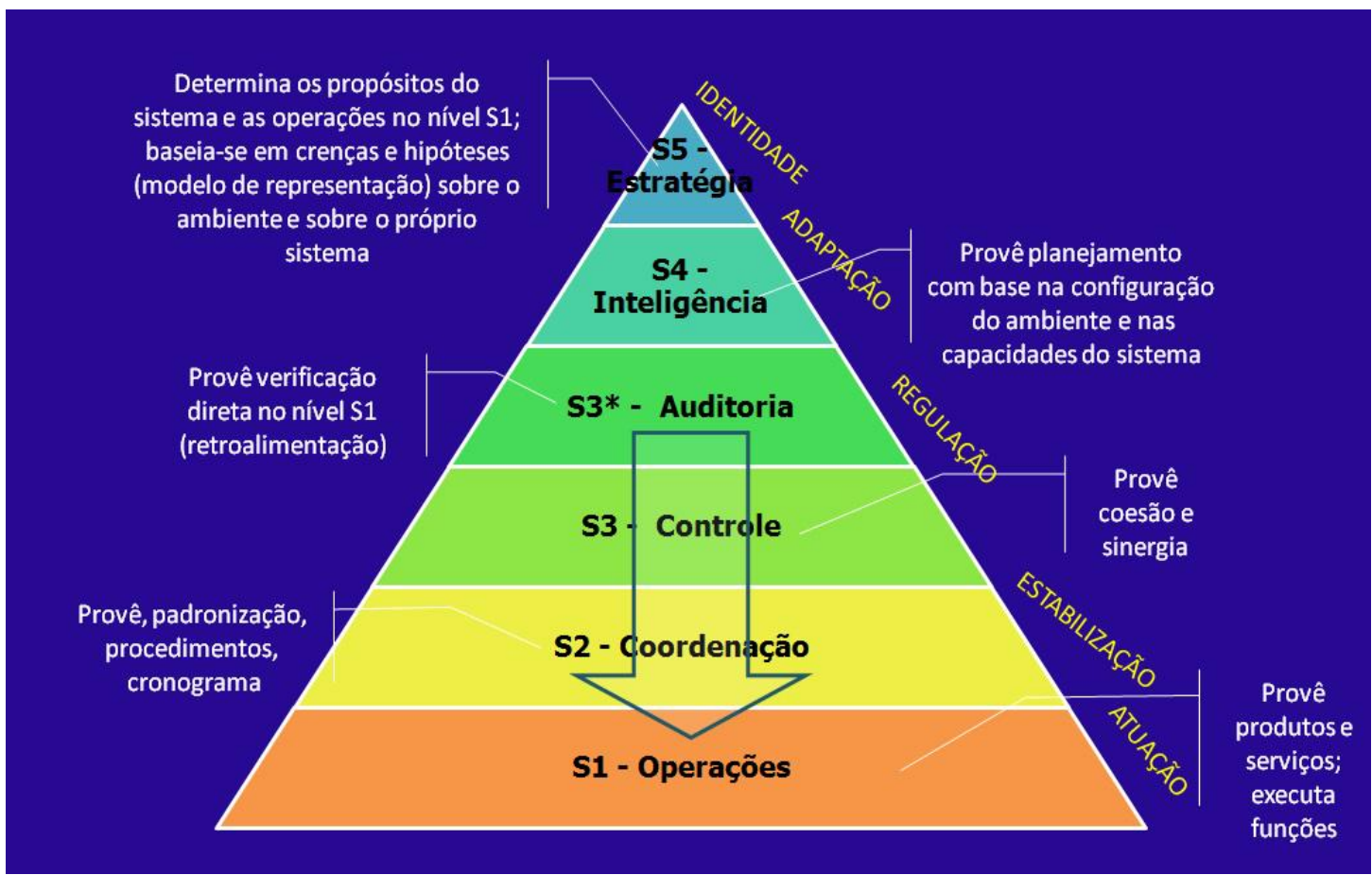

Figura 3 - VSM: Representação das cinco funcionalidades necessárias e suficientes para os sistemas se manterem íntegros.

\subsubsection{O contexto deste trabalho}

Através de um estudo de caso aplicado às áreas de pesquisa e desenvolvimento na área naval nuclear, que detectou a necessidade de um SI, verifica-se a aplicabilidade de um modelo desenvolvido para a gestão administrativa a fim de definir uma arquitetura de SI mais próxima da realidade organizacional (Figura 4).

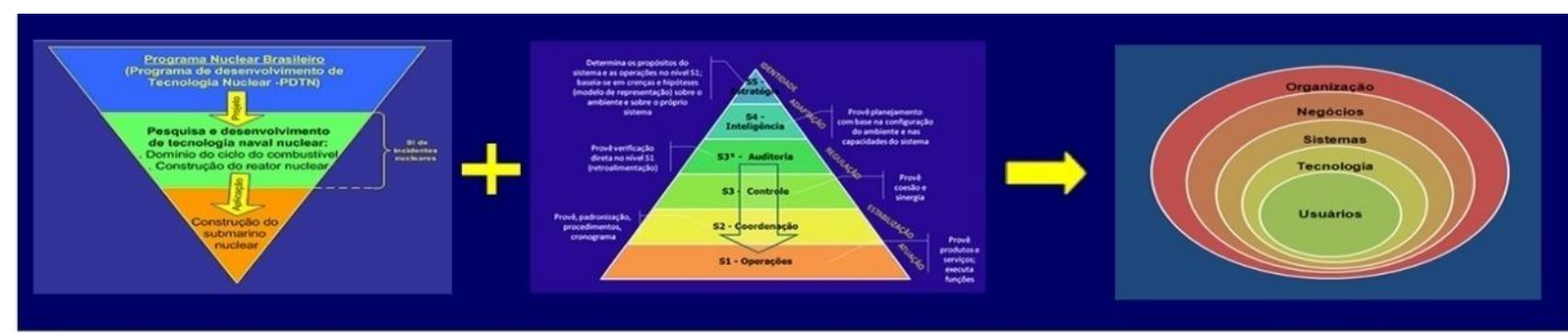

Figura 4 - Contexto deste trabalho: SI de incidentes nucleares + aplicação dos conceitos do VSM = verificação da aplicabilidade do VSM na definição de uma arquitetura de SI.

\subsection{Revisão bibliográfica}


Uma organização é viável se possuir mecanismos que lhe permitam sobreviver em um determinado ambiente. O VSM é um modelo baseado nas leis da Cibernética e tem como objetivo facilitar a estruturação das organizações e torná-las viáveis.

Para apoiar a administração das organizações, é conveniente o uso de SI. Porém nem sempre os SI estão alinhados ao posicionamento estratégico da organização e assim não cumprem sua função de suportar os processos da organização com eficiência e eficácia.

Coloca-se então a questão: é possível aplicar os conceitos do VSM para criar uma arquitetura de SI mais robusta capaz de melhorar a qualidade destes sistemas?

\subsubsection{Modelos organizacionais}

A organização segundo a escola clássica é definida como um conjunto de duas ou mais pessoas que realizam tarefas, seja em grupo, seja individualmente, mas de forma coordenada e controlada, atuando num determinado contexto ou ambiente, com vista a atingir um objetivo pré-determinado através da aplicação eficaz de diversos meios e recursos disponíveis, liderados ou não por alguém com as funções de planejar, organizar, liderar e controlar.

Parsons $^{3}$ (1960) apud Curvello (1996) define organização como "unidades sociais ou grupamentos humanos intencionalmente construídas e reconstruídas, a fim de atingir objetivos específicos".

A Teoria Neoclássica surge como uma crítica à doutrina clássica e como uma reação à sua omissão em relação ao fator humano. Para Drucker (1997), o propósito da organização é tornar eficazes os pontos fortes das pessoas e tornar irrelevantes suas fraquezas. Seus autores consideram que, para mudar a estrutura organizacional, não basta mudar a organização, tem que se mudar a cultura.

\footnotetext{
${ }^{3}$ Parsons, Talcott. Structure and process in modern societies. Glencoe, III.: Free Press
} 
O período que sucedeu à chamada sociedade industrial foi marcado pelo início de mudanças ambientais marcantes, causadas por empresas pioneiras e agressivas que determinaram a natureza e o ritmo do progresso (ANSOFF, 1993).

Nos anos 60 o ambiente já era descrito como de mudanças e turbulências constantes. Surge o planejamento estratégico substituindo o planejamento de médio e longo prazo (DAVENPORT \& SHORT, 1990).

A Teoria Geral dos Sistemas (TGS) desenvolvida por Bertalanffy preconiza que a realidade é um todo constituído da integração de suas partes e deve ser entendido como um sistema e suas interfaces. A teoria tornou evidente a natureza sistêmica das organizações em geral e foi amplamente reconhecida na administração nos anos 60 (CHIAVENATO, 2004). Alguns dos seus principais desdobramentos foram: a teoria da informação, a cibernética e a ecologia ${ }^{4}$.

A organização passa a ser vistas como uma unidade que possui transações com elementos externos e é composta por subunidades ou subsistemas que são mutuamente dependentes e interagem continuamente entre si (KATZ \& KAHN, 1987).

Numa perspectiva de gestão, Beer definiu Cibernética como a ciência das organizações eficientes (BEER, 1969).

O modelo de organização particionada implementada na General Motors no início do século XX tornou-se sinônimo de organização empresarial. Porém, diante do movimento da globalização e do aumento do grau de competição entre as empresas, mostrou-se incompatível com as necessidades de flexibilidade, mudanças rápidas e inovação constante (WOOD Jr., 1997).

\footnotetext{
${ }^{4} \mathrm{~A}$ ecologia de G. Bateson não se refere tanto à preservação de sistemas vivos existentes, mas à compreensão da articulação sistêmica de padrões e metas-padrão de auto-regulação. Ele acreditava que uma compreensão destes fenômenos levaria a agir de maneira adequada de modo a garantir a auto-regulação da qual o ser humano depende, quer do ponto de vista filogenético, quer do ponto de vista ontogenético. Daí que a sua ecologia seja uma ecologia da mente e não propriamente do ambiente.
} 
A continuidade e o sucesso das organizações nos ambientes atuais exigem mudanças constantes apoiadas pela TI (DAVENPORT \& SHORT, 1990).

A onda da globalização com seu processo de aceleração tem imposto às organizações profundas mudanças. O conceito de organização baseado em pessoas, estrutura e tecnologia entra em cheque, uma vez que este tripé não precisa mais estar em um mesmo ambiente, nem operar ao mesmo tempo para configurar uma organização (CURVELLO, 1996).

\subsubsection{Cibernética e o modelo de sistema viável - VSM}

A Cibernética ${ }^{5}$ foi desenvolvida por Norbert Wiener durante os anos de 1943 e 1947 e definida em seu trabalho "The science of control and communication" (BEER, 1969) como a ciência da comunicação e do controle nos sistemas, pois oferece, a partir da circularidade dos processos de feedback e auto-regulação, meios para se compreender os fluxos de informações e a comunicação que se estabelecem entre partes de um sistema, no intuito de se atingir um objetivo qualquer, e que pode ser, nas palavras do autor, qualquer animal ou máquina. É chamada de "Cibernética de Primeira Ordem" por se basear na observação pura dos sistemas.

$\mathrm{Na}$ década de 1960, é introduzida a noção do observador por Fperstier e Pask. O objetivo é estudar os movimentos entre o observador e o sistema no que diz respeito à conversação e à interação que se efetiva entre eles, marcada pelos processos circulares. Neste período é reconhecida a inseparabilidade entre o observador e o sistema.

Os estudos de Wiener foram direcionados para um contexto interdisciplinar de conexão das ciências com o objetivo de esclarecer as "áreas brancas", ou seja, as interfaces entre as ciências especializadas, que não eram exploradas e formavam

${ }^{5}$ A palavra cibernética do grego kubernetes, ou "piloto", a mesma palavra grega de que se deriva a palavra "governador". A natureza do estudo advém da essência da palavra, onde "piloto" é aquele que deve constantemente zelar e controlar o veículo de modo a se chegar a algum lugar. 
barreiras que impediam os cientistas de compartilhar conhecimentos nos outros campos científicos (LAUDON \& LAUDON, 2002). A Teoria Geral dos Sistemas por Bertalanffy e a Teoria da Comunicação por Shannon e Weaver contribuíram para ampliar o campo de aplicação da cibernética (CHIAVENATO, 2004).

Por volta dos anos cinqüenta, vários campos de investigação interdisciplinares surgiram. Além da Cibernética, podem ser citados: a teoria das organizações, a teoria da decisão, as ciências da computação, a teoria da informação, as ciências políticas, entre outras.

$\mathrm{Na}$ administração, aparecem as primeiras abordagens baseadas em princípios sistêmicos, tais como a engenharia de sistemas, a análise de sistemas, a cibernética organizacional, além da pesquisa operacional. O princípio comum entre elas é a necessidade de abordar o assunto como um todo. As interfaces entre as partes é ponto relevante e não são entendidas se a análise for executada nos elementos isolados (Checkland, 1981).

Os princípios da Cibernética se prestam a diversas aplicações, como o desenvolvimento de máquinas com comportamento auto-regulável, semelhantes aos comportamentos observáveis nos homens ou animais. A cibernética foi considerada uma ciência que oferece um método para o tratamento cientifico de sistemas no qual a complexidade é muito importante para ser ignorada (ASHBY, 1970).

"A organização é um sistema complexo e aberto, em dinâmica interação com numerosos ambientes, tentando atingir objetivos e executar tarefas em muitos níveis e variáveis graus de complexidade, evoluindo e desenvolvendo-se à medida que a interação com um ambiente em modificação obriga à novas adaptações internas" (SCHEIN, 1982).

A Cibernética possui particular relevância para manter a viabilidade e o desenvolvimento de uma organização em um cenário de transformações dinâmicas ou em situações de instabilidade, que por meio dos controles tradicionais da administração é uma tarefa difícil ( SCHWANINGER, 1998). 
Operacionalmente, a natureza da organização sistêmica passou a ser compreendida com as formulações cibernéticas, cujos estudos ligaram a auto-regulação aos processos de realimentação de informação. Corning (1996) enfatiza que a Cibernética trata de metas, fluxos de informação, processos de controle decisórios e avaliação em todos os níveis de sistemas.

Uma estrutura organizacional normalmente é entendida como sendo uma hierarquia formal de funcionalidades como representado em organogramas. Para Espejo (2003), uma organização emerge de relações estáveis de formas de comunicação ou mecanismos aos quais permitam que partes da organização trabalhem como um todo. A organização é definida por pessoas e outros recursos que operando juntos definem a totalidade da estrutura.

Os pesquisadores da Cibernética foram os pioneiros no reconhecimento das interações circulares, como princípio fundamental para a compreensão dos padrões da organização em geral, ao apontar a realimentação de informação como mecanismo central na estabilidade e no comportamento de sistemas complexos (CAPRA, 1996).

Assim, a evolução da Cibernética e suas aplicações ultrapassa o campo da engenharia e chega à teoria administrativa. Os conceitos derivados desta ciência, como noções de sistemas, retroação, homeostasia, comunicação e autocontrole, são utilizados na teoria administrativa e fazem parte da linguagem utilizada na Administração (CHIAVENATO, 2004).

Beer define o modelo de Sistema Viável - VSM com o objetivo de buscar soluções para o problema administrativo enfrentado pelas organizações de se adaptarem às mudanças constantes e continuarem a se desenvolver, com base na Cibernética, utilizando o processo de investigação sistemática das analogias entre a fisiologia do controle do cérebro e o funcionamento de uma organização.

Modelar uma empresa sob o conceito de aptidão organizacional significa criar e manter uma instituição como uma entidade operacional, capaz de executar suas tarefas sem perder sua capacidade de controle e de desenvolvimento 
(SCHWANINGER, 1998).

Beer usou o VSM durante quatro décadas e demonstrou aumentos em eficiência de 30 a 60\% (WALKER, 2001). O VSM é o modelo mais efetivo comparado a qualquer outro modelo já apresentado (BECHLER, 2002).

O VSM visa encontrar soluções para problemas fundamentais das organizações, principalmente os que se relacionam com a sua complexidade. Uma organização é um sistema complexo e os princípios de comunicação e controle da Cibernética se adaptam perfeitamente às organizações que pretendam ser "viáveis" (CHIAVENATO, 2004).

Uma organização viável é dotada de uma estrutura e conduta própria, deve ser autônoma e possuir a capacidade de sobreviver num determinado ambiente de mudança, à custa de processos de auto-atuação, auto-regulação e auto-organização (BEER, 1995).

\subsubsection{Tecnologia da Informação no contexto organizacional}

Tecnologia da Informação (TI), são os computadores, software, redes de comunicação eletrônica públicas ou privadas, rede digital de serviços, tecnologia de telecomunicações, protocolos de transmissão de dados e outros serviços (TAIT, BARCIA, \& PACHECO, 2001).

Segundo Barreto (2005) encontra-se a TI nas disciplinas científicas, tecnológicas e engenharias. Está inserida, também, nas técnicas da gestão do processamento, armazenamento e distribuição e nas aplicações da informação. Além disso, ressalta que o conceito de tecnologia se refere a um conjunto de conhecimentos científicos, empíricos e intuitivos. A tecnologia, quando se refere a um produto, representa o conhecimento que permite construir ou modificar o produto, não o produto em si.

Pelas definições de TI fica clara a sua complexidade. Nas últimas décadas a TI tem se apresentado com um subsistema das organizações. O conjunto formado por $\mathrm{Tl}$ e organização é peculiar de cada relação. Os aspectos técnicos de TI nem sempre são 
usados na sua totalidade, pois são influenciados por fatores culturais, por estruturas formais e informais de poder, e pelas pessoas envolvidas (BOH, FONG, YELLIN, DILL, \& HERBSLEB, 2003).

O uso da TI na organização como fator de posicionamento estratégico causa impacto e aumenta a complexidade no segmento de atuação da organização (PORTER, 1999).

No cenário organizacional resultante das mudanças impostas pela globalização, fica evidente como a informação toma nova forma, mais circular, dinâmica e acessível neste novo contexto de comunicação (CURVELLO, 1996).

A informação permeia todo 0 processo de reestruturação dos modelos organizacionais desde o salto tecnológico causado pela introdução da TI na realidade organizacional (SANTOS \& PAIM, 2000).

Os SI podem acelerar e refinar a adaptação organizacional a condições de mudança e o seu planejamento pode criar oportunidades para introdução de mudanças organizacionais que a administração pode achar desejável WALTON ${ }^{6}$ (1993) apud TAIT (2000).

A reestruturação, o uso da tecnologia e dos recursos humanos para alcançar vantagem estratégica, o re-planejamento da estrutura e das fronteiras da organização, resulta em benefícios concretos para as diferentes partes interessadas da organização (KOCHAN \& USEM, 1992).

As transformações organizacionais e a incorporação de tecnologia têm redimensionado o processo de trabalho. Observam-se o rompimento das estruturas típicas de organização do processo de trabalho, baseadas na administração científica que se consolidaram no decorrer do século XX e predominaram até a

${ }^{6}$ Walton R. E. Tecnologia de Informação - O uso de TI pelas empresas que obtêm vantagem competitiva. São Paulo : Atlas, 1993. Tradução: Edson Luiz Riccio. 
década de 70 (SANTOS \& PAIM, 2000).

$\mathrm{Na}$ década de 80, a utilização da TI é reconhecida como essencial pelos administradores no gerenciamento das organizações. A partir dos anos 90 as organizações vêem a TI como o centro da estratégia empresarial e o conhecimento, como fonte de geração de valor. Esta abordagem agrega aspectos econômicos, legais, políticos e culturais (REINHARD \& ZWICKER, 1993).

O reconhecimento do valor da informação como um diferencial competitivo (LAUDON \& LAUDON, 2002) e a necessidade das organizações mudarem a própria concepção das estratégias de gestão de negócio, devido às pressões do ambiente cada vez mais exigente, são fatores que alavancam a evolução da $\mathrm{TI}$, associada aos avanços científicos e tecnológicos na área de informática (BRITO, 1996).

A informação estratégica e sua utilização na tomada de decisão é objeto de interesse em todo tipo de organização. A capacidade de reagir e o tempo de reação são diferenciais para aquelas que desejam estar orientadas para o mercado, aproveitar oportunidades e ter capacidade de antecipar alterações do ambiente (POZZEBON, FREITAS, \& PETRINI, 1997).

A necessidade de mudanças observadas devido às condicões do ambiente e consequente incorporação de tecnologia tem refletido nas mudanças organizacionais.

Segundo Venkatraman (1994), modificações básicas introduzidas pela TI, quando acompanhadas de mudanças internas nos processos de negócio, podem resultar em vantagens significativas. Além disto, afirma que os benefícios potenciais da TI são diretamente relacionados com o grau de transformação nas rotinas organizacionais (estratégias, estrutura, processos e habilidades).

\subsubsection{Arquitetura de Sistemas de Informação (SI)}

O enfoque do gerenciamento de informações está dividido em dois períodos: o primeiro, a fase do processamento de dados onde a característica predominante foi 
o uso de SI transacionais ou legados que processavam as atividades rotineiras, e a segunda, a fase da TI propriamente dita, que combina aspectos de TI, SI e negócios (EARL, 1981). Esta divisão reflete a evolução dos conceitos que orientaram a evolução da arquitetura de SI.

A evolução do termo arquitetura (de informação) mostra claramente a trajetória técnica pela qual ela passou. Até os anos 80 este termo esteve associado com o projeto de hardware, em 1987 passou a ser associado à área de software, nos anos 90 passou a ser relacionado a SI, já enfocando o negócio. No final dos anos 90 o termo "arquitetura de SI" começa a ser visto como arquitetura de informação da empresa (REINHARD, 1996).

Para Freeman (1980), o projeto de arquitetura de um SI é um processo composto por vários passos, no qual, a partir dos requisitos de informação, são elaboradas representações das estruturas de dados, características de interface e detalhes dos procedimentos. É uma atividade de tomada de decisões importantes, quase sempre de natureza estrutural. O projeto elabora representações de programas coerentes e bem planejados, que se concentram nos inter-relacionamentos das partes em alto nível e nas operações lógicas envolvidos no nível inferior.

A arquitetura do SI permite ao engenheiro de sistemas analisar a efetividade do projeto em atender aos requisitos levantados, considerar alternativas enquanto é relativamente fácil implementar modificações e reduzir riscos na construção do software (PRESSMAN, 2002).

Para Zachman (1987), a arquitetura de SI é um conjunto que vai desde a estrutura de um programa de computador até a estrutura organizacional. Em sua visão, o conjunto que forma uma arquitetura deve considerar como seus elementos: a cultura organizacional; a missão, os objetivos e as metas da organização; os sistemas formais e informais; o relacionamento da organização com o meio externo; a metodologia de planejamento e desenvolvimento de SI; a tecnologia; os sistemas; os recursos humanos.

Para Jerrold Gochow (1991), apud Pressman (2002), a arquitetura de um SI é um 
arcabouço abrangente que descreve sua forma, sua estrutura, seus componentes e como eles se articulam.

Para Tait, Barci e Pacheco (2001) arquitetura de SI é o mapeamento de um conjunto de elementos da organização que estão envolvidos com o processo de desenvolvimento / implantação de um SI.

\subsubsection{Estrutura do trabalho}

Capítulo 1 - Apresenta questões relativas à definição do problema. O objetivo da pesquisa é estabelecido e são traçados os limites da aplicação. Também é apresentado o contexto da aplicação do estudo de caso. Ainda neste capítulo é relatada uma pesquisa bibliográfica onde são abordados os referenciais teóricos dos assuntos envolvidos.

Capítulo 2 - Aborda a metodologia de desenvolvimento do trabalho e fornece questões relativas ao estudo de caso.

Capítulo 3 - É definido, através da pesquisa bibliográfica, o referencial teórico destinado ao aprofundamento dos fundamentos dos assuntos relacionados a esta pesquisa.

Capítulo 4 - Este capítulo é dedicado ao estudo de caso. É realizada a caracterização dos sistemas adjacentes e do próprio sistema de interesse. São aplicadas técnicas utilizadas no VSM para a exploração do estudo de caso.

Propõe um modelo que visa criar uma alternativa para a especificação de uma arquitetura de $\mathrm{SI}$ incorporando as cinco funcionalidades do VSM.

Finalmente, é realizada uma correlação das partes de SI com os 5 níveis do VSM proposto por Beer, resultando no diagnóstico preliminar do sistema de interesse.

Capítulo 5 - Neste capítulo são descritos os resultados da pesquisa.

Capítulo 6 - São apresentadas as conclusões do estudo de caso. 
As referências bibliográficas utilizadas na pesquisa vêm no final. 


\section{METODOLGIA}

\subsection{Método de pesquisa}

A pesquisa é um procedimento racional e sistemático que tem como objetivo proporcionar respostas aos problemas que são propostos (GIL, 1991). Este conceito também é compartilhado por Cervo e Bervian (1996) que a definem como uma atividade que busca respostas para problemas propostos utilizando métodos científicos. Existem inúmeras formas de classificar pesquisas e parece não haver consenso entre autores. Vergara (2007) apresenta dois critérios básicos para classificar as pesquisas acadêmicas: quanto aos fins e quanto aos meios (Figura 5).

\section{Tipos de pesquisa Vergara (2007)}

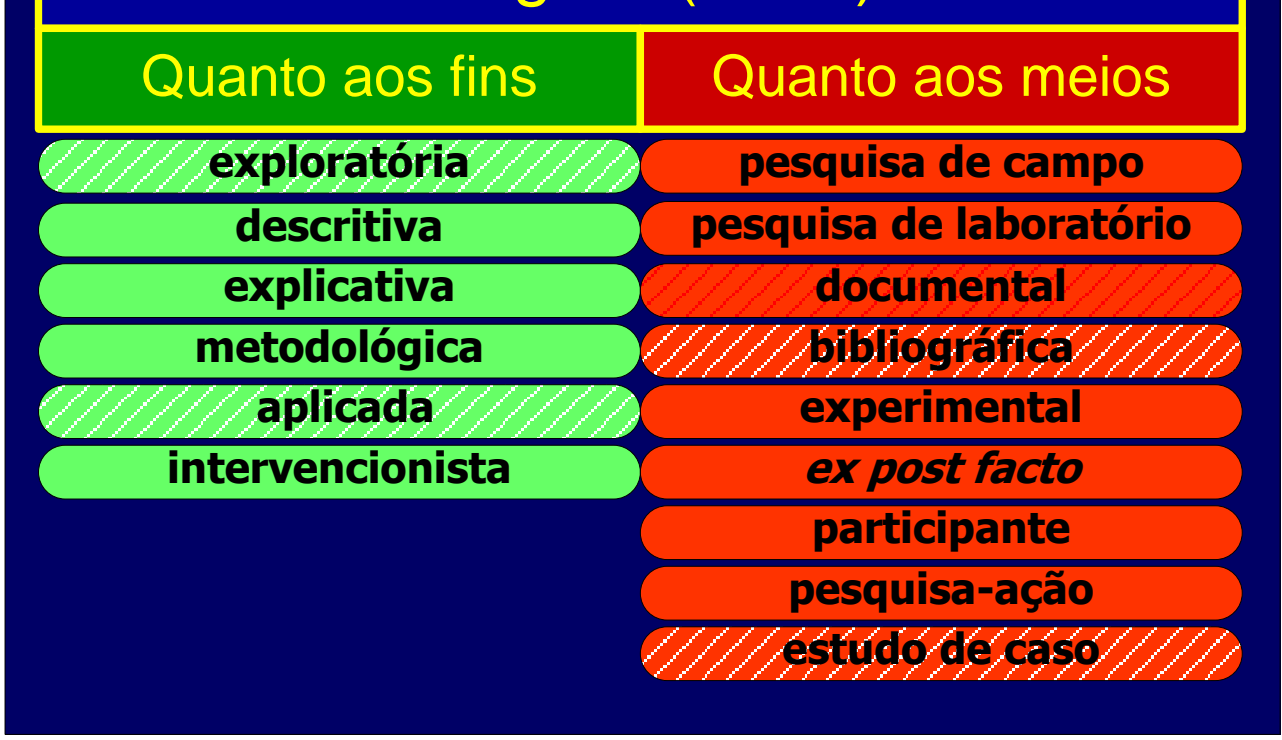

Figura 5 - Classificação das pesquisas acadêmicas. Fonte Vergara (2007).

O presente estudo caracteriza-se por uma pesquisa aplicada, uma vez que visa gerar conhecimento para aplicação prática na solução de um problema específico (VERGARA , 2007).

Entretanto, o estudo pode ser também enquadrado como uma pesquisa exploratória, apesar do conhecimento acumulado sobre os temas envolvidos. A construção do modelo que esta pesquisa se propõe utiliza uma ferramenta 
concebida para aprimorar a gestão das organizações para a especificação da arquitetura de um SI. Portanto, é realizada em uma área na qual há pouco conhecimento acumulado e sistematizado (VERGARA, 2007). Devido à sua natureza de sondagem, seu objetivo é buscar o "aprimoramento de idéias ou a descoberta de intuições". Além disto, são apresentados aspectos descritivos e explicativos, visando localizar e fundamentar a exploração do caso, e assim, "proporcionar maior familiaridade com o problema, com vistas a torná-lo mais explícito" (GIL, 1991).

Quanto aos meios de investigação, segundo a taxionomia de Vergara (2007), ou aos procedimentos técnicos (GIL, 1991), a pesquisa enquadra-se em bibliográfica e estudo de caso.

A pesquisa bibliográfica é um meio importante de investigação para este trabalho uma vez que se procura evidenciar através do encadeamento lógico uma relação causal e assim, propiciar uma visão sistêmica do problema. Os assuntos explorados são:

1 - Modelos organizacionais;

2 - Cibernética organizacional e o Modelo de Sistema Viável (VSM);

3 - Tecnologia da Informação no contexto organizacional; e

4 - Arquitetura de Sistemas de Informação.

Vergara (2007) afirma que a pesquisa bibliográfica fornece instrumental para qualquer tipo de pesquisa, mas afirma também que "pode esgotar-se em si mesma".

Para Gil (1991), de um modo geral os dados bibliográficos são dados complementares.

A pesquisa bibliográfica coloca o pesquisador em contato com a bibliografia já tornada pública em relação ao tema de estudo. Para Lakatus \& Marconi (2001), "A sua finalidade é colocar o pesquisador em contato direto com tudo o que foi dito, escrito ou filmado sobre determinado assunto". É uma ferramenta que, usada de maneira estruturada, apóia e reforça a pesquisa, alem de abrir caminho para uma nova visão sobre o problema e assim, propiciar a uma conclusão inovadora. 
O estudo de caso é em um método largamente utilizado para a realização da pesquisa exploratória, o que não significa que outro tipo de pesquisa não possa utilizar-se de tal método (FERNADES \& GOMES, 2003).

O estudo de caso tem se tornado a estratégia preferida quando os pesquisadores procuram responder às questões "como" e "por quê", quando existe pequena possibilidade de controle sobre os eventos estudados e quando o foco de interesse é sobre fenômenos atuais, que só poderão ser analisados dentro de algum contexto da vida real (YIN, 2005).

Para esta pesquisa, o estudo de caso se presta como ferramenta útil para a verificação. É um típico caso de "como" e o modelo será aplicado para verificar sua viabilidade e porque ele pode trazer algum benefício.

O Estudo de caso é circunscrito a uma ou poucas unidades, entendidas como pessoa, família, produto, empresa, órgão público, comunidade ou mesmo país. Tem caráter de profundidade e detalhamento (VERGARA ,2007).

O fato de o estudo de caso poder ser aplicado em ambiente restrito, incentiva e justifica a sua escolha como ferramenta de pesquisa, pois o caráter de informação deve ficar restrito à organização.

A pesquisa pode ser considerada como descritiva no que se refere à interpretação do estudo de caso. Em paralelo à pesquisa bibliográfica realizada, foram exploradas outras fontes de conhecimento visando conhecer o contexto em que seria testada a possibilidade de aplicação do VSM na elaboração da arquitetura de SI de incidentes nucleares.

O levantamento de informações foi amplo, mas não exaustivo, pois o interesse do presente estudo não é a especificação de um software e sim a verificação da possibilidade da aplicação de um modelo inovador para fins de elaboração da arquitetura do SI. 
De forma a permitir sua aplicação, são listadas a seguir pesquisas adicionais executadas para formação de conhecimento:

- os procedimentos de segurança de algumas instalações;

- os planos de emergência;

- os estudos de análise de risco para cada instalação, as normas de segurança do trabalho e do público em geral;

- documentos de relatos de históricos dos incidentes ocorridos desde o início do projeto e de incidentes em bancos de dados internacionais para se dispor de um referencial teórico.

O estudo de caso possui "um papel científico importante. Sabe-se que proposições científicas significativas têm a forma de proposição universal e uma proposição universal pode ser falsificada por um único contra-argumento. Assim, um único estudo de caso bem planejado pode representar um desafio importante para uma teoria e, simultaneamente, ser a fonte de novas hipóteses e constructos" Cooper \& Schindler ${ }^{7}$ apud (VERGARA, 2004).

O estudo de caso é recomendável na fase inicial de investigações com temas complexos, onde é exigida a construção de hipóteses ou reformulação do problema. "Também se aplica com pertinência nas situações em que o objeto de estudo já é suficientemente conhecido a ponto de ser enquadrado em determinado tipo ideal" (GIL, 1991).

Yin apud Roesch (2005) apresenta situações em que é recomendável o estudo de caso único ou de casos múltiplos. O caso único é apropriado quando se tem um caso crítico para testar (confirmar, desafiar, expandir) e quando se trata de um caso extremo ou singular, tão raro que vale a pena documentar. Também se aplica quando se trata de caso revelatório que ofereça a oportunidade de observar e examinar um fenômeno previamente inacessível à investigação científica.

7 COOPER,D. R.; SCHINDLER, P. S. (2002) Métodos de Pesquisa em Administração (7ª Ed). Boockman. 
Para Yin (2005), o estudo de caso é uma estratégia empírica, e representa uma boa estratégia quando a pesquisa enfoca fenômenos contemporâneos inseridos em algum contexto da vida real e os limites entre o fenômeno e o contexto não são claramente definidos. Além disto, foram pesquisadas a documentação da organização, relativa à qualidade e segurança nuclear, e a documentação normativa sobre segurança. As funcionalidades do SI de incidentes nucleares bem como as interfaces entre os sistemas envolvidos foram colhidas através de entrevistas informais e observação participante, baseada na experiência do pesquisador.

Neste aplicação é difícil a possibilidade de manipulação ou controle de variáveis por parte do pesquisador, características que recomendam o estudo de caso como método de investigação. Além disso, a escolha do estudo de caso é também justificado pela necessidade de investigar "um fenômeno dentro de seu contexto da vida real", ou seja, a aplicação do contexto real no modelo proposto.

\subsection{Etapas do trabalho}

- Pesquisa bibliográfica e de campo para obter subsídios para o enfrentamento da questão;

- Escolha do Sistema de Informação a ser testado;

- Aplicação dos conceitos no estudo de caso;

- Avaliação do resultado; e

- Conclusão

\subsection{Procedimentos adotados}

- Identificação do sistema de interesse através da aplicação da recursividade inerente aos sistemas viáveis;

- Identificação dos componentes do SI, e só aqueles que fazem parte do SI de interesse;

- Elaboração da descrição constitutiva do sistema de interesse, dos sistemas paralelos e dos níveis imediatamente superior e inferiror;

- Identificação dos fluxos de dados entre os sistemas;

- Verificação da existência de mecanismos homeostáticos; 
- Aplicação dos conceitos de variedade requerida;

- Coordenação da associação entre os elementos e o VSM;

- Verificação se o sistema diagnosticado é um sistema viável;

- Caso necessário, fazer uma compensação e nova tentativa de se obter um sistema viável; e

- Descrição das etapas durante o processo para obter uma documentação do processo adotado, para futura repetição se necessário; 


\section{FUNDAMENTOS}

Neste capítulo são descritos fundamentos teóricos que são aplicados na construção do estudo de caso.

\subsection{Cibernética}

\subsubsection{Sistemas, complexidade e conceito de "caixa-preta"}

A matéria prima de estudo da Cibernética são os sistemas. Para Ackff (1974) "Sistema é um todo com partes inter-relacionadas". Beer (1996-b) descreve sistema como um conjunto de elementos que estão dinamicamente relacionados.

Chiavenato (2004) amplia o entendimento de sistema para um conjunto de elementos dinamicamente relacionados (partes do sistema), formando uma atividade (operação) para atingir um objetivo (finalidade do sistema), operando sobre entradas e fornecendo saídas processadas.

A Cibernética utiliza a representação de sistemas através de modelos, ou seja, outros sistemas, físicos ou matemáticos, comparáveis ao original (CHIAVENATO, 2004).

De acordo com Ashby (1970), sociedades, organizações e cérebros são sistemas 'excessivamente complexos' para serem compreendidos em todos os seus detalhes. A abordagem analítica fica inviável devido ao grande número de elementos, conexões e as variedades de influências externas e internas a que sistemas dessa ordem estão sujeitos.

A Cibernética está interessada no comportamento, nas respostas e nas relações entre as partes que formam o sistema. Seu interesse está focado nas possíveis respostas diante de um conjunto de situações e não em como cada resposta é 
produzida. Esta abordagem é de especial interesse quando estes sistemas possuem alta complexidade e se relacionam fortemente com o ambiente. (ASHBY, 1970).

Um sistema cujos elementos internos são desconhecidos, devido à sua complexidade excessiva, utiliza o conceito de caixa preta, ou seja, entradas causam perturbações no interior do sistema que produzem outras perturbações (saídas) geradas pelas primeiras. Nesta visão, nada se sabe de como as perturbações de entrada se articulam com as de saída no interior da caixa (ASHBY, 1970). Muitos problemas administrativos, inicialmente, são tratados na periferia do sistema e, somente quando se desvenda o conteúdo interno, é que são considerados os aspectos operacionais e de processamento (CHIAVENATO, 2004).

O investigador poderá assim descobrir regularidades e deduzir as regras de operação do sistema manipulando ou observando as entradas e classificando as respostas na saída (ASHBY, 1970 e BEER, 1995).

\subsubsection{Controle, auto-regulação, homeostase e a lei da variedade requerida}

Beer (1995) afirma que um sistema controlado tem ciência de si mesmo. O sistema é ciente quando, ao reagir a um estímulo, é capaz de reconhecer a alteração em si e alterar sua própria representação. Para a cibernética o controle é intrínseco ao sistema, ou seja, pode ser visto como um mecanismo de "criar condições para alguma coisa".

A teoria do controle é formulada na matemática e trata dos princípios básicos sob os quais são analisados e elaborados os sistemas de controle. Na engenharia, trata do comportamento dos sistemas dinâmicos e sua função é manter um grau constante de fluxo ou de funcionamento de um sistema (CHIAVENATO, 2004).

A teoria do controle de sistemas dinâmicos tem contribuído de maneira fundamental para o progresso tecnológico em muitas áreas nas últimas décadas e tem sido uma das bases da tecnologia moderna. Sua característica interdisciplinar está alinhada às tendências da ciência e aos avanços teóricos e tecnológicos em áreas estratégicas, tais como redes de comunicação, comunicações sem fio, robótica, análise de 
imagens e sistemas críticos de segurança, entre outros. Todas estas áreas foram influenciadas pelo modelo da teoria do controle, o que sugere sua importância e potencial (IM-AGIMB, 2004).

A essência da teoria do controle baseia-se na intercalação de um agente corretivo no fluxo do processo de modo a balizar seu comportamento, para que se processe dentro de padrões predeterminados (FLORENTINO, 1988).

Chiavenato (2004) afirma que o controle é um processo cíclico composto por quatro fases (Figura 6):

Especificação de padrões ou critérios. Os critérios são as normas que devem ser seguidas e os padrões que representam o desempenho desejado. Estes dois fatores é que vão determinar o que será normal ou aceitável para o sistema.

Os objetivos que o controle deve assegurar são objeto de observação do desempenho, que busca obter informação precisa do desempenho do sistema.

Comparação do desempenho com o padrão estabelecido. Nem toda variação exige correções, somente aquelas que ultrapassam os limites estabelecidos como normais. É suposto que se conheça tudo o que deva ser controlado e a ação corretiva (retroação) que envia informação para que o sistema se ajuste e volte a operar dentro da normalidade.

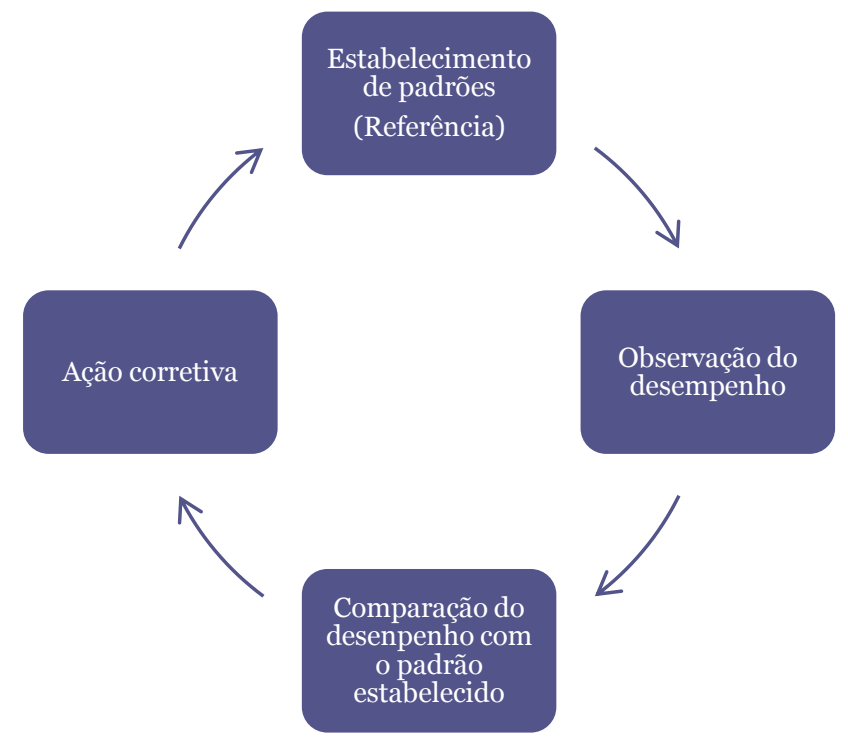

Figura 6 - As quatro fases do controle. Fonte: (CHIAVENATO, 2004). 
Sistemas de natureza física, química ou mecânica tendem a ter um comportamento previsível e os controles agem com mais eficácia. Esta previsibilidade facilita o estabelecimento de controles automáticos.

Nos casos em que o ser humano interage com o sistema controlado, essa atividade torna-se mais complexa em função da inserção da imprevisibilidade decorrente das seguintes características inerentes ao homem:

- fadiga mental ou física;

- aptidão para a desorganização; e

- tendência a fazer variar os resultados em proveito próprio (FLORENTINO, 1988).

Deste modo, a probabilidade de sucesso dos sistemas de controle é inversamente proporcional ao grau de intervenção humana no processo (CHIAVENATO, 2004).

Uma importante característica de um sistema de controle é a homeostase, que é a capacidade de um sistema se manter dentro dos limites de normalidade, mesmo quando perturbações externas incidem sobre ele.

O comportamento auto-regulador, responsável pelo equilíbrio dinâmico, depende do processo de troca de informação via retroação ou feedback. A base deste equilíbrio é a comunicação e a conseqüente retroação positiva ou negativa (BEER, 1969).

A auto-regulação é incrementada através da medida entre a saída e um determinado padrão. Esta diferença entre o padrão e o efetivamente efetuado é usada como uma nova entrada para levar a parte regulada a um ponto mais próximo do padrão (WIENER, 1970).

Realimentar com informação permite a redução da incerteza, pois torna 0 comportamento de um sistema mais previsível (PORTER, 1969). Os processos sistêmicos de controle que possuem regulação baseada em comportamento efetivo, e não em desempenho, dependem do processo de realimentação de informação.

Para Beer (1959), a introdução do controle em sistemas muito complexos torna possível a redução da complexidade ao possibilitar a simplificação da sua 
manipulação.

A estabilidade interna de um sistema se baseia no critério de operação regular. Desta forma, o sistema pode medir sua tendência de se afastar deste equilíbrio e encontrar respostas que tendam para o retorno da sua estabilidade interna (BEER, 1995).

O controle é uma rede fortemente integrada (BEER, 1996). Ele pode ser entendido neste contexto como um sistema que reage com coerência.

Os sistemas complexos, adaptativos ou não, funcionam através de feedbacks (realimentação ou retroação). Realimentação ou retroação significa que, à medida que o sistema funciona, uma parte do resultado (output) deste funcionamento é enviada, como informação (input), para a entrada do sistema, que por sua vez vai influir sobre o seu comportamento subseqüente (VASCONCELLLOS, 2004).

Retroação é o mecanismo segundo o qual uma parte da energia de saída de um sistema volta à entrada. A retroação é um processo de comunicação que responde a cada entrada. Se a informação amplifica o desempenho do sistema, ela é positiva, ao contrário, negativa (BEER, 1969).

Retroação positiva é a ação estimuladora, que amplifica e reforça o sinal de entrada. Retroação negativa é uma ação inibidora da saída que atua sobre a entrada do sistema.

O conceito de variedade introduzido por Ashby em 1956 está relacionado aos possíveis estados que um sistema pode assumir (ASHBY, 1970) e (CHIAVENATO, 2004). Estes possíveis estados do sistema são definidos pelas configurações distinguíveis dos valores dos conjuntos de variáveis que descrevem este sistema (ASHBY, 1970).

O diagrama da Figura 7 representa a lei da variedade requerida de um sistema de regulação: "S" é o sistema; "R" é o regulador que faz parte deste sistema; " $A$ " é o ambiente que causa perturbações no sistema; e "O" é a situação desejada. 


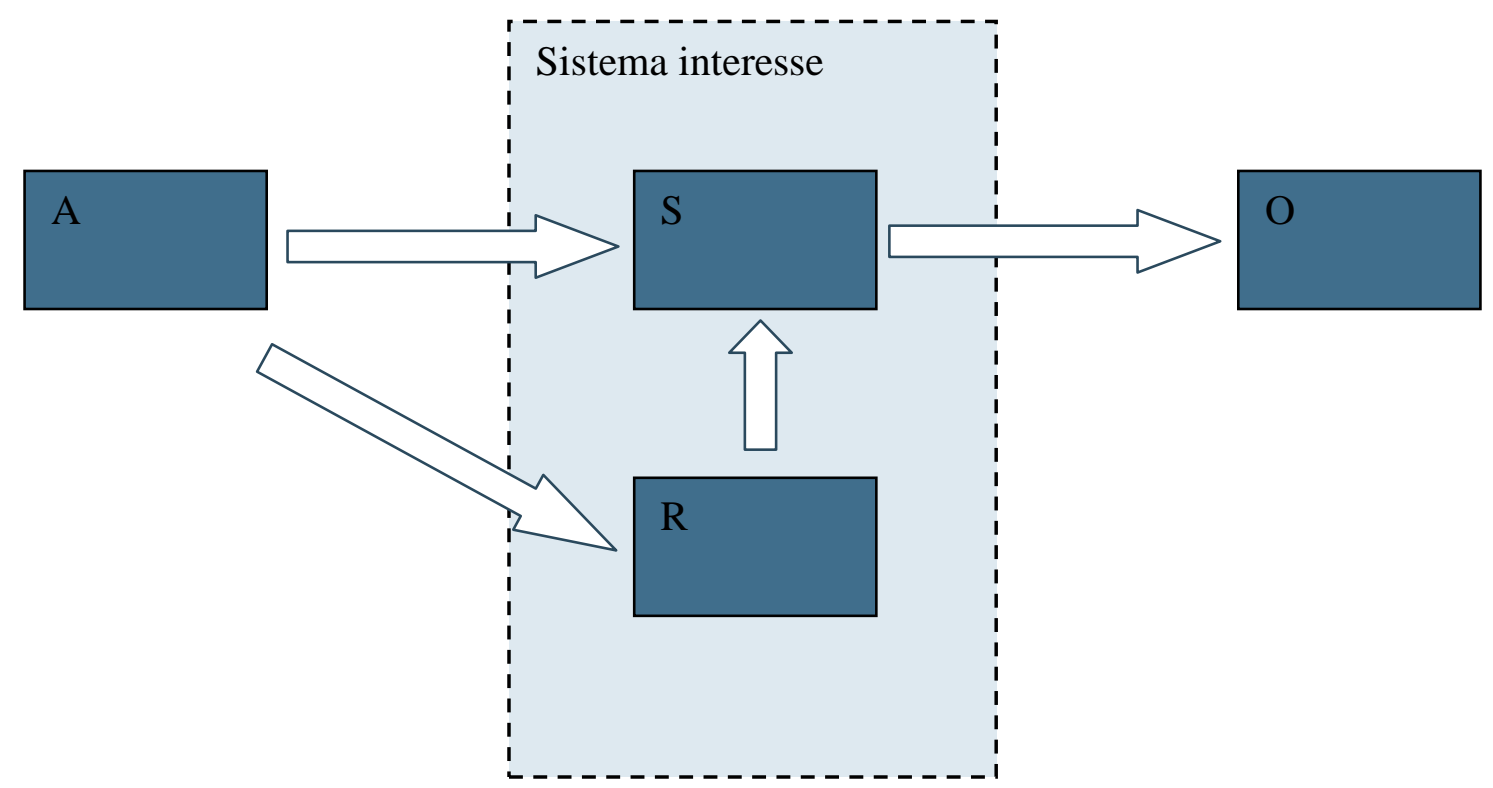

Figura 7 - Lei da variedade Requerida. Fonte: Adaptação (ASHBY, 1970).

Uma perturbação do ambiente "A" é introduzida no sistema "S", que, por meio de intervenção do regulador, se ajusta e tenta produzir a saída desejada "O". Desta forma, só é possível manter a situação desejada se existir um auditor apropriado para cada ação perturbadora "A", isto é, o regulador " $R$ " só pode manter o controle se contiver no mínimo o mesmo número de ações das perturbações " $A$ ".

Pela lei da variedade requerida, a variedade de "O" deve ser pelo menos a variedade de "A" menos a variedade de "R". Porém, a variedade de "A" tende a ser muito grande e, dificilmente, "R" consegue igualar-se a ela. Existem duas maneiras de aumentar a variedade de "O" também referidas como a própria variedade do sistema, aumentando a variedade de "R", ou restringindo as possibilidades do sistema, isto é, diminuindo a variedade de "S".

De acordo com a lei de Ashby os sistemas só podem ser totalmente controlados se os seus administradores tiverem capacidade para gerenciá-lo com o mesmo grau de variedade que ele possui.

Não é possível conhecer ou considerar todas as variedades do ambiente; então, fazse necessário o seu corte ou filtro para que os seus estados possam ser manipulados pela entidade recebedora. Aparecem aqui os conceitos de atenuadores e amplificadores, ou seja, redutores ou amplificadores da variedade que servem para 
balancear a variedade de um sistema (BEER, 1995). Este processo é conhecido como engenharia de variedade (ASHBY, 1970) e (BEER, 1995).

Existe o outro lado desta questão, pois a variedade é uma característica do sistema ser adaptável e, se a restrição de variedade for feita de uma maneira excessiva, existe a possibilidade de comprometimento de sua adaptabilidade (BEER, 1995). Desta forma, manter o controle da variedade não significa acabar com ela.

A lei de Ashby fornece uma medida de complexidade dos sistemas, fato que a torna fundamental para a Cibernética.

\subsubsection{Comunicação}

A Teoria da Informação, cuja autoria se atribui a Shannon, iniciou-se com seu trabalho "A Mathematical Theory of Communication" que foi publicado em 1948. Foi o primeiro trabalho a considerar comunicação como um problema matemático rigorosamente embasado na estatística. A base para o seu estudo foram teorias tratadas nos artigos de Nyquist ${ }^{8}$ e Hartley $^{9}$ apud SHANNON, 1948.

Sua abrangência vai além da teoria da comunicação e está relacionada também com outras áreas de conhecimento como teoria da probabilidade, criptografia, inteligência artificial entre outras. No contexto do presente trabalho, o foco será relativo à comunicação.

O problema fundamental da comunicação é reproduzir, em um determinado ponto, exatamente ou aproximadamente, uma mensagem que foi transmitida por outro (SHANNON, 1948). Freqüentemente estas mensagens têm significado. porém, os aspectos semânticos de comunicação são irrelevantes no ponto de vista da engenharia. Por outro lado, pode envolver aspectos relacionados com a perda de

\footnotetext{
${ }^{8}$ Nyquist, H., "Certain Factors Affecting Telegraph Speed," Bell System Technical Journal, April 1924, p. 324; "Certain Topics in Telegraph Transmission Theory," A.I.E.E. Trans., v. 47, April 1928, p. 617.

9 Hartley, R. V. L., “Transmission of Information,” Bell System Technical Journal, July 1928, p. 535.
} 
informação na compressão e na transmissão de mensagens com ruído no canal e isto sim é relevante sob este ponto de vista.

Um Sistema de Comunicação, segundo é tratado por (SHANNON, 1948), é formado por cinco partes e está mostrado esquematicamente na Figura 8.

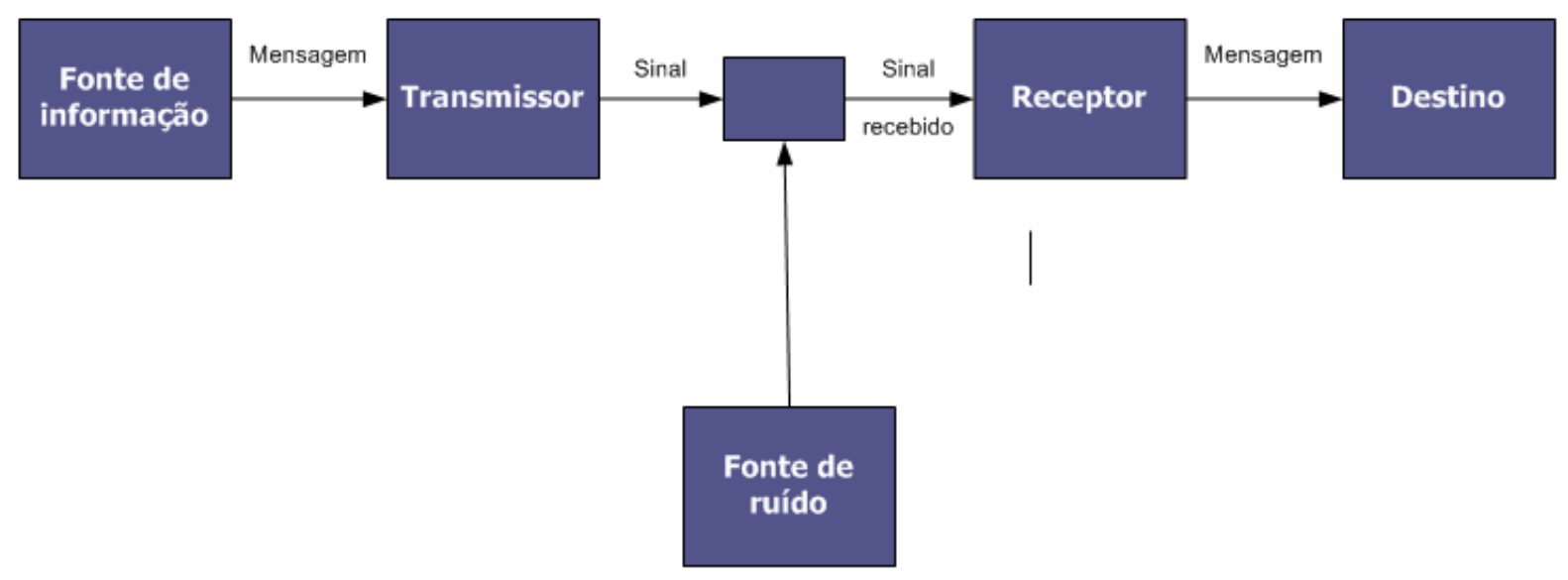

Figura 8 - Modelo esquemático de um sistema geral de comunicação

\subsection{VSM - O modelo de sistema viável}

O VSM é baseado nas leis da Cibernética e tem como objetivo facilitar a estruturação das organizações e torná-las viáveis. Uma organização viável é dotada de uma estrutura e conduta próprias, deve ser autônoma e possuir a capacidade de sobreviver num determinado ambiente de mudança, a custa de processos de autoatuação, auto-regulação e auto-organização.

Neste sentido, gerir é uma atividade reguladora e, portanto, responsável por tornar as organizações eficientes, com base nos princípios da Cibernética. Uma organização para ser eficiente tem, em primeira instância, deve ser viável.

Isto é a base dos princípios fundamentais da cibernética em organizações complexas: comunicação e controle.

A identidade de uma organização é configurada pela relação entre as suas partes. As relações fundamentais são constantes e independentes das pessoas 
participantes. No entanto, esta identidade é alterada quando as relações mudam, mesmo que as pessoas permaneçam as mesmas (SYNCHO, 1992)

O VSM é uma ferramenta que facilita a criação de organizações flexíveis e adaptáveis, através do equilíbrio entre perspectivas internas e externas, assim como formas de pensamento, a longo e curto prazos. Seu principal objetivo é fornecer uma ferramenta válida para lidar com a gestão da complexidade dos sistemas organizacionais (ESPEJO \& GILL, 1997).

Com o objetivo de buscar soluções para o desafio administrativo enfrentado pelas organizações de se adaptar às mudanças constantes e ir além da sobrevivência, isto é, continuarem a se desenvolver, Beer baseou-se na Cibernética e começou a estudar a fisiologia do controle do cérebro, para, a partir da sua compreensão, estabelecer analogias por meio de um modelo que reduzisse os problemas da administração (BEER, 1969).

Utilizando este processo de investigação sistemática das analogias entre as duas áreas, criando um "mapa topológico”, foi definido o VSM (Viable System Model).

Para validar o VSM, foram mapeados vários modelos de sistemas viáveis. A metodologia utilizada foi seguir a cadeia de similaridades analógicas e homomorfismo em relação a outro modelo até que se encontrasse um modelo isoformo. As invariâncias eram analisadas durante o processo. Terminado, iniciavase novamente do topo da cadeia com o sistema mais recente, dando origem ao mapeamento de outro sistema (BEER, 1969).

As organizações foram modeladas como sistemas autônomos e adaptativos que funcionam semelhantemente aos organismos vivos.

O VSM tenta capturar o que é essencial e as invariâncias do que constitui um sistema viável. Foi encontrado um conjunto de cinco subsistemas ou componentes, descritos abaixo. Estes subsistemas que compõem um sistema viável se relacionam homeostaticamente entre si e também com o ambiente. 
Estes subsistemas são considerados necessários e suficientes para um organismo ou uma organização realizar as funções de manutenção da identidade, em qualquer contexto. Uma representação baseada no esquema original de Beer está na figura 9.

\subsubsection{Sistema-1: Operações.}

Corresponde a cada parte da organização destinada à execução das tarefas para a qual é constituída.

Estas unidades correspondem às subsidiárias ou departamentos. Cada unidade possui suas próprias relações com o ambiente externo e pode interagir com as outras subsidiárias ou departamentos. Além disto, cada uma tem seu próprio gerenciamento local.

Cada parte do sistema-1 é autônoma no que lhe diz respeito, e assim, interage com o seu ambiente local. Ela pode e deve assumir a variedade encontrada no seu ambiente. Tudo o que acontece na unidade deve ser repassado pelo seu centro de controle local ao sistema-2.

Cada unidade de um sistema viável possui todas as características de qualquer sistema viável. Sendo assim, elas podem ser representadas da mesma forma do sistema do qual fazem parte. Este é o princípio da recursividade.

\subsubsection{Sistema-2: Coordenação}

É constituído pelas regras e regulamentos que atuam nas unidades do sistema-1.

Seu objetivo principal é assegurar que os vários elementos que constituem o sistema-1, sua coordenação e a regulação própria local, atuem em harmonia. 
É responsável pelo controle das suas oscilações e das monitorações ${ }^{10}$ esporádicas efetivadas pelo sistema-3.

\subsubsection{Sistema-3: Controle e monitoração}

Sua função é controlar a auto-organização e regulação do sistema-1 (retroalimentação). Assim, assegura o efetivo cumprimento das políticas. Monitora os sistemas 1 e 2 .

\subsubsection{Sistema-4: Inteligência}

Possui duas tarefas principais: a primeira, de fazer a troca de informações entre o sistema-5 e os níveis inferiores da organização; a segunda, capturar para a organização, toda a informação relevante acerca do ambiente.

É aqui o ponto na organização onde informações interna e externa se reúnem.

Este é o local da empresa no qual todas as decisões superiores são viabilizadas. Este sistema deve prover para a organização um modelo do ambiente, de modo que sejam possíveis previsões acerca o seu estado futuro.

Aqui se posicionam as atividades como planejamento, pesquisa de mercado, pesquisa operacional, pesquisa e desenvolvimento e relações com algum sistema maior. Ele provê um sistema de si próprio para o sistema de interesse ${ }^{11}$.

\subsubsection{Sistema-5: Estratégia.}

Determina os propósitos do sistema. É o responsável pela política.

A sua principal função é fazer o balanceamento das demandas internas e externas

\footnotetext{
${ }^{10}$ Referenciada também como auditoria.

${ }^{11}$ Sistema-em-foco ou Sistema de interesse são as recursões que se deseja estudar em uma determinada organização após ter sido estabelecido os seus limites.
} 
(as vezes antagônicas) que se apresentam nos sistema-3 e sistema-4.

Este sistema também representa as qualidades essenciais do sistema todo, para um sistema mais amplo do qual é parte integrante.

Beer esquematizou uma organização viável em um diagrama onde são mostrados os cinco sistemas e seus relacionamentos (Figura 9).

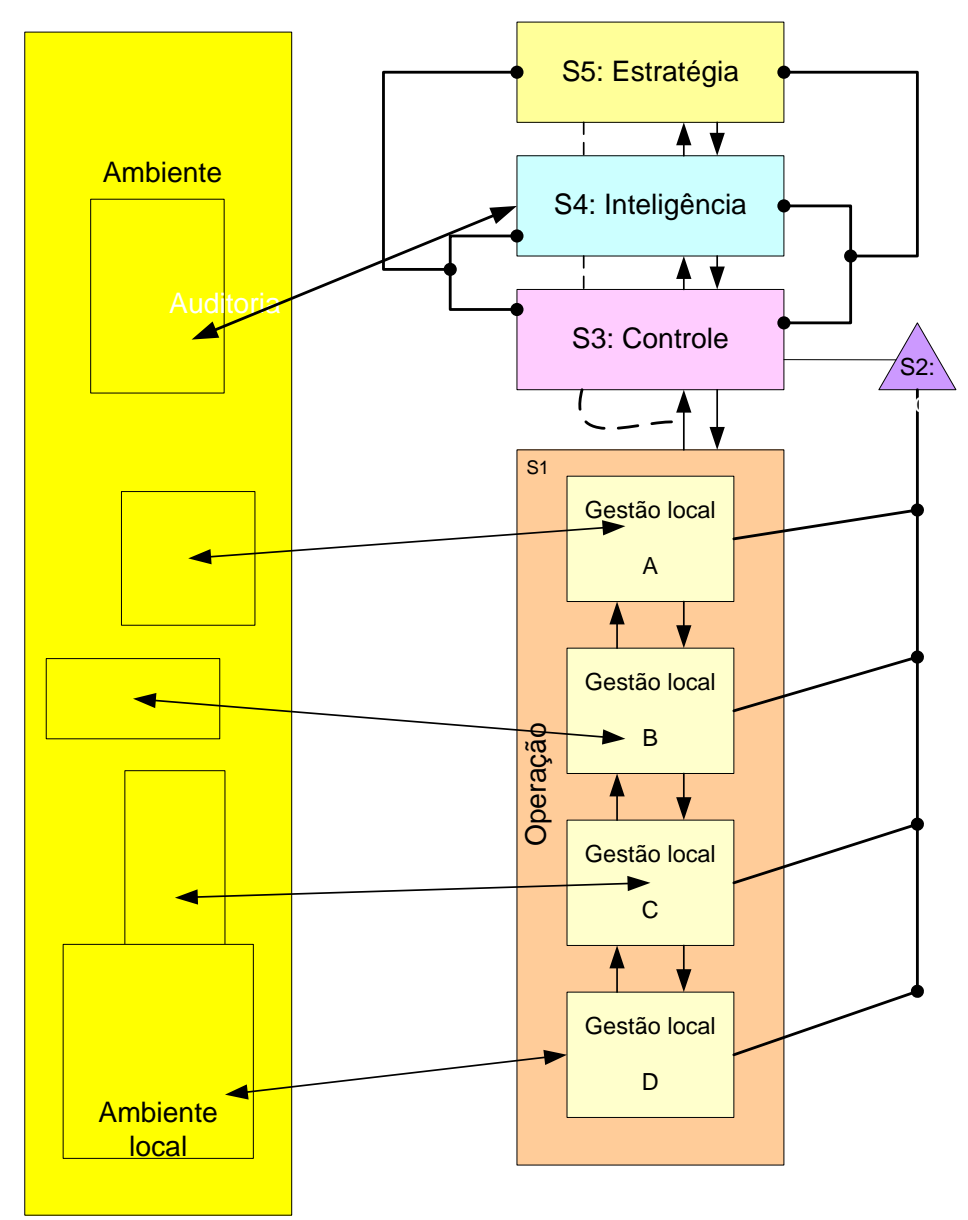

Figura 9 - Visão das funcionalidades do VSM baseada no diagrama original de Beer

O conjunto das funcionalidades que um sistema viável deve ter está representado no diagrama, enumerados de S1 a S5. 
As setas são os canais de informação entre os cinco sistemas. Estes canais são estabelecidos por uma hierarquia de conteúdo e variedade de acordo com a atribuição de cada sistema (S1...S5).

Os relacionamentos de coordenação e controle são representados por linhas terminadas com nós.

A linha tracejada representa os sinais de alerta de S5 para o S1 indicando os riscos que S1 está correndo.

Os sistemas, para serem capazes de responder ao seu ambiente, devem ser capazes de incorporar variedade, tanta quanto for necessária para fazer frente às ameaças e garantir continuidade da sua sobrevivência. Assim sendo, perturbações como descontroles monetários e financeiros de sistemas econômicos decorrem da insuficiência da variedade interna desses sistemas, e baseado nos princípios da Cibernética, esta organização deve ser replanejada.

A partir da lei de requisitos de variedade de Ashby ${ }^{12}$, Beer identificou quatro princípios fundamentais da Organização, que permitem o estabelecimento de mecanismos indispensáveis ao controle e à comunicação, tendo em vista a viabilidade dos sistemas organizacionais:

Primeiro Princípio: A variedade do ambiente, da gestão e das atividades operacionais deve ser difundida por intermédio de sistemas institucionais, especificamente concebidos para essa finalidade. $\mathrm{O}$ custo destes sistemas deve ser o mínimo para ser viável sua utilização.

Segundo Princípio: Os canais que divulgam a variedade entre a unidade de gestão, as unidades operacionais e o ambiente devem possuir uma largura de banda suficiente para conter a variedade total do sistema.

Terceiro Princípio: Sempre que a variedade transportada pelos canais atravessa as fronteiras do sistema, esta deve ser adaptada de acordo com as necessidades do

\footnotetext{
${ }^{12}$ A lei de Ashby - Lei dos Requisitos de Variedade - descreve as condições sob as quais um sistema complexo (organização) pode ser controlado externamente (ESPEJO, 2003). A Lei de Ashby está para a ciência da gestão como as leis de Newton estão para a física (BEER, 1995). Por isso mesmo, esta lei é um dos fundamentos básicos do VSM.
} 
novo ambiente, mas sem sofrer perdas.

Quarto Princípio: Os três princípios anteriores devem ser mantidos ciclicamente através do tempo, sem intervalos ou atrasos. Eles são os responsáveis pelo equilíbrio da variedade no interior de qualquer sistema organizacional e conseqüentemente, indutores do processo homeostático.

A homeostase dos sistemas conta com o conjunto de retroações positivas e negativas, entre os diversos subsistemas internos.

Os principais responsáveis pela homeostase são os mecanismos de regulação interna.

A gestão, sob o ponto de vista da complexidade do sistema, deve garantir a existência do conjunto de mecanismos de regulação interna, pois é isto que permite regular o desempenho global do sistema (ESPEJO, 2000). Esta complexidade é controlada com base na informação fornecida pelos mecanismos de regulação interna dos diversos subsistemas autônomos viáveis da organização.

A gestão deve lidar apenas com a variedade relevante para o desempenho global do sistema. A alta variedade, resultante no ambiente externo, deve ser filtrada, "atenuada", de forma a que a variedade a transmitir para os diversos sistemas operacionais seja apenas a indispensável para o seu desempenho (BEER, 1995). Em contrapartida, a variedade específica de cada sistema operacional deve ser amplificada, para que a unidade de comando possa ter um conhecimento suficientemente aprofundado acerca do desempenho das unidades internas do sistema (BEER, 1996).

Este processo de amplificação ou de atenuação da variedade permite diluir a variedade global do sistema pelos diversos sistemas operacionais. Cada subsistema vai lidar apenas com a porção de variedade que the diz respeito. Este aspecto facilita a atribuição de níveis de responsabilidade pelos diversos sistemas operacionais e fortalece os princípios da gestão descentralizada (BEER, 1995).

O modelo de sistema viável seria a base para o diagnóstico e desenho da nova arquitetura. Além da variedade requerida, o sistema deve ser dotado de mecanismo 
de monitoramento para capturar a emergência de novas situações, utilizando a informação selecionada para atualizar a capacidade de resposta da organização (ESPEJO, 2003).

De acordo com a teoria do VSM, a viabilidade é alcançada pela interação de vários princípios: autonomia e adaptação; recursão e hierarquia; e invariantes e autoreferência. A viabilidade do sistema é a medida de quanto melhor estas políticas são realizadas em um determinado ambiente (ESPEJO \& GILL, 1997).

De acordo com Beer (1995), em uma estrutura organizacional recursiva, qualquer sistema viável contém e é contido em outro sistema viável.

Sistemas viáveis dependem de outros sistemas viáveis em pelo menos três níveis:

1 - O sistema de nível imediatamente inferior ou aqueles sistemas que incluam ou produzam o sistema;

2 - Sistemas no mesmo nível que têm ligações de entradas e saídas; e

3 - O Sistema de nível superior

A recursão dá uma visão maior quando se consideram sistemas contidos em múltiplos sistemas. A noção de dimensão recursiva descreve o maior contexto de sistemas nos quais sistemas são colocados encadeados com outros sistemas que juntos delineiam a esfera global que define o limite do sistema total.

A noção de dimensão recursiva descreve o grande contexto de sistemas nos quais sistemas estão encadeados em outros sistemas recursivos que juntos delineiam uma esfera, que envolve todos, e define o limite do sistema inteiro (Figura 10). 


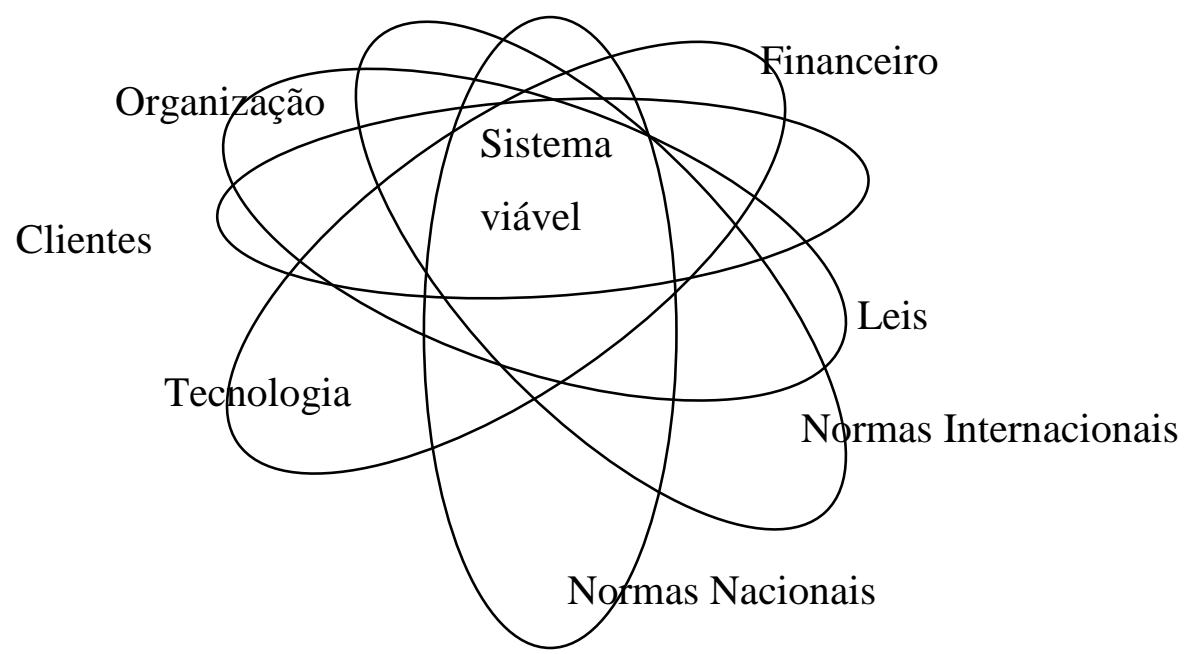

Figura 10 - Dimensões recursivas de um sistema viável

Auto-referência é a descrição que se refere a algo que influencia, afeta ou que tem habilidade para modificar a forma ou validar esta descrição (BEER, 1995). Um exemplo é a descrição do sistema por um observador que faz parte do sistema. Esta propriedade faz sentido no diagrama do VSM, onde cada parte se relaciona com uma outra parte e assim, o todo se define.

O VSM tem se mostrado eficaz no entendimento e diagnóstico de organizações. Este modelo se baseia em princípios fundamentais da Cibernética tais como a variedade requerida, o uso da noção de caixa preta e o princípio da realimentação negativa, com vistas à obtenção de regulação homeostática e adaptação de organizações (LEONARD, 1999; ESPEJO, 2003). Este modelo proporciona um arcabouço para uma arquitetura de organização flexível e adaptável que equilibra perspectivas internas e externas a longo ou em curto prazo (ESPEJO, 2003).

\subsection{Arquitetura de SI}

Existem três atividades básicas em um SI (Figura 11) que permitem que o SI cumpra sua função: entrada, processo e saída. Existe um tipo especial de saída que é 
chamada de realimentação ${ }^{13}$., a saber, uma saída com uma informação para ser avaliada por uma pessoa ou uma atividade do sistema e que, após ser refinada, retorna ao sistema como uma entrada.

O ambiente pode ser considerado como sendo o conjunto de entidades que interagem com a organização e, direta ou indiretamente, com o SI. Estas entidades externas podem ser fornecedores, clientes, agências reguladoras, acionistas, competidores, governo, dentre outras.

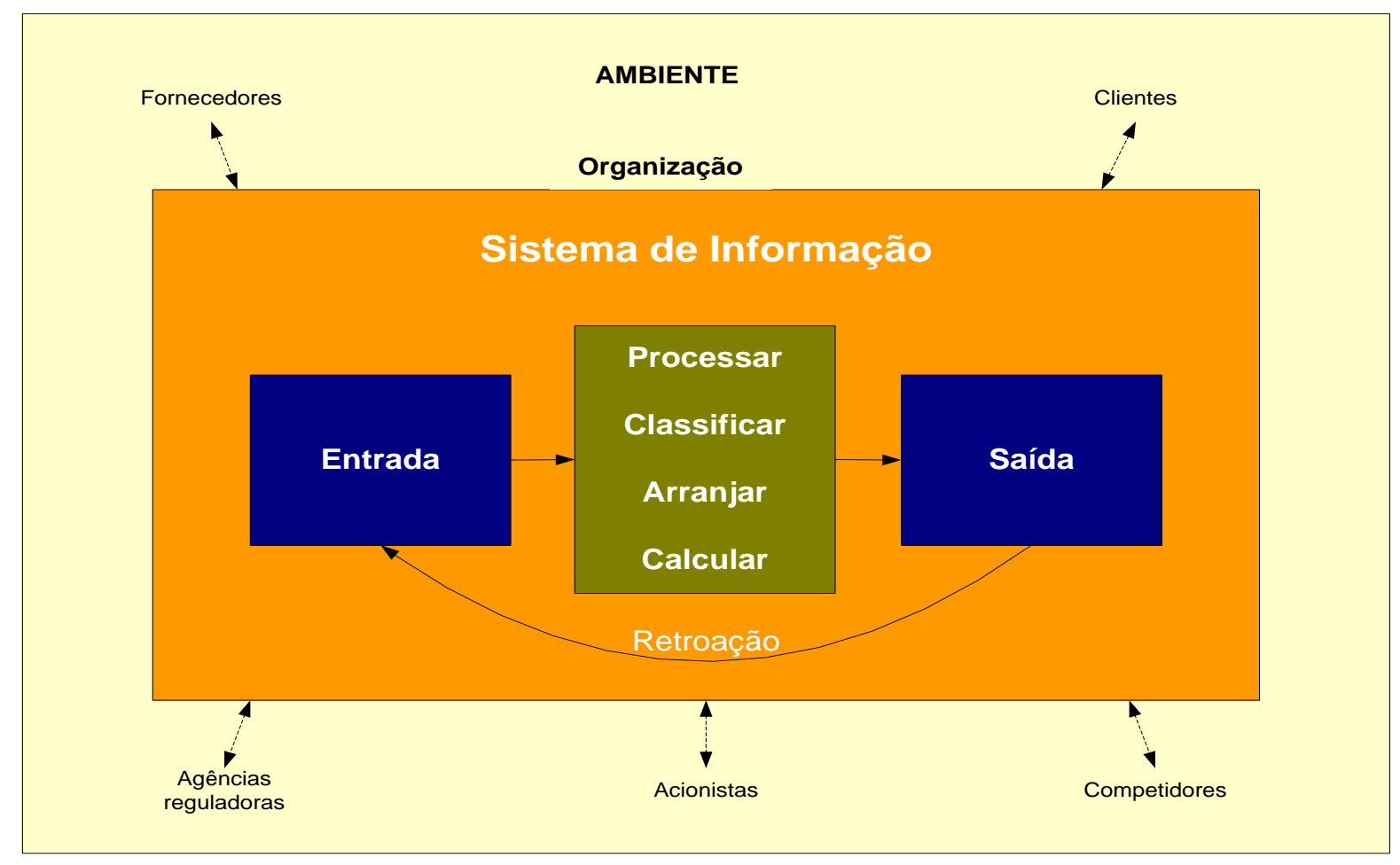

Figura 11 - Esquema geral de um Sistema de Informação - Fonte: (LAUDON \& LAUDON, 2002).

A engenharia de sistemas de informação tem como objetivo gerar uma representação efetiva do sistema, que pode ser uma especificação, um protótipo ou um modelo, que deve descrever as características operacionais, funcionais e comportamentais do sistema a ser construído (PRESSMAN, 2002), ou seja, especificar a arquitetura do SI.

13 São encontrados na literatura para significar "feedback": retroação, realimentação, retroalimentação ou servomecanismo. 
A figura 12 mostra a hierarquia de domínios onde a engenharia de sistemas atua. São utilizadas técnicas descendentes ou ascendentes para percorrer todos os níveis, independente do domínio de interesse, de forma a abranger o conhecimento necessário para a modelagem do SI.

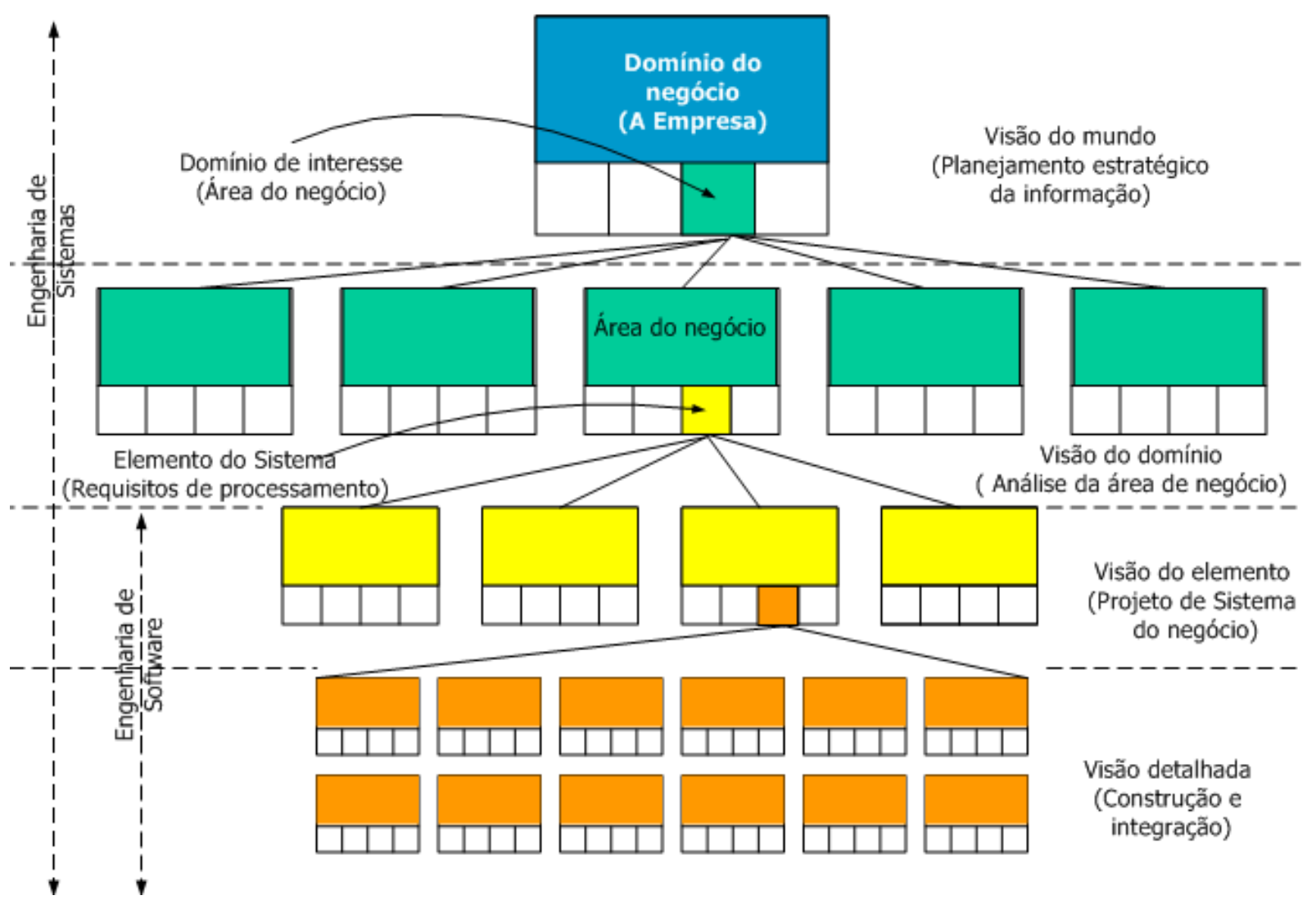

Figura 12 - Hierarquia da engenharia de Sistemas - Fonte: (PRESSMAN, 2002).

As atividades básicas da engenharia de SI são: determinar o objetivo do SI e identificar seus elementos, tais como o hardware, o software, pessoal, base de dados e procedimentos; e levantar, analisar, especificar, modelar, validar e gerenciar os requisitos operacionais (FAIRLEY, 1987).

Um SI pode ser definido tecnicamente como um conjunto de componentes interrelacionados que trabalham juntos em um determinado ambiente, para coletar, processar, armazenar e distribuir informações que dão suporte a tomada de decisões, a coordenação, ao controle, à análise e a visualização em uma organização (LAUDON \& LAUDON, 2002). 
As funções do negócio no ambiente de TI são construídas por meio do software que será elaborado, utilizando o conhecimento individual e organizacional, equipamentos de hardware e infra-estrutura de redes. A modelagem do SI a partir do conhecimento da organização é uma tarefa para a engenharia de sistemas de informação.

Um desafio para a comunidade de engenharia de software é construir sistemas que possam extrair conhecimento de dados e informações de um modo prático e benéfico (PRESSMAN, 2002)

Com a evolução dos SI, eles passaram a ser classificados de acordo com sua finalidade (TAIT, BARCIA, \& PACHECO, 2001). Sistemas de nível operacional são direcionados aos procedimentos rotineiros da organização. Os sistemas de nível de conhecimento auxiliam a integração do negócio e novos conhecimentos, além de ajudar a controlar o fluxo de papéis. Os sistemas de nível gerencial monitoram e controlam os processos e ajudam a gerencia a tomar decisões. Os sistemas de nível estratégico têm a função de ajudar no planejamento das atividades da alta direção e suportar o planejamento de longo prazo.

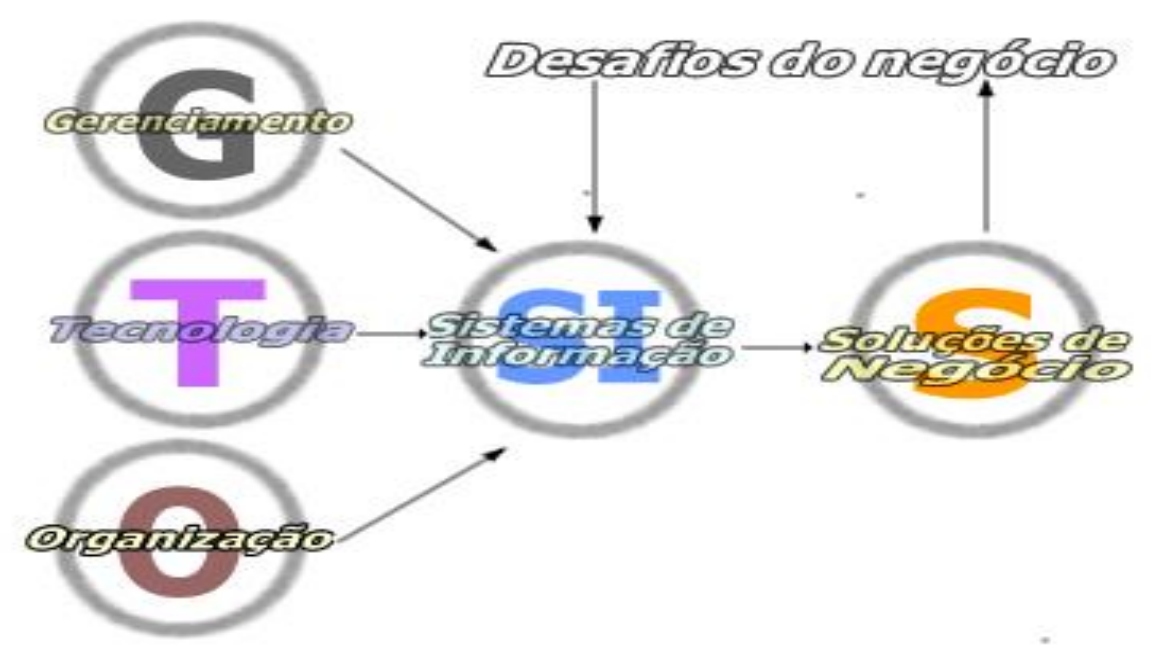

Figura 13 - O domínio dos Sistemas de Informação. Fonte: adaptação de (LAUDON \& LAUDON, 2002)

O domínio dos SI (Figura 13) é formado por três elementos: Gerenciamento, Tecnologia e Organização. 
Gerenciamento: gerentes percebem desafios no ambiente. Estes gerentes devem responder às necessidades alocando recursos para alcançar estratégias e coordenar os trabalhos. Porém, suas atividades ultrapassam estes limites. Muitas vezes devem criar novos serviços ou produtos, serem criativos utilizando novos conhecimentos e tecnologias.

Tecnologia: a Tl é uma das ferramentas que os gerentes têm para lidar com as mudanças. Hardware, software, base de dados e redes são recursos tecnológicos que constituem a infra-estrutura para a organização ter seu SI.

Organização: cada organização possui uma cultura única, valores e maneira de fazer as coisas. Parte desta cultura organizacional freqüentemente está embutida nos seus SI.

A arquitetura do processo de negócio e a TI são naturalmente parceiros. A TI é usada como ferramenta de análise e modelagem da organização e, freqüentemente, tem sido aplicada em ambientes industriais. Porém esta abordagem ainda não foi explorada na sua totalidade. Na maioria dos casos em que a TI vem sendo usada como ferramenta de re-planejamento do negócio, os processos têm sido beneficiados (DAVENPORT \& SHORT, 1990).

A relação entre a implantação de SI e processos de mudança organizacional pode ser observada a partir de dois enfoques: tecnológico ou organizacional (Figura 14). O enfoque tecnológico considera a implantação de SI como um elemento desencadeador da mudança, enquanto o enfoque organizacional dá ênfase ao aspecto da reestruturação dos processos e conscientização de pessoas, e utiliza os SI como ferramenta para executar a mudança. 
Como a TI pode suportar os processos de negócio?

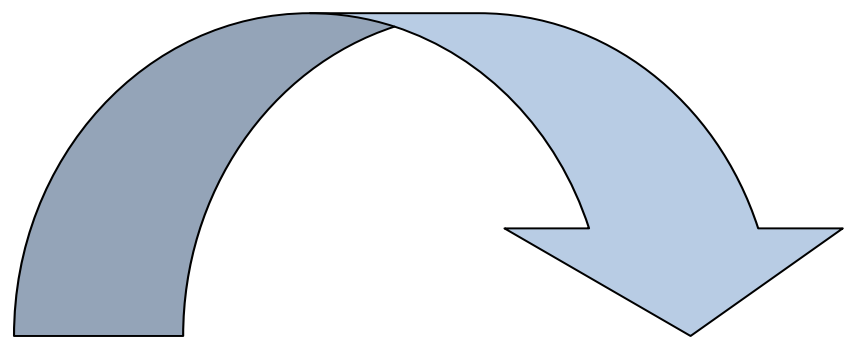

Recursos de Tecnologia da Informação

Replanejamento do processo do negócio

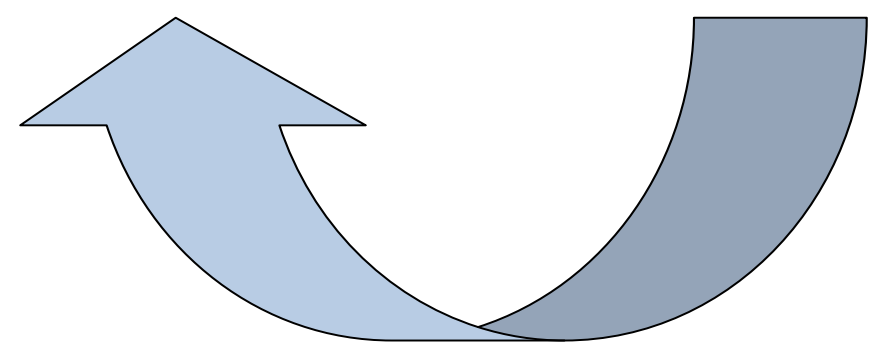

Como os processos de negócio podem ser transformados usando recursos de $\mathbf{T I}$ ?

Figura 14 - Relação de recursividade ente recursos de TI e re-planejamento do negócio organizacional. Fonte: (DAVENPORT \& SHORT, 1990).

De uma forma ou de outra, a construção de um SI para uma organização pode ser uma forma de produzir mudanças organizacionais. Analistas e projetistas são responsáveis por garantir que os elementos chaves da organização participem do processo de planejamento e permitam sua influencia na forma atualizada do sistema. (LAUDON \& LAUDON, 2002).

A arquitetura de SI tem como objetivo mapear a organização através da definição e controle das interfaces e a integração de todos os componentes do sistema, desde seu planejamento estratégico até o armazenamento dos dados. Surgiu como resposta ao aumento dos níveis de complexidade e de escopo sua concepção (ZACHMAN, 1987).

Não existe um consenso na literatura para "arquitetura de SI" (BOH, YELLIN, DILL, \& HERBSLEB, 1994). Associado à evolução do termo, surgiram linhas diversas de interpretação. 
A contribuição de uma arquitetura de SI abrangente é a maneira de tratar os elementos envolvidos desenvolvimento de um software com o mesmo grau de importância e não focando apenas em tecnologia ou dados (ZACHMAN, 1987); (TAIT, BARCIA, \& PACHECO, 2001).

Existem enfoques de pesquisa variados para a arquitetura de SI. A visão abrangente apresentada por (ZACHMAN, 1987) extrapola a dimensão de dados ou tecnologia.

A arquitetura integrada, (Figura 15), (Scheer, 1992) apud (TAIT, BARCIA, \& PACHECO, 2001) foca a atenção na organização, dados, controle e função.

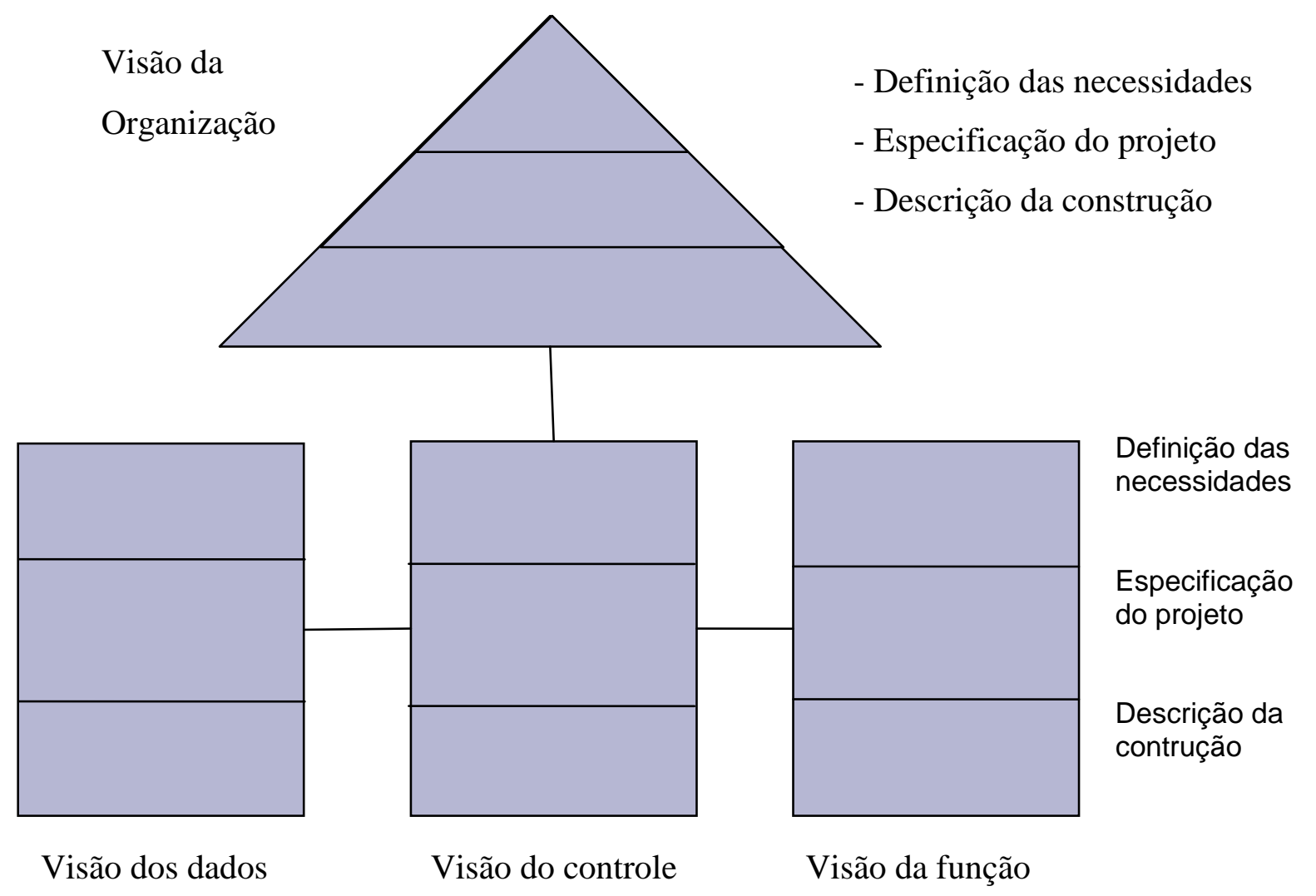

Figura 16 - Visão de arquitetura integrada - Organização, dados, controle e função.

O planejamento estratégico é associado à arquitetura de SI por (FURLAN, 1991) e sugere a definição de arquitetura de dados, a arquitetura de sistemas, estratégias gerenciais e definição de tecnologias a serem empregadas. 
Para (LAUDON \& LAUDON, 2002) a arquitetura está estritamente ligada ao aspecto tecnológico, pelo arranjo de hardware, software, dados e redes de computadores.

A visão de arquitetura de $\mathrm{SI}$, focada em negócios, fornece um conjunto conceitual de SI e seus relacionamentos através de dados e processos Cook(1996).

O trabalho de Tait, Barcia \& Pacheco (2001) propõe uma arquitetura de SI simplificada, para aplicação em qualquer organização, independente do porte, do ramo de atividade e dos tipos de sistemas existentes. Ela parte do princípio que devem ser combinados três componentes básicos: organização, sistemas e tecnologia, extensivo à inclusão de negócios e usuários. Esta proposta trata no mesmo nível todos os seus componentes (Figura 16).

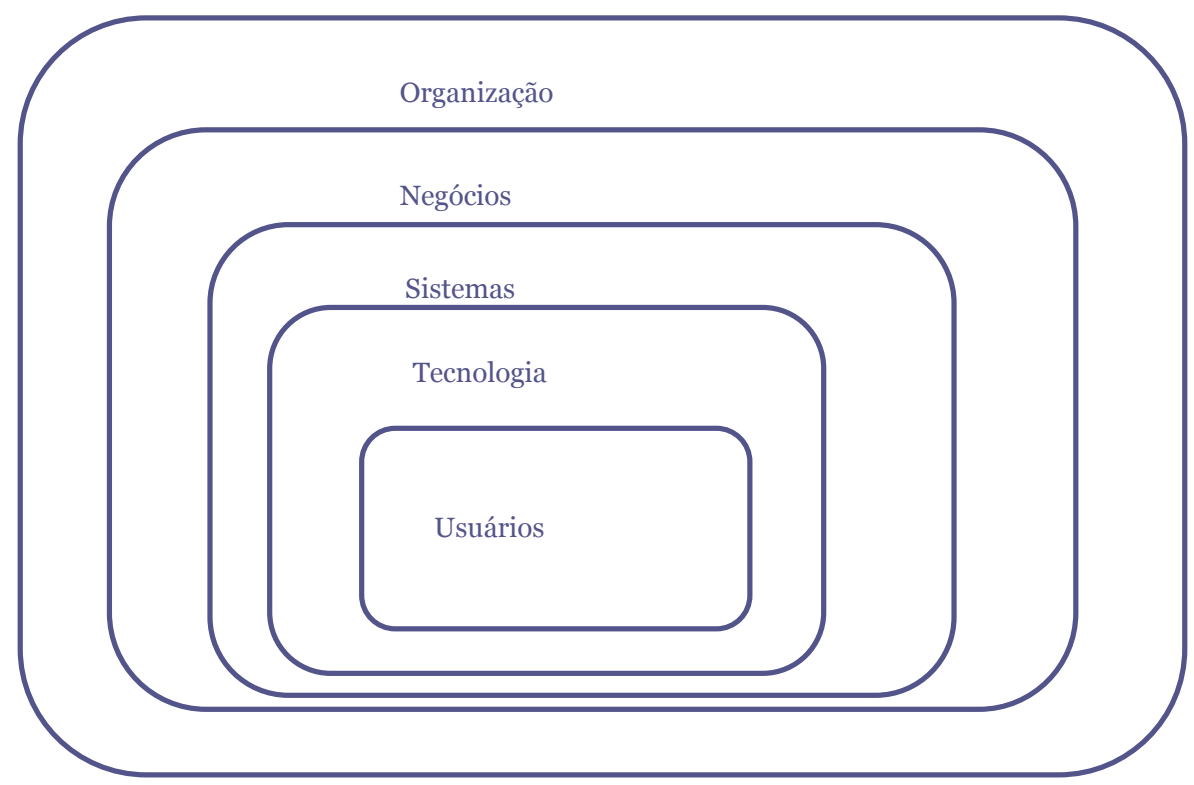

Figura 17 - Visões de uma arquitetura de sistema de informação simplificada

Visão da organização:

Elementos: missão, estratégia e metas. Esta visão deve conter: escopo do negócio, estrutura administrativa e Integração dos sistemas.

Planejamento do negócio: Devem ser considerada globalização, ciclo de desenvolvimento de produtos, mudanças organizacionais rápidas, tais como: legislação e restrições governamentais, relação de negócio com SI, escopo do negocio, satisfação do cliente, planejamento estratégico e relacionamento com 
ambiente externo.

Sistemas: Dados, recursos, cilclo de vida, planejamento estratégico de SI, sistemas inter-organizacionais, metodologias de planejamento e desenvolvimento do SI.

Tecnologia da Informação: Políticas e regras para uso de TI na organização, hardware, software, fatores ambientais e recursos humanos.

Usuário: Qualquer nível de atuação.

Construir um novo SI pode ser um processo de mudança organizacional planejado, porém, isto não significa que a mudança sempre possa ser planejada ou controlada. Indivíduos e grupos na organização possuem interesses variados, e eles podem resistir às mudanças nos processos, relacionamento de tarefas e tecnologias(LAUDON \& LAUDON, 2002).

Davenport em 1990 propõe um modelo com cinco passos para replanejar o negócio apoiado na TI (Figura 18). Com o objetivo de promover uma mudança organizacional apoiada por um SI ele acreditava ser necessário desenvolver um SI que ajustasse ao seu plano empresarial, redesenhando os processos de negócio e tarefas. 


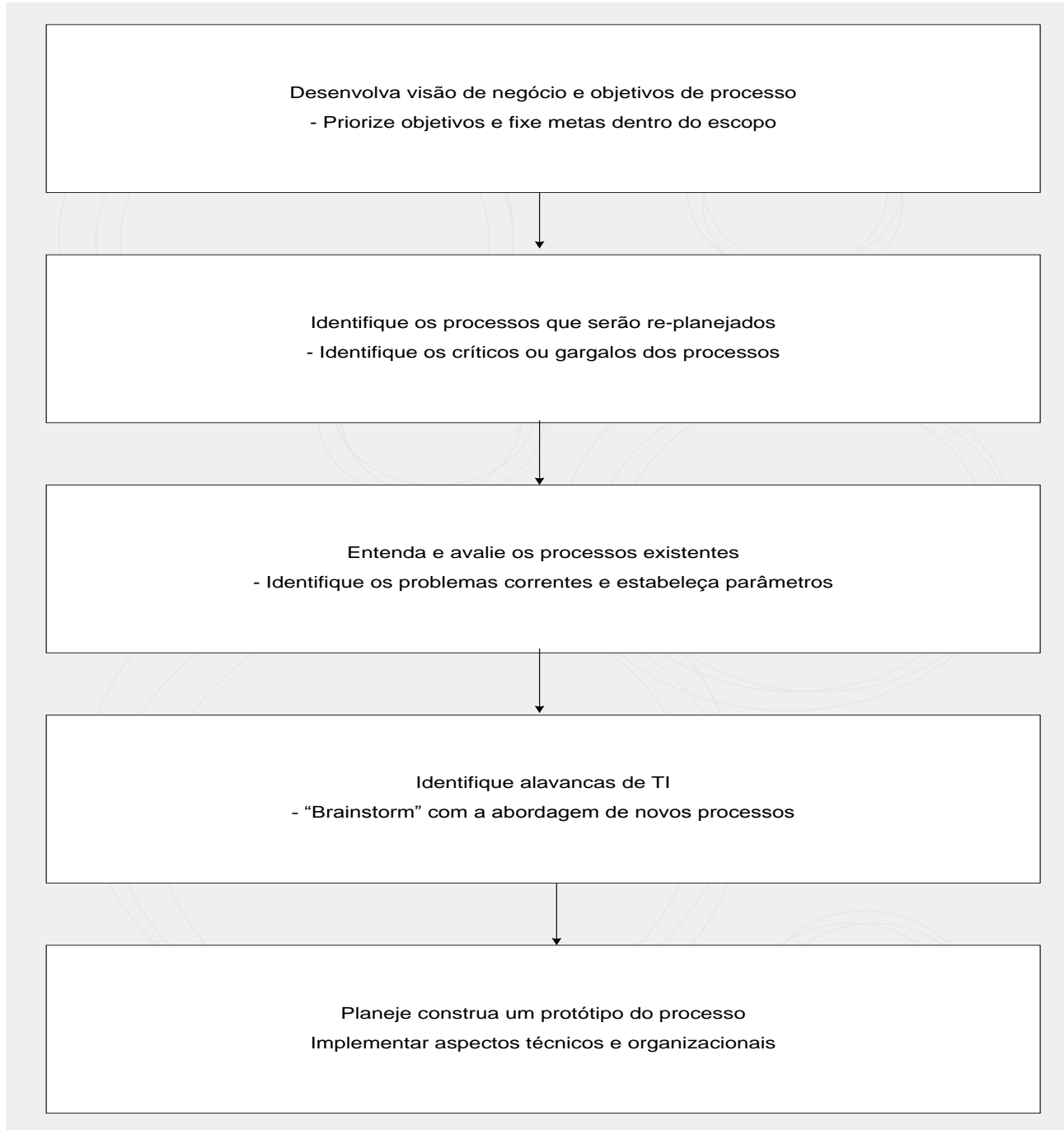

Figura 18 - Modelo proposto por Davenport: 5 passos para o re-planejamento de uma organização

Este enfoque é aplicado de um modo geral nas organizações. No entanto, em parte dos casos o investimento em TI parece não ter o retorno esperado.

Quanto ao modelo de desenvolvimento, os mais tradicionais são: sequencial linear, incremental e espiral. 
O modelo seqüencial linear (Figura 19) também é chamado de ciclo de vida clássico. Este modelo é o mais antigo e é mais amplamente usado, apesar de apresentar problemas principalmente de tempo de desenvolvimento.

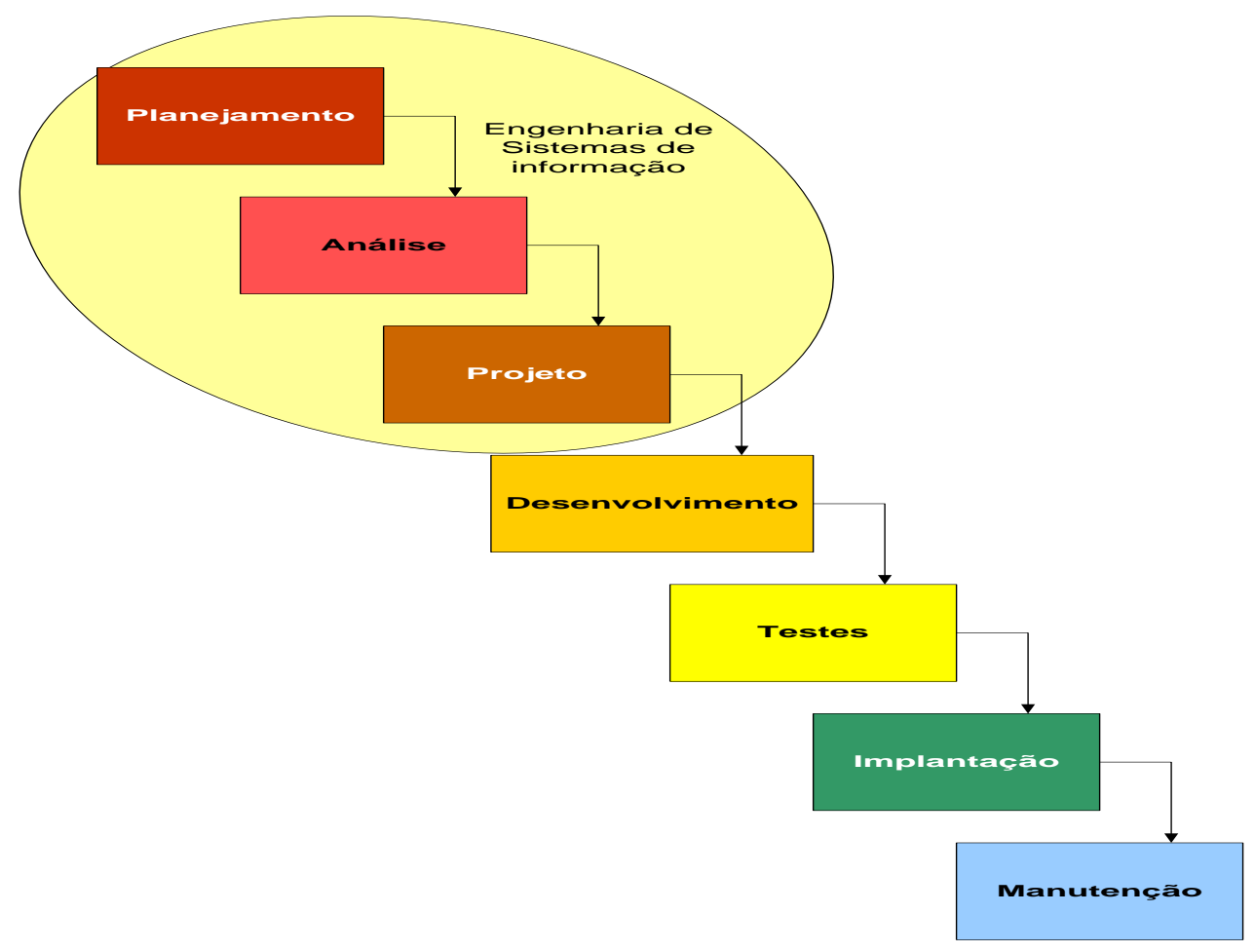

Figura 19 - Modelo seqüencial linear. Fonte: (PRESSMAN, 2002)

Os softwares como todo modelo complexo, evoluem durante um período de tempo. Nos modelos clássicos de desenvolvimento de software a natureza evolutiva é desconsiderada. Por este motivo, estes modelos não atendiam às necessidades de evolução no processo de desenvolvimento de software.

Os modelos evolucionários foram criados e possuem a característica de serem interativos. Assim, permite ao engenheiro de software desenvolver uma versão cada vez mais completa.

O modelo incremental (Figura 20) combina o modelo seqüencial com a filosofia interativa da prototipagem. 


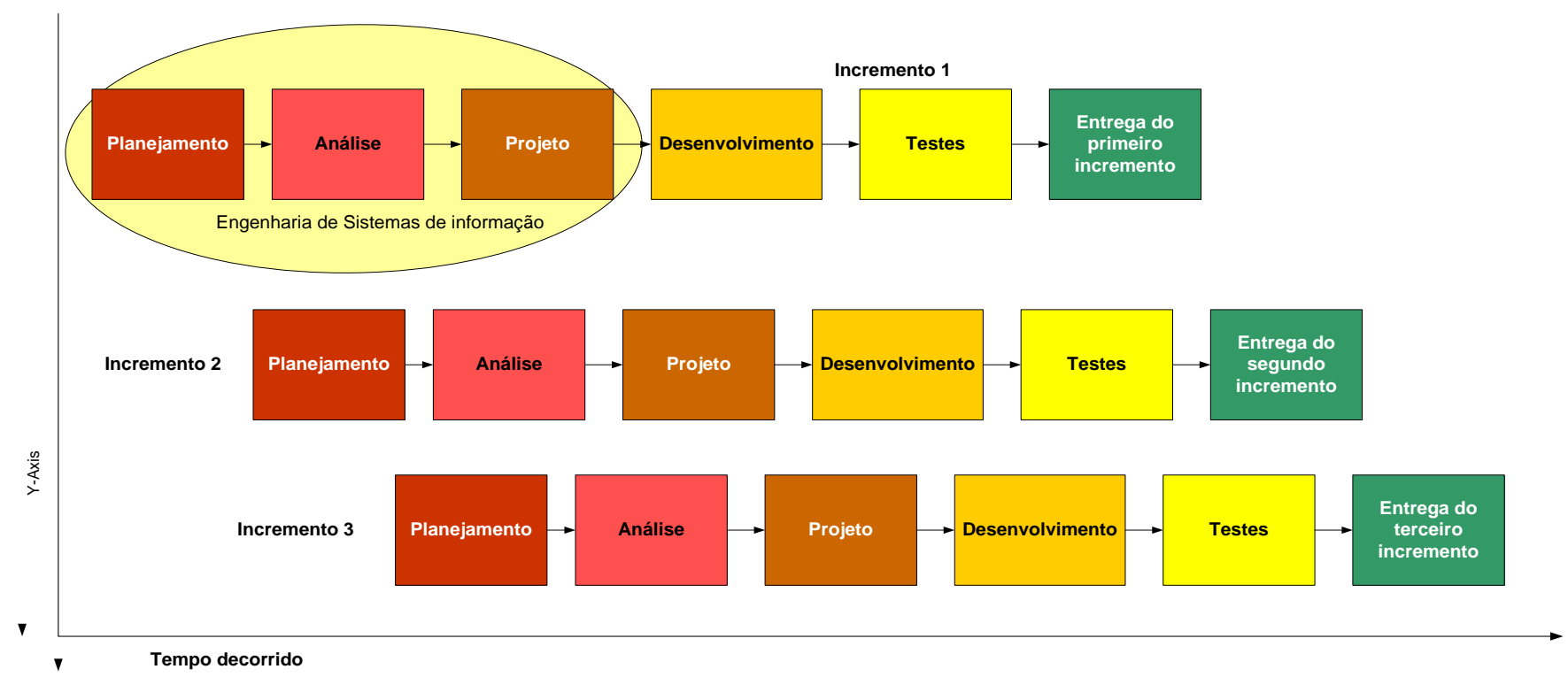

Figura 20 - Modelo incremental. Fonte: (PRESSMAN, 2002).

O modelo espiral (Figura 21) também é um processo de desenvolvimento de software evolucionário combina natureza interativa dos protótipos com aspectos do modelo seqüencial linear. Fornece potencial para desenvolvimento rápido.

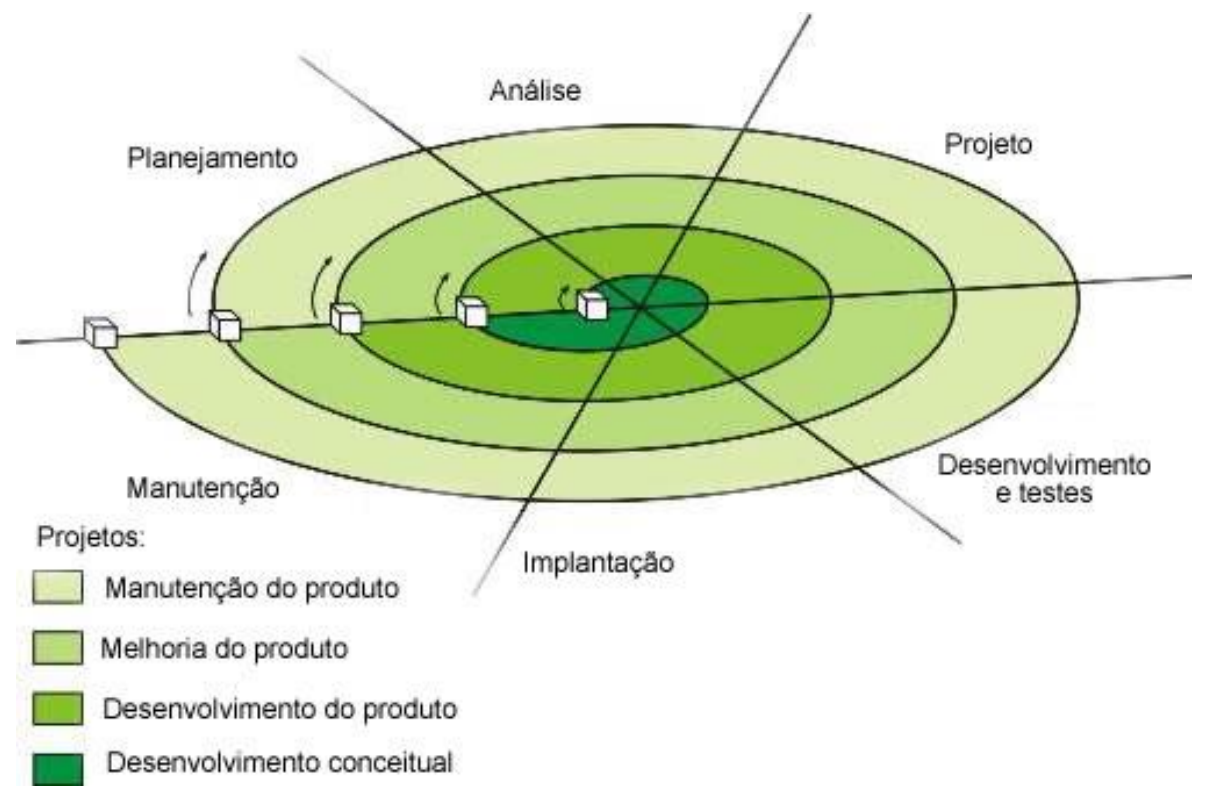

Figura 21 - Típico modelo de espiral. Fonte (PRESSMAN, 2002) 


\section{ESTUDO DE CASO}

O objetivo deste estudo de caso é verificar a aplicabilidade do Modelo do Sistema Viável (VSM - Viable System Model) na construção da arquitetura do SI de incidentes nucleares (SIN) nas instalações de apoio à pesquisa e desenvolvimento de tecnologias navais nucleares, referenciado daqui em diante apenas como "instalações". Desta forma, o modelo proposto deve incorporar o conjunto de funcionalidades especificadas pelo VSM.

É adotada a premissa que o SIN é uma unidade organizacional do "Sistema de gestão de radioproteção e da segurança" (Figura 22).

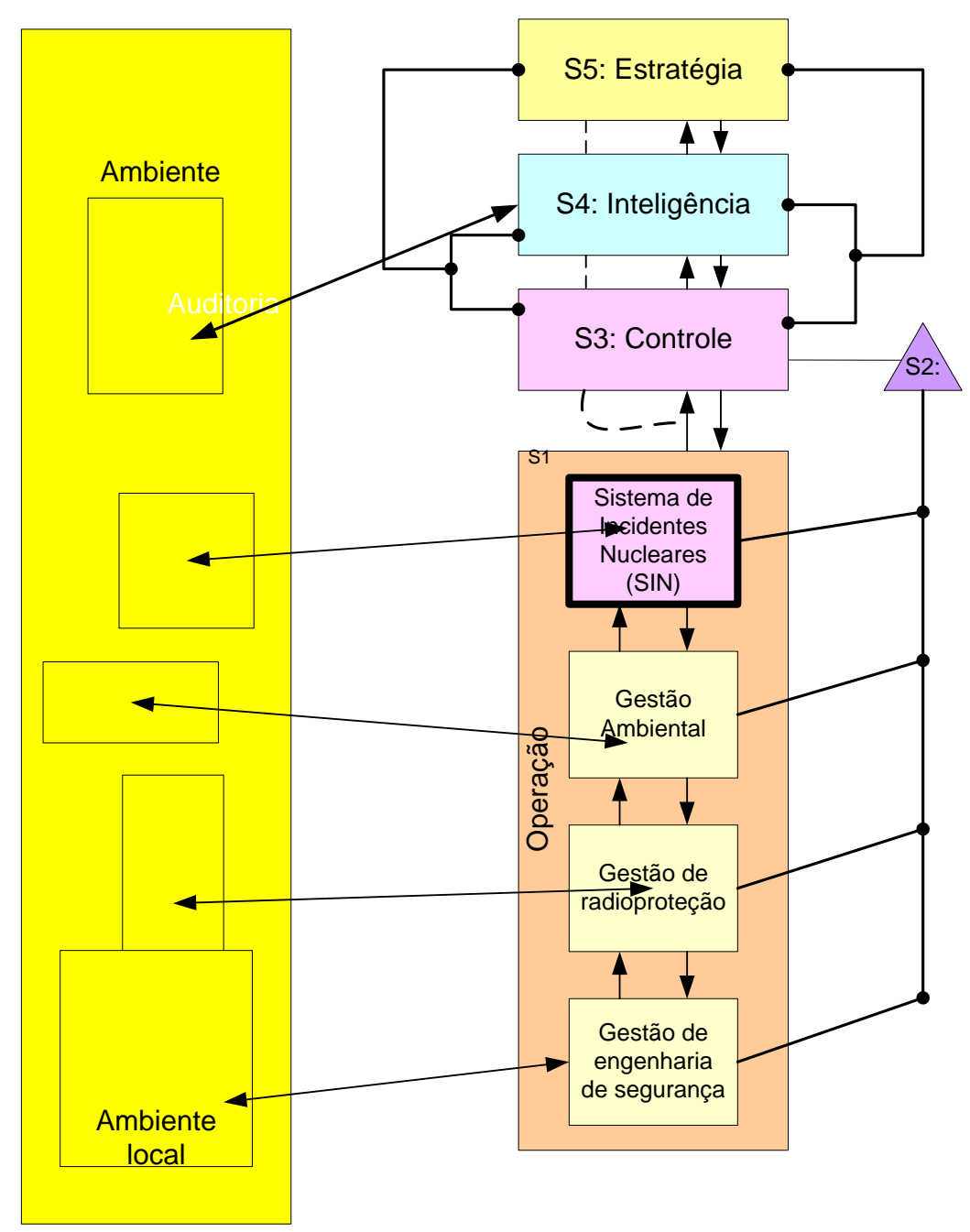

Figura 22 - Sistema de gestão de radioproteção e da segurança, representado como um Sistema Viável, onde o sistema o SIN é uma das suas unidades organizacionais. 


\subsection{Descrição do estudo de caso}

\subsubsection{Sistema de interesse}

O sistema de interesse escolhido é o SIN (Sistema de Incidentes Nucleares). Seu objetivo é armazenar as informações sobre todos os incidentes ocorridos nas instalações, para prover dados às entidades reguladoras, disponibilizar elementos que possam auxiliar a identificar possíveis vulnerabilidades de segurança para evitar novos incidentes ou orientar mitigações de perigos identificados.

\subsubsection{Atividades de levantamento de informações para a modelagem}

Com o objetivo de promover o entendimento do contexto, mapeamento dos elementos do sistema de interesse e o ambiente, são desenvolvidas as seguintes atividades de levantamentos documentais e ambientais:

Pesquisa de documentos dos históricos dos incidentes, análises de segurança das instalações e procedimentos internos de segurança.

Visitas às instalações e conversas informais com os responsáveis pelo projeto e operação das instalações.

Pesquisa das principais normas dos órgãos reguladores da área nuclear no Brasil e exterior.

\subsubsection{Instrumentos utilizados para a modelagem}

A modelagem de um sistema requer um entendimento dos seus objetivos, suas interações com elementos externos e internos, e, uma delimitação clara dos seus limites. São usados três instrumentos auxiliares para criar e documentar este entendimento:

Conceito de recursividade.

Mapeamento entre os componentes da arquitetura de SI e os elementos do SIN. Conceitos de caixa preta, comunicação e controle.

\subsubsection{Recursividade utilizada para identificar o foco}

O princípio da recursividade, como possibilita ver a organização como sistemas 
aninhados sob um determinado foco, é escolhido como instrumento para a identificação do foco do SIN neste estudo. Assim, é traçado um esboço da organização, entendida como sistemas aninhados, sob o ponto de vista do sistema de interesse (Figura 23).

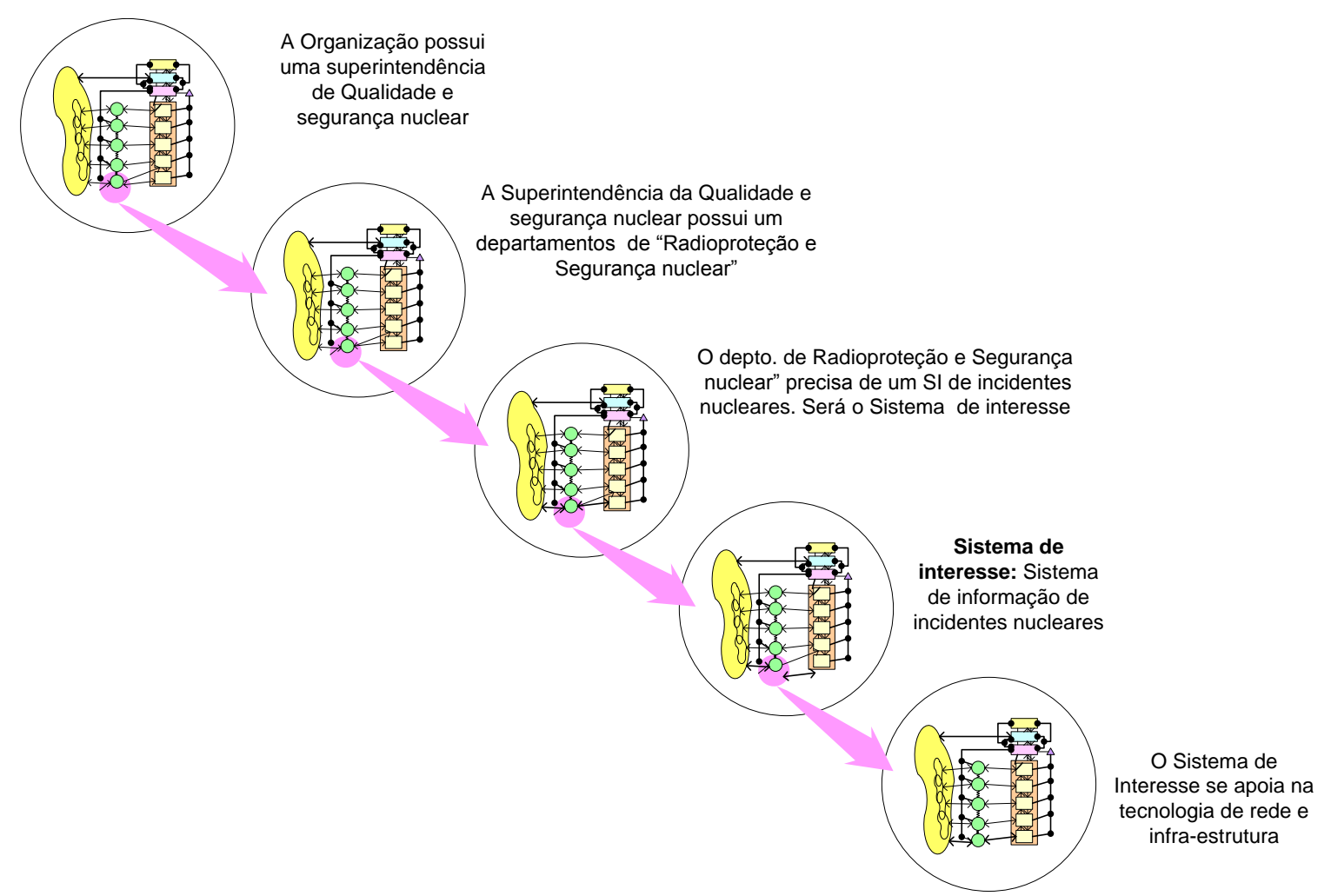

Figura 23 - Esboço da organização como sistemas aninhados sob o ponto de vista do sistema de interesse

\subsubsection{Mapeamento entre os componentes da arquitetura de SI e os elementos} do SIN.

A partir dos dados coletados nas atividades de levantamento de informações, mencionadas no item 4.1.2, e dos elementos constituintes do modelo de arquitetura de sistema de informação sugerida no trabalho de Tait, Barcia \& Pacheco (2001), são elaboradas as Quadros 1 a 6 . Esta visão tabular consolida informações de diversas fontes pesquisadas nas atividades sobre o contexto onde o SIN está inserido. 


\section{Organização}

A organização é um órgão público que trabalha em pesquisa e desenvolvimento, cujo objetivo é desenvolver sistemas nucleares e energéticos para serem aplicados na propulsão de navios da MB. O mapeamento entre a organização e os aspectos/característica do SIN está representado na Quadro 1.

\begin{tabular}{|c|c|}
\hline $\begin{array}{l}\text { Elemento da Arquitetura de SI: } \\
\text { Organização }\end{array}$ & $\begin{array}{l}\text { Aspectos / características do SIN: Órgão governamental } \\
\text { de pesquisa e desenvolvimento de tecnologia de ponta }\end{array}$ \\
\hline Escopo do negócio & Pesquisa de desenvolvimento tecnológico \\
\hline - Estrutura administrativa & Hierárquica \\
\hline - Integração dos sistemas & Fraca \\
\hline - Cultura organizacional & $\begin{array}{l}\text { Burocrática e centralizadora } \mathrm{X} \text { necessidade de gestão } \\
\text { empreendedora que o projeto requer }\end{array}$ \\
\hline
\end{tabular}

Quadro 1 - Aspectos e características do SIN relativos à organização onde está inserido

\section{Negócio}

O negócio desta organização é pesquisa e desenvolvimento em áreas tecnológicas, tais como o desenvolvimento de sistemas térmicos, químicos e eletromecânicos, de processos químicos e projeto, fabricação e testes de componentes.

Com o objetivo de viabilizar o negócio da organização existe um suporte com diversas instalações de testes, laboratórios de validação experimental e algumas oficinas especiais.

O contexto em que o SIN está inserido está mais especificamente ligado à área de gestão da qualidade e segurança nuclear, ou seja, radioproteção e segurança nuclear relativa à saúde humana e ambiental. O mapeamento entre o negócio e os aspectos/característica do SIN está representado na Quadro 2. 


\begin{tabular}{|c|c|}
\hline $\begin{array}{l}\text { Elemento da Arquitetura de SI: } \\
\text { Negócio }\end{array}$ & $\begin{array}{l}\text { Aspectos / características do SIN: } \\
\text { Gestão da qualidade e segurança nuclear -> } \\
\text { radioproteção e segurança nuclear relativa à saúde } \\
\text { humana e ambiental. }\end{array}$ \\
\hline - Mudanças organizacionais & Inércia estrutural \\
\hline $\begin{array}{ll}\text { - Legislação e restrições } \\
\text { governamentais }\end{array}$ & $\begin{array}{l}\text { Grande quantidade de natureza tanto administrativa como } \\
\text { técnica }\end{array}$ \\
\hline - Relação do negócio com SI & Alta e em constante desenvolvimento. \\
\hline - Escopo do negócio & $\begin{array}{l}\text { Sua macro função é desenvolver e coordenar as } \\
\text { atividades de radioproteção, segurança nuclear } \\
\text { monitoração ambiental e de segurança industrial. }\end{array}$ \\
\hline - Satisfação do cliente & $\begin{array}{l}\text { No presente caso, os clientes são os usuários, a alta } \\
\text { administração, funcionários das instalações e público em } \\
\text { geral, mas que talvez desconheça o sistema de interesse. }\end{array}$ \\
\hline - Planejamento estratégico & Obter e manter o licenciamento das instalações \\
\hline $\begin{array}{l}\text { - Relacionamento com ambiente } \\
\text { externo }\end{array}$ & $\begin{array}{l}\text { Forte, controlado por normas de segurança e pelo público } \\
\text { em geral }\end{array}$ \\
\hline
\end{tabular}

Quadro 2 - Aspectos e características do SIN relativos ao negócio onde está inserido

\section{Sistemas}

Os sistemas de informação desta área são classificados como confidenciais e por esta razão, o nível de segurança das informações deve ser compatível com sua classificação. Os sistemas são confinados em redes estanques em locais de acesso controlado. Muitas informações se encontram em arquivos de papel que também são controlados. Os back-ups devem possuir a mesma classificação de segurança.

Existe um projeto de melhoria de ferramentas para análise de segurança e neste escopo se encaixam sistemas de informação.

O SIN apesar de estar inserido em um contexto de alta tecnologia e em ambiente crítico é um sistema para cadastro de incidentes e não é caracterizado como sistema crítico. Desta forma, em sua modelagem e em seu desenvolvimento se aplicam as técnicas tradicionais, porém, deve ser levado em consideração o caráter das informações tratadas que são classificadas como confidenciais. O mapeamento entre os sistemas existentes e os aspectos/característica do SIN está representado na Quadro 3. 


\begin{tabular}{|c|c|}
\hline $\begin{array}{l}\text { Elemento da Arquitetura de SI: } \\
\text { Sistemas }\end{array}$ & $\begin{array}{c}\text { Aspectos / características do SIN: } \\
\text { SI que apóiam as atividades do sistema de interesse, no } \\
\text { presente caso, é o próprio sistema de interesse. }\end{array}$ \\
\hline Dados & $\begin{array}{l}\text { Dados de relevantes para o sistema de interesse que } \\
\text { podem se transformar em informações }\end{array}$ \\
\hline - Modelagem de dados & $\begin{array}{l}\text { Levantamento dos dados e seus relacionamentos, } \\
\text { pesquisa de campos já utilizados em base de dados de } \\
\text { incidentes nucleares e tipo de classificação }\end{array}$ \\
\hline - Administração dos dados & $\begin{array}{l}\text { Back-up, restauração, gatilhos, procedimentos, } \\
\text { otimização, alta segurança (security) dos dados }\end{array}$ \\
\hline Ciclo de vida & $\begin{array}{l}\text { Levantamento de requisitos, projeto, desenvolvimento, } \\
\text { testes, implantação, manutenção }\end{array}$ \\
\hline - Planejamento estratégico de SI & $\begin{array}{l}\text { Incluído no projeto de melhoria das ferramentas para } \\
\text { análise de segurança }\end{array}$ \\
\hline - Sistemas inter-organizacionais & Não existe \\
\hline $\begin{array}{lll}\text { - } & \text { Metodologias } & \text { de } \\
\text { desenvolvimento do SI } & \end{array}$ & $\begin{array}{l}\text { UML utilizando requisitos de qualidade em todas as fases } \\
\text { do ciclo de vida, software livre, alta segurança (security). }\end{array}$ \\
\hline \multicolumn{2}{|l|}{ Processos } \\
\hline - Cadastro análise de segurança & \multirow{11}{*}{$\begin{array}{l}\text { Estes são os requisitos funcionais que deverão ser } \\
\text { descritos na fase de especificação dos requisitos. Neste } \\
\text { estudo de caso estas funcionalidades deverão estar } \\
\text { contidas nas unidades organizacionais do sistema de } \\
\text { incidentes nucleares. }\end{array}$} \\
\hline - $\quad$ Cadastro materiais & \\
\hline $\begin{array}{l}\text { - Cadastro matriz instalação } X \\
\text { materiais }\end{array}$ & \\
\hline - Cadastro funcionários & \\
\hline - Cadastro exames funcionários & \\
\hline $\begin{array}{l}\text { - Cadastro de níveis aceitáveis } \\
\text { para cada material }\end{array}$ & \\
\hline - Cadastro de incidentes & \\
\hline - Emissão relatórios incidentes & \\
\hline - Emissão alerta de incidentes & \\
\hline - Postulados de acidentes & \\
\hline $\begin{array}{l}\text { - Cadastro de normas (parâmetros } \\
\text { a serem seguidos) }\end{array}$ & \\
\hline
\end{tabular}

Quadro 3 - Aspectos e características do SIN relativos aos SI onde está inserido

\section{Tecnologia da informação}

A tecnologia de informação do ambiente em questão é determinada pelo departamento de $\mathrm{TI}$ e suporte da organização. As políticas e regras se aplicam a toda organização e são classificadas por níveis de segurança. O contexto onde está inserido o SIN é classificado como nível 1 e deve ser tratado como confidencial. A rede onde o SIN será implantado é uma rede segura e segregada. O hardware disponível constitui-se de servidores e estações de trabalho com tecnologia atualizada. É possível, salvo melhor juízo, a implantação de um SI deste porte sem impacto nestes recursos. O pessoal da área usuária deste SI é capacitado e não 
requer treinamento além das funcionalidades do novo sistema. Existem softwares homologados para o desenvolvimento. O quadro 4 reflete o mapeamento entre os aspectos de TI existentes e os aspectos/característica do SIN.

\begin{tabular}{|c|c|}
\hline $\begin{array}{l}\text { Elemento da Arquitetura de SI: } \\
\text { Tecnologia da Informação }\end{array}$ & $\begin{array}{l}\text { Aspectos / características do SIN: } \\
\text { Tecnologia da Informação. }\end{array}$ \\
\hline - Políticas e regras para uso de TI & $\begin{array}{l}\text { O SIN deve conter requisitos de segurança compatíveis } \\
\text { com sua classificação de confidencial. }\end{array}$ \\
\hline - Hardware & O hardware disponível é compatível com o porte do SIN. \\
\hline - Software & $\begin{array}{l}\text { Existe política de homologação de sw. Desta forma, o } \\
\text { projeto e o próprio sw deverão ser homologados. }\end{array}$ \\
\hline - $\quad$ Fatores ambientais & Não são relevantes neste contexto. \\
\hline - Recursos humanos & $\begin{array}{l}\text { Não requer treinamento além das funcionalidades do SIN. } \\
\text { Motivados. }\end{array}$ \\
\hline
\end{tabular}

Quadro 4 - Aspectos e características do SIN relativos a TI onde está inserido

\section{Recursos humanos}

Os recursos humanos para o desenvolvimento do SI são funcionários da própria organização, possuem treinamento nas ferramentas homologadas e são comprometidas com a confidencialidade que o projeto como um todo requer.

O desenvolvimento do SIN está patrocinado, pois a gerência está comprometida com a equipe de radioproteção e segurança nuclear e são os próprios patrocinadores do novo SI.

Para a modelagem e o desenvolvimento de um SI é essencial o conhecimento dos requisitos do SI. Para que esta necessidade seja satisfeita, além da pesquisa documental é essencial ter entrevistas com o pessoal da área que conhece o negócio e que será o utilizador do sistema. Assim, para que o SI atenda as expectativas e contenha as funcionalidades necessárias, os usuários e os patrocinadores devem ser ouvidos e o escopo deve ser alinhado entre os usuários, os patrocinadores e o arquiteto do SI. Neste caso, os patrocinadores e os usuários são os clientes que receberão o novo SI. O mapeamento entre os sistemas existentes e os aspectos/característica do SIN está representado na Quadro 5. 


\begin{tabular}{|c|l|}
\hline $\begin{array}{c}\text { Elemento da Arquitetura de SI: } \\
\text { Usuários (todos os níveis de atuação) }\end{array}$ & \multicolumn{1}{c|}{$\begin{array}{c}\text { Aspectos / características do SIN: } \\
\text { Recursos humanos. }\end{array}$} \\
\hline$\bullet \quad$ Gerenciais & Patrocinadores \\
\hline - Operacionais & Usuários da área de radioproteção e segurança nuclear \\
\hline • Desenvolvedores & Funcionários da organização \\
\hline - Clientes & Patrocinadores e usuários \\
\hline
\end{tabular}

Quadro 5 - Aspectos e características do SIN relativos aos usuários

\subsubsection{Caixa preta utilizada para detalhar os processos}

O conceito de caixa preta diz que entradas causam perturbações no interior do sistema que produzem outras perturbações (saídas) geradas pelas primeiras. Não é conhecido como as perturbações de entrada se articulam com as de saída no interior da caixa.

O SI de incidentes nucleares interage com o meio ambiente através de entradas e saídas, que são os canais de comunicação entre o sistema e o meio externo (Figura 24).

Através dos canais de comunicação, entre o SI e o meio externo, o SI percebe um estímulo externo e é capaz de dar uma resposta para as mudanças que ocorrem internamente. Esta resposta é a ação do controle.

A adoção destes conceitos permite uma estruturação do pensamento em diversas fases e assim as funcionalidades são conhecidas através do detalhamento em camadas, sempre considerando quais são as entradas e saídas do SI. 


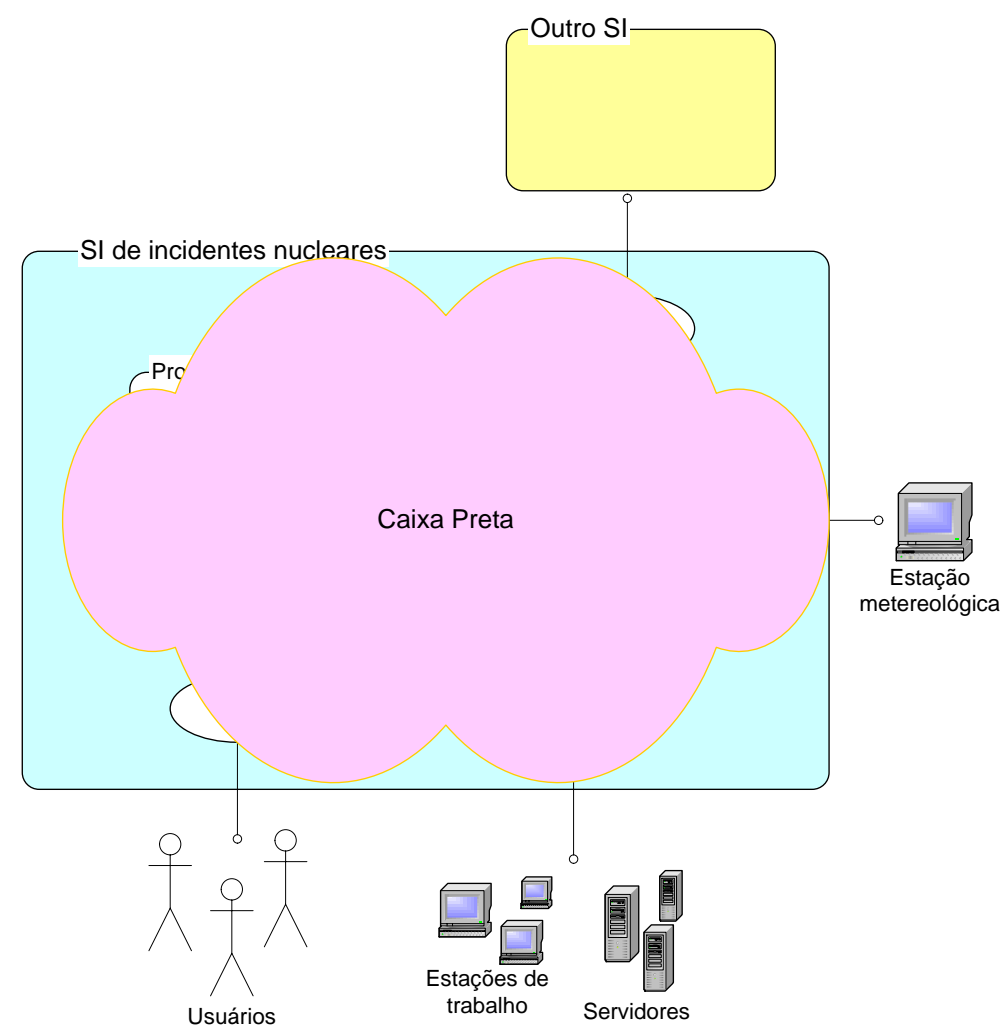

Figura 24 - Interação do SI de incidentes nucleares com o meio ambiente - Fase 1.

Para facilitar a interpretação, será usada a simbologia utilizada em diagramas de SI para organizações (Figura 25).

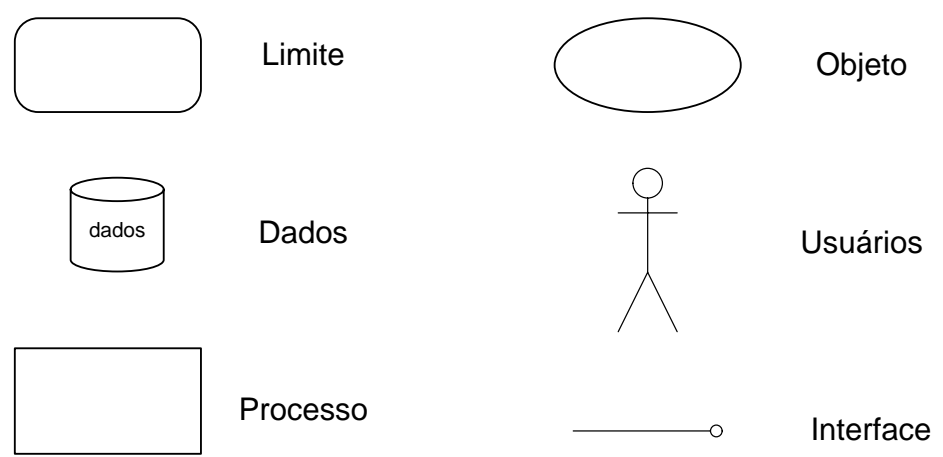

Figura 25 - Legenda dos símbolos utilizados.

A fase 2 de observação detalha um pouco melhor as partes que o compõem (Figura 26). Entretanto, o foco é o próprio sistema de interesse, uma vez que o refinamento se refere à abertura de uma "caixa preta". 


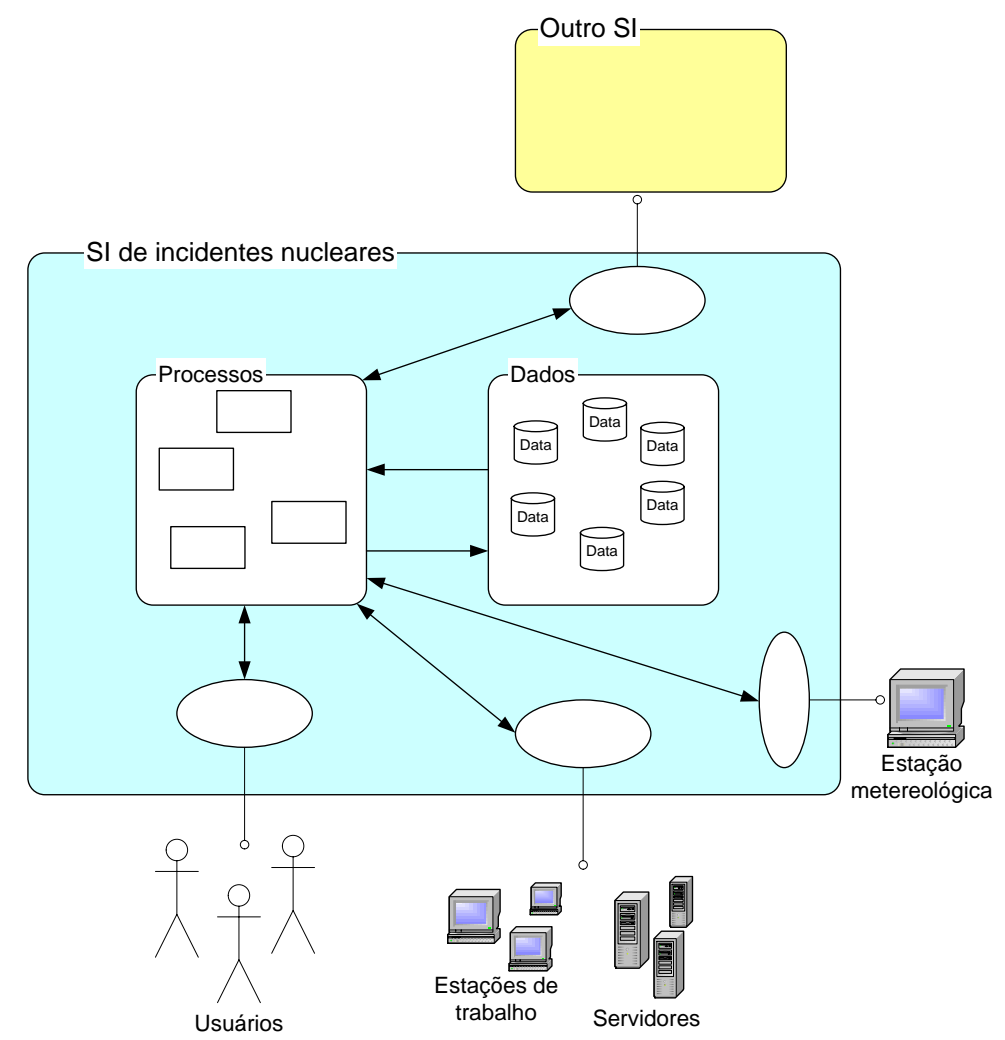

Figura 26 - O SI interage com o meio externo através de objetos ${ }^{14}$ construídos para fazer a interface ente eles.

O meio externo pode ser constituído por pessoas, outros SI, sinais vindos de unidades receptoras, processos iniciados por aplicações em estações de trabalho ou servidores.

Existem os usuários que são os responsáveis por cadastrar os incidentes, outras informações relevantes para dar suporte ao SIN e solicitar informações do SIN. A interface entre os usuários e o SIM são as estações de trabalho. Os servidores fornecem dados já cadastrados, recebem informações e as registram além de executar aplicações do SIN.

A estação metereológica fornece dados ao SI. Outros SI fornecem dados para o SI. Um exemplo deste caso são os dados dos funcionários.

Existem internamente processos que trocam informações com estruturas de dados de acordo com sua função pré-determinada.

\footnotetext{
${ }^{14}$ Objeto é uma entidade atômica, formado pela união de um estado e comportamento. Possui um "encapsulamento" que assegura uma forte coesão interna, e uma fraca ligação com o exterior. O objeto mostra sua verdadeira função e responsabilidade quando, envia mensagens e torna-se parte do cenário de comunicação(MULLER, 1997).
} 
Os processos são constituídos por objetos. Eles podem ser extremamente complexos, no entanto, formados de vários objetos simples.

A continuação da abertura das caixas pretas vai possibilitar o detalhamento de todos os processos, estrutura de dados e troca de informações. O engenheiro de sistema determina o grau de detalhamento adequado ao seu projeto.

Cada objetivo do sistema é detalhado até encontrar cada parte do SI de incidentes.

\subsubsection{Definição de um modelo}

O modelo visa criar uma proposta alternativa para a especificação da arquitetura do SIN. Os conceitos do VSM estão explorados no capítulo 3, e aqui são utilizados para a definição desta modelagem.

Baseado, novamente no conceito de recursividade, são escolhidos dois cenários para dar suporte à definição da arquitetura do SIN.

Primeiro cenário: o sistema de interesse no ambiente, ou seja, o SIN contido no sistema de gestão de radioproteção e da segurança. Neste caso, o sistema de interesse é uma unidade operacional do Sistema de gestão de radioproteção e da segurança.

Segundo cenário: o sistema de interesse é um sistema viável e desta forma deve possuir os cinco funcionalidades do VSM. Este cenário é dividido em duas representações: a primeira, como o engenheiro de software pode estruturar seu pensamento para definir a arquitetura de um SI que se enquadre em um sistema viável; e a segunda, deverá ser o produto desta estruturação, ou seja, a definição da arquitetura do SI. 


\subsection{Primeiro cenário}

O primeiro cenário considera o SIN como parte do Sistema de gestão de radioproteção e da segurança(Figura 27 ).

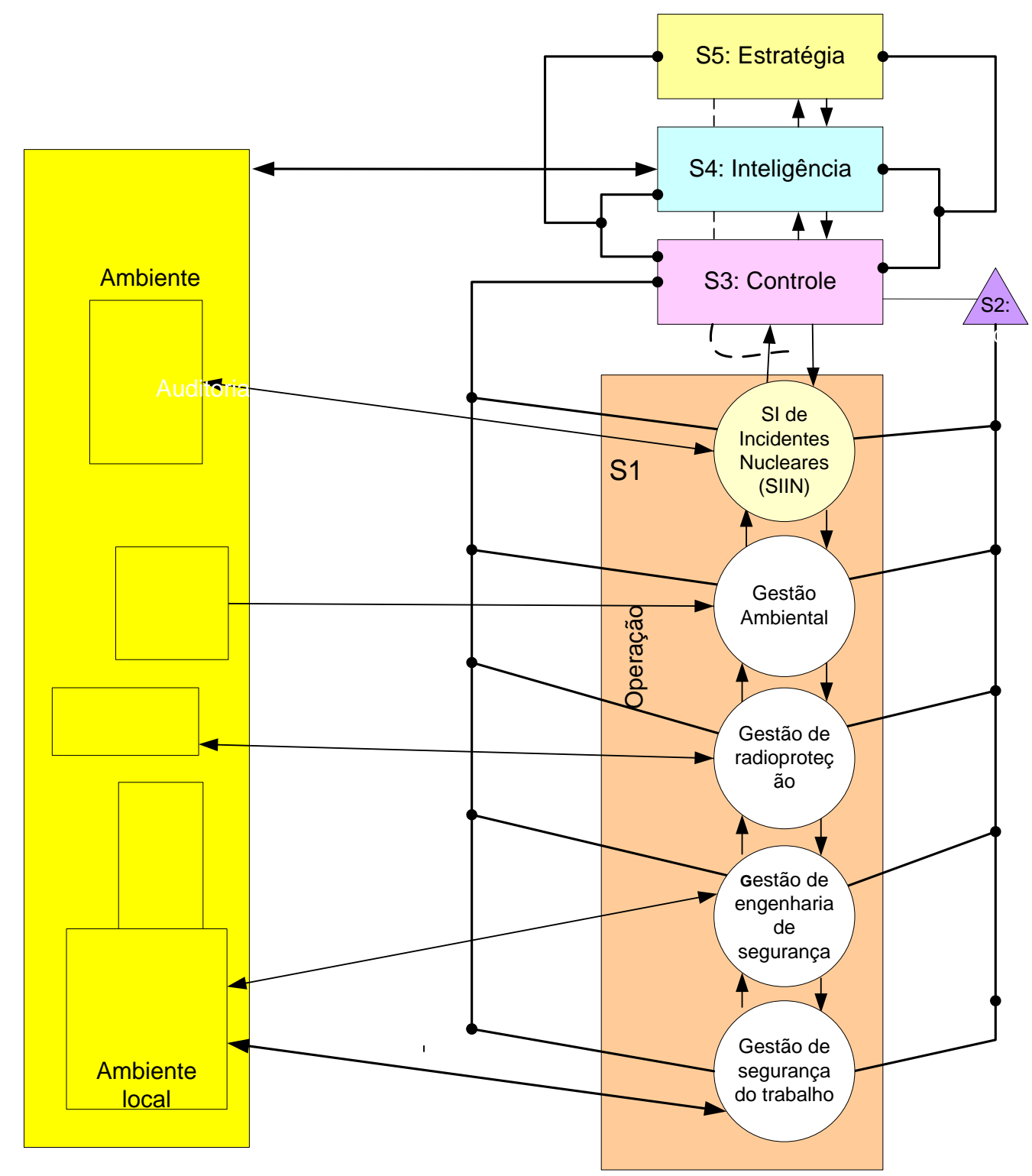

Figura 27 - Primeiro cenário: SI de incidentes nucleares contido no Sistema de gestão de radioproteção e da segurança 


\subsubsection{Descrição constitutiva das partes}

O objetivo da descrição constitutiva é posicionar o SIN (Figura 28) como um sistema viável interagindo com outros sistemas viáveis. Esta interação pode ocorrer no mesmo nível entre sistemas paralelos (Figura 29), com o nível imediatamente superior (Figura 30) e com o nível imediatamente inferior (Figura 31). O SIN será descrito no segundo cenário.

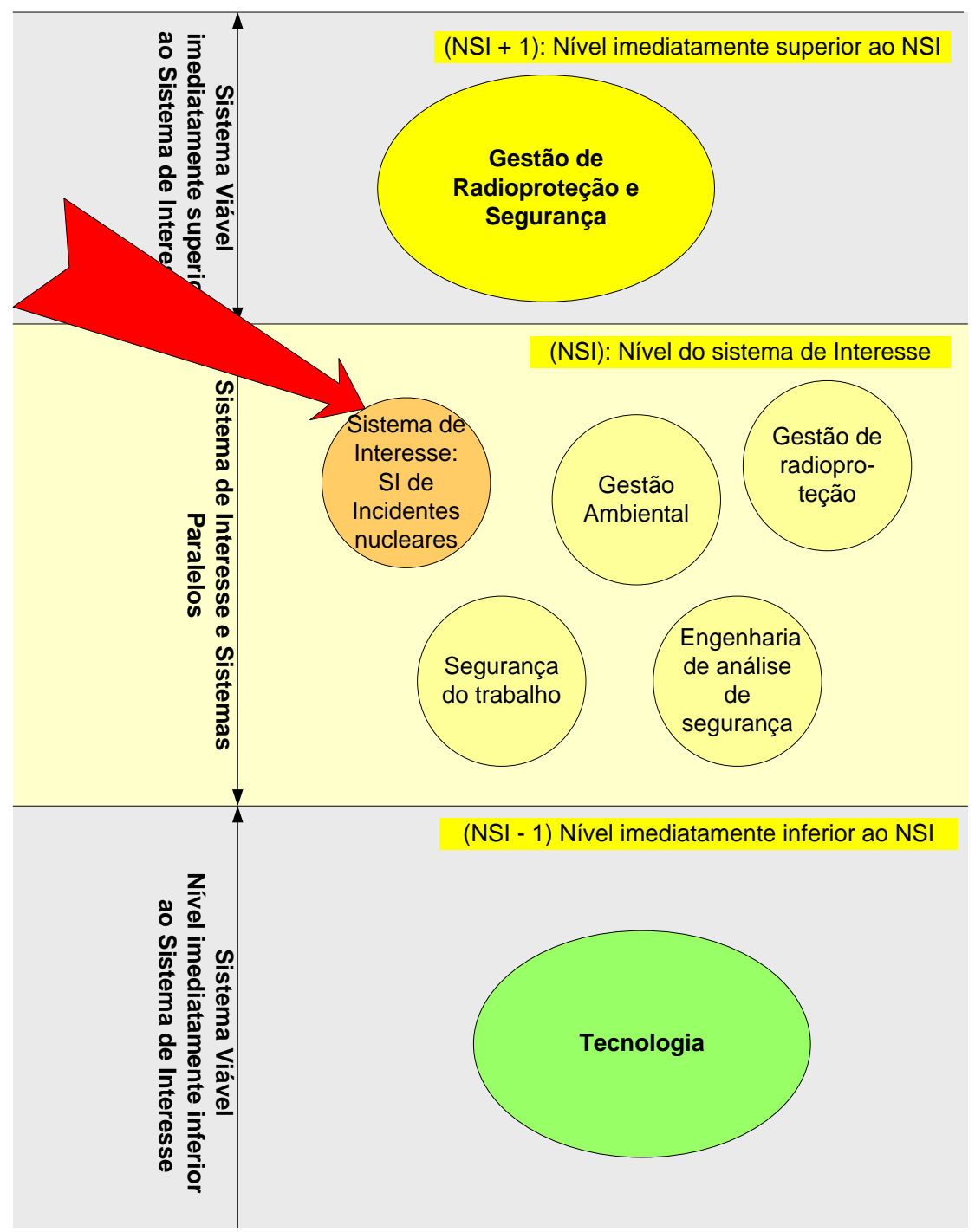

Figura 28 - SIN faz parte do Sistema de gestão de radioproteção e da segurança

O sistema em um nível imediatamente superior é o sistema de gestão de radioproteção e da segurança (safety) relativa à saúde humana e ambiental. Ele representa o Sistema viável analisado no primeiro cenário. 
O sistema de gestão de radioproteção e da segurança possui a macro função de desenvolver e coordenar as atividades de radioproteção, segurança nuclear, monitoração ambiental e de segurança industrial.

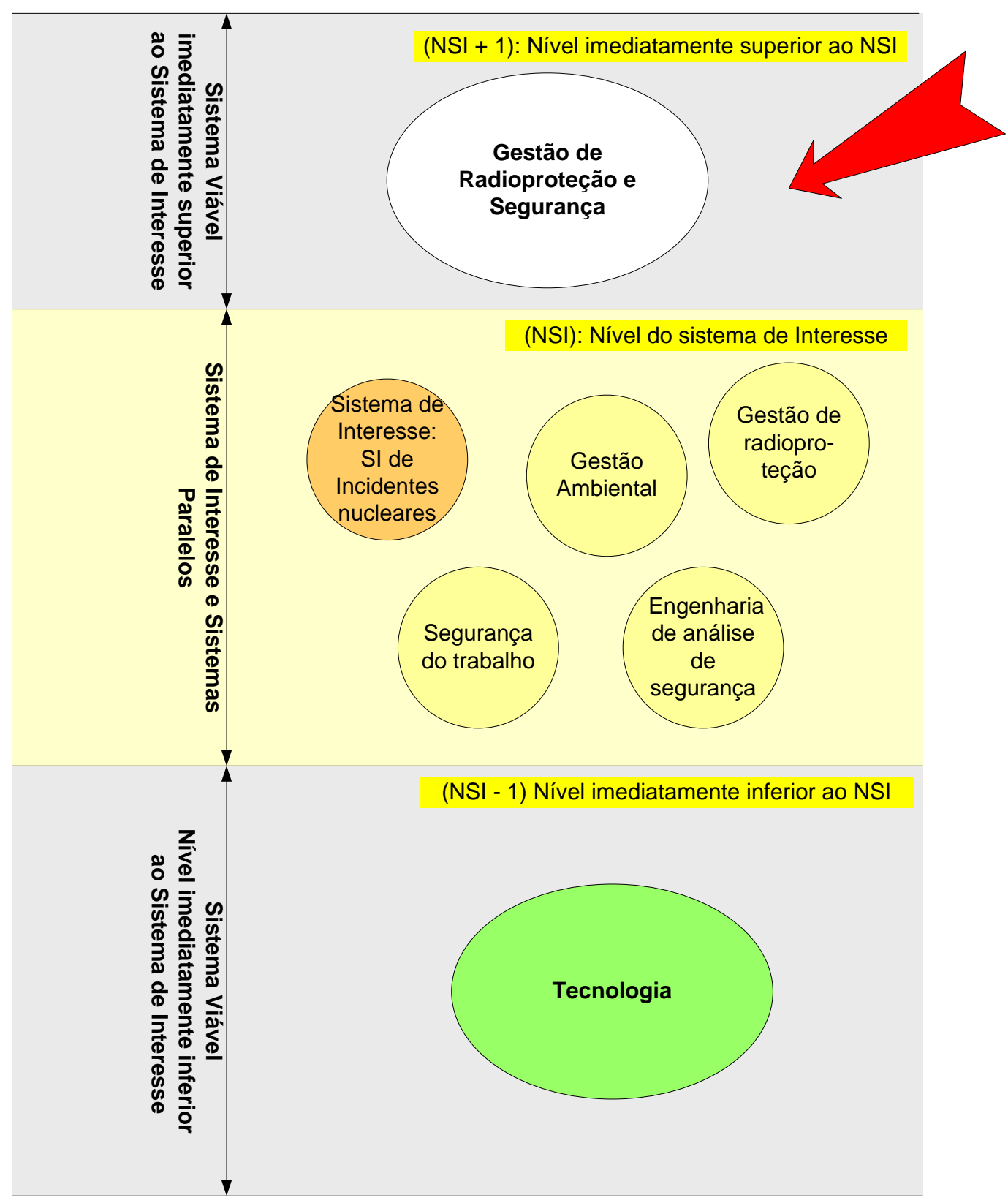

Figura 29 - Nível de recursão imediatamente superior 


\section{Sistemas em nível paralelo}

Primeiro sistema paralelo: Sistema de gestão ambiental (SGA).

Suas funções principais são: controlar, de acordo com as normas vigentes, as liberações de efluentes radioativos líquidos e gasosos gerados pelas unidades operacionais; monitorar a área de influência estabelecida em um raio de 10 km; avaliar impactos ambientais que possam ser gerados pelas unidades organizacionais e participar direta ou indiretamente das suas correções; e gerenciar as atividades referentes à aquisição dos dados metereológicos da região em questão.

Segundo sistema paralelo: Gestão de Radioproteção (SGR).

Suas funções principais são: exercer o controle radiológico de indivíduos ocupacionalmente expostos à radiação; estabelecer a classificação, o controle de acesso, o balizamento, a sinalização, a monitoração e orientar na descontaminação de áreas contaminadas; identificar fontes de radiação nas unidades organizacionais inclusive os rejeitos que, por norma, devem ser sinalizados e registrados; controlar os equipamentos de radioproteção, isto significa: colocar identificação, registrar, inspecionar, calibrar, aferir, ajustar, realizar manutenção e descontaminação; treinar os indivíduos ocupacionalmente expostos à radiação; estabelecer e manter sistema atualizado e centralizado de dados radiológicos, planos de radioproteção, procedimentos, regulamentos, funções, atividades, relatórios e outras informações exigidas pela Comissão Nacional de Energia nuclear (CNEN); dar alertas sobre qualquer eventualidade de ultrapassagem de doses; segregar e monitorar rejeitos radioativos sólidos; e providenciar a manutenção e aferição para os equipamentos utilizados na monitoração, bem como os que dão apoio a estes equipamentos.

Terceiro sistema paralelo: Análise de segurança (SGaS).

Suas principais funções são: realizar análise de segurança; apoiar tecnicamente o projeto e a operação sobre aspectos relacionados com a confiabilidade e a segurança através da análise probabilística de segurança, análise de confiabilidade 
e análise de risco; estimar o impacto ambiental; e analisar o transporte atmosférico ou aquático de liberações acidentais e de rotina para o meio ambiente.

Quarto sistema paralelo: Análise de segurança Engenharia de segurança (SGeS).

Suas principais funções são: exercer atividades de prevenção de acidentes; orientar as áreas na maximização da segurança do trabalho; efetuar inspeções; e identificar riscos de acidentes.

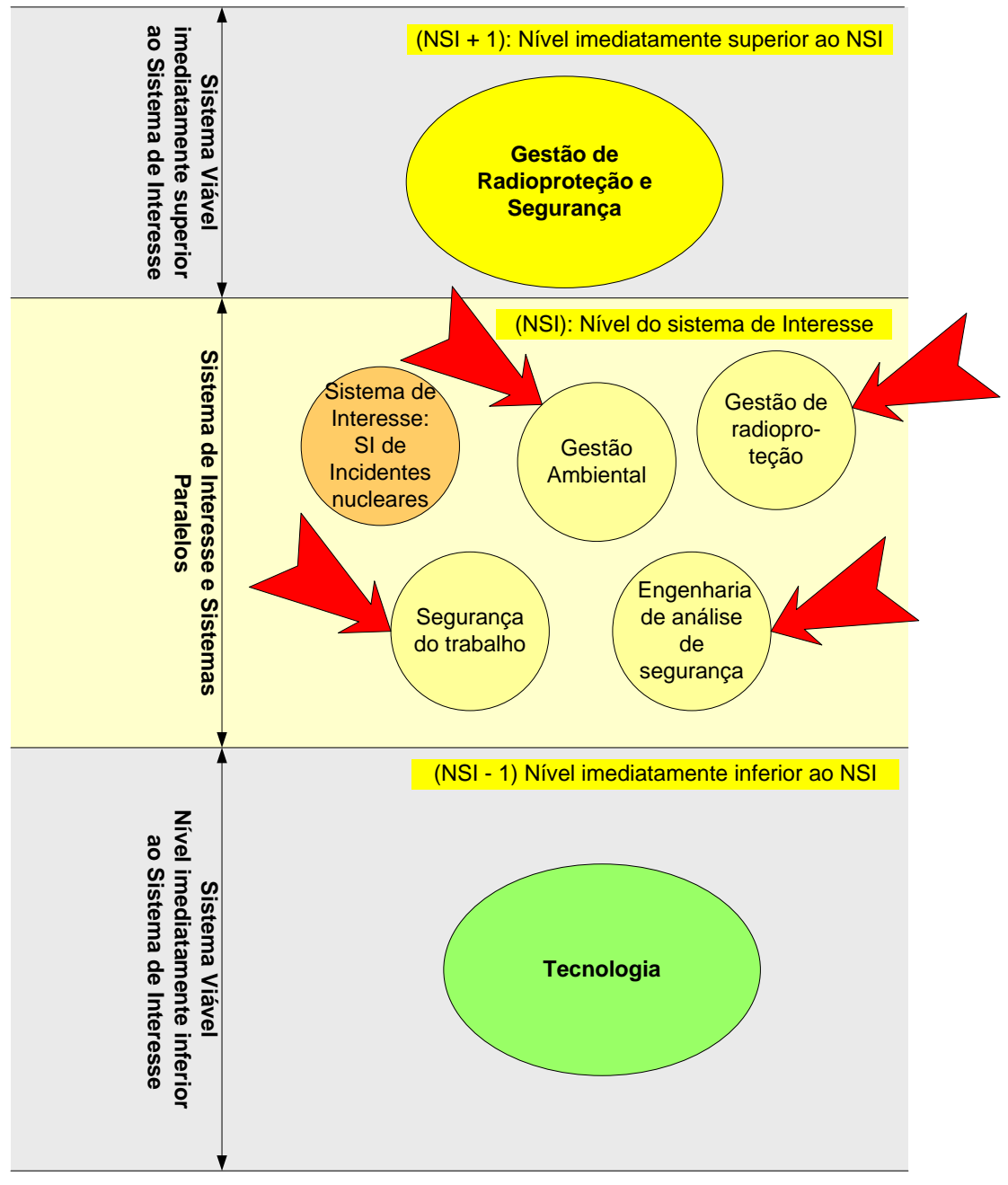

Figura 30 - Níveis de recursão paralelos

Sistema em um nível imediatamente inferior 
Tecnologia, isto é, Software básico: Sistema operacional e linguagem de desenvolvimento, hardware, infra-estrutura de redes, ambiente físico, banco de dados. Neste nível serão considerados também os operadores apesar de não se encaixarem em tecnologia, mas por exercerem um papel no sistema em um mesmo nível.

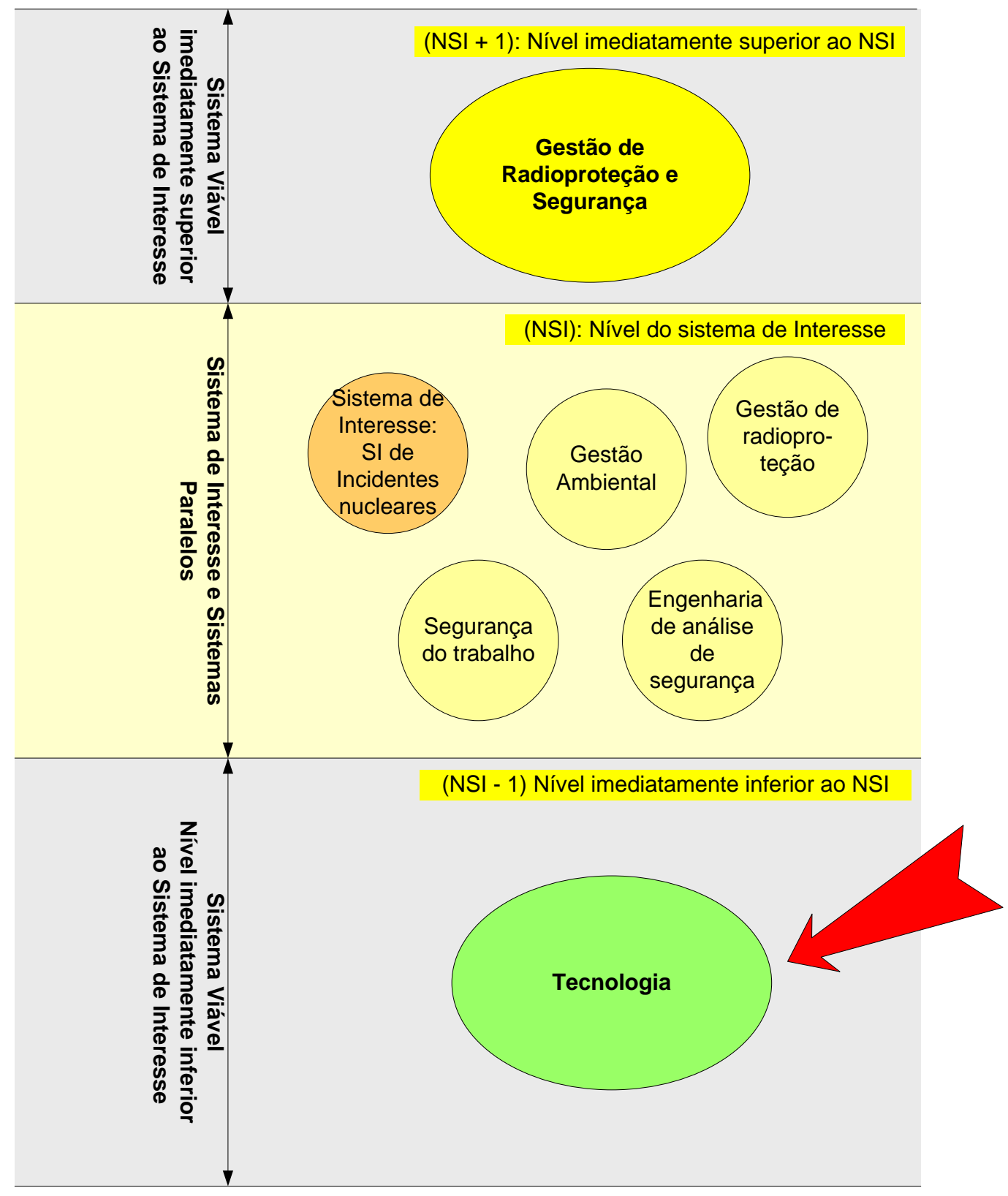

Figura 31 - Nível de recursão imediatamente Inferior. 


\subsubsection{Descrição funcional}

Aqui são descritos como os sistemas paralelos, o sistema localizado imediatamente no nível superior e no nível inferior se relacionam com o sistema de interesse e entre si. O objetivo desta descrição funcional é identificar os fluxos de informação entre os sistemas.

\section{Fluxo de informações entre sistemas paralelos}

Os sistemas paralelos trocam informações entre si. Abaixo são apresentados, em forma de quadros, os fluxos identificados entre o sistema de interesse SIN e os demais sistemas de mesmo nível. As setas indicam a direção que a informação flui entre os sistemas.

A comunicação entre o SIN e o sistema de gestão ambiental (SGA) está representada no Quadro 6.

\begin{tabular}{|l|l|}
\hline Fluxo informação SIN $\rightarrow$ SGA & Fluxo informação SGA $\rightarrow$ SIN \\
\hline $\begin{array}{l}\text { Informações sobre incidentes onde os limites } \\
\text { estabelecidos por norma de liberação de } \\
\text { efluentes líquidos e gasosos foram } \\
\text { alcançados ou ultrapassados }\end{array}$ & $\begin{array}{l}\text { Valores limites estabelecidos por norma de } \\
\text { liberação de efluentes líquidos e gasosos }\end{array}$ \\
\hline & $\begin{array}{l}\text { Informações sobre alterações que } \\
\text { alcançaram ou excederam aos valores limites } \\
\text { na área de influência monitorada (10 km) - } \\
\text { Associadas à incidente ocorrido ou como } \\
\text { indício de operação anormal da planta }\end{array}$ \\
\hline & $\begin{array}{l}\text { Sugestões de alteração de procedimentos } \\
\text { relativos à diminuição de impacto ambiental } \\
\text { no caso de incidentes ou no caso de ser } \\
\text { percebida uma oportunidade para melhoria }\end{array}$ \\
\hline & $\begin{array}{l}\text { Dados metereológicos no momento de } \\
\text { incidente caso seja relevante para o evento }\end{array}$ \\
\hline
\end{tabular}

Quadro 6 - Interface entre o SIN e o SGA

O quadro 7 identifica os fluxos de informação entre os sistemas paralelos SIN e o Sistema de gestão análise de segurança (SGaS). 


\begin{tabular}{|l|l|}
\hline Fluxo informação SIN $\rightarrow$ SGaS & Fluxo informação SGaS $\rightarrow$ SIN \\
\hline Informações sobre incidentes & $\begin{array}{l}\text { Cenários de incidentes postulados na análise } \\
\text { de risco / probabilística de segurança / } \\
\text { análise de confiabilidade }\end{array}$ \\
\hline $\begin{array}{l}\text { Informações sobre transporte atmosférico, } \\
\text { aquático de liberações acidentais e de rotina } \\
\text { para o meio ambiente no caso de incidentes, } \\
\text { quando possível quantificar. }\end{array}$ & \\
\hline
\end{tabular}

Quadro 7 - Interface entre o SIN e o SGaS

O Quadro 8 identifica os fluxos de informação entre o SIN e o Sistema de gestão de Radioproteção (SGR).

\begin{tabular}{|l|l|}
\hline Fluxo informação SIN $\rightarrow$ SGR & Fluxo informação SGR $\rightarrow$ SIN \\
\hline $\begin{array}{l}\text { Informações sobre incidentes (inclui } \\
\text { envolvidos) }\end{array}$ & $\begin{array}{l}\text { Valores limites estabelecidos por norma de } \\
\text { doses de radiação }\end{array}$ \\
\hline & $\begin{array}{l}\text { Conseqüências nos indivíduos envolvidos no } \\
\text { incidente }\end{array}$ \\
\hline & $\begin{array}{l}\text { Identificação se incidente foi causado por falta } \\
\text { de Classificação, controle de acesso, } \\
\text { balizamento ou sinalização e sugerir alguma } \\
\text { correção caso necessário }\end{array}$ \\
\hline & $\begin{array}{l}\text { Descrição das ações de monitoramento e } \\
\text { descontaminação nos ambiente/pessoal } \\
\text { envolvido no incidente }\end{array}$ \\
\hline $\begin{array}{l}\text { Descrição de problemas identificados em } \\
\text { equipamentos de radioproteção falta de } \\
\text { identificação, sinalização, registros, inspeção, } \\
\text { calibração, aferição, ajuste, manutenção ou } \\
\text { descontaminação que porventura estejam } \\
\text { associados ao incidente. Sugestão de } \\
\text { correção. Descrição da ação corretiva. }\end{array}$ \\
\hline $\begin{array}{l}\text { Rescrição de erro humano. Descrição da } \\
\text { ação corretiva. }\end{array}$ \\
\hline inciatório para a CNEN padronizado sobre o & \\
\hline
\end{tabular}

Quadro 8 - Interface entre o SIN e o SGR

O Quadro 9 identifica os fluxos de informação entre o SIN e Sistema de gestão de engenharia de segurança (SGeS). 


\begin{tabular}{|l|l|}
\hline Fluxo informação SIN $\rightarrow$ SGaS & Fluxo informação SGeS $\rightarrow$ SIN \\
\hline Informações sobre incidentes & $\begin{array}{l}\text { Informações de riscos identificados em } \\
\text { inspeços }\end{array}$ \\
\hline & Ações de prevenção de incidentes \\
\hline
\end{tabular}

\section{Quadro 9 - Interface entre o SIN e o Sistema SGeS}

O Quadro 10 identifica os fluxos de informação entre o SIN e o sistema de gestão radioproteção e da segurança (safety) relativa à saúde humana e ambiental (SGRS).

\begin{tabular}{|l|l|}
\hline Fluxo informação SIN $\rightarrow$ SGRS & Fluxo informação SGRS $\rightarrow$ SIN \\
\hline Informações sobre incidentes & Solicitações de relatórios \\
\hline Relatórios para entidades reguladoras & \\
\hline $\begin{array}{l}\text { Possíveis pontos de mitigação de futuros } \\
\text { incidentes }\end{array}$ & \\
\hline & \\
\hline
\end{tabular}

Quadro 10 - Interface entre o SIN e o SGRS 


\subsection{Segundo cenário}

O Sistema de interesse é um sistema viável e desta forma deve possuir os cinco sistemas do VSM.

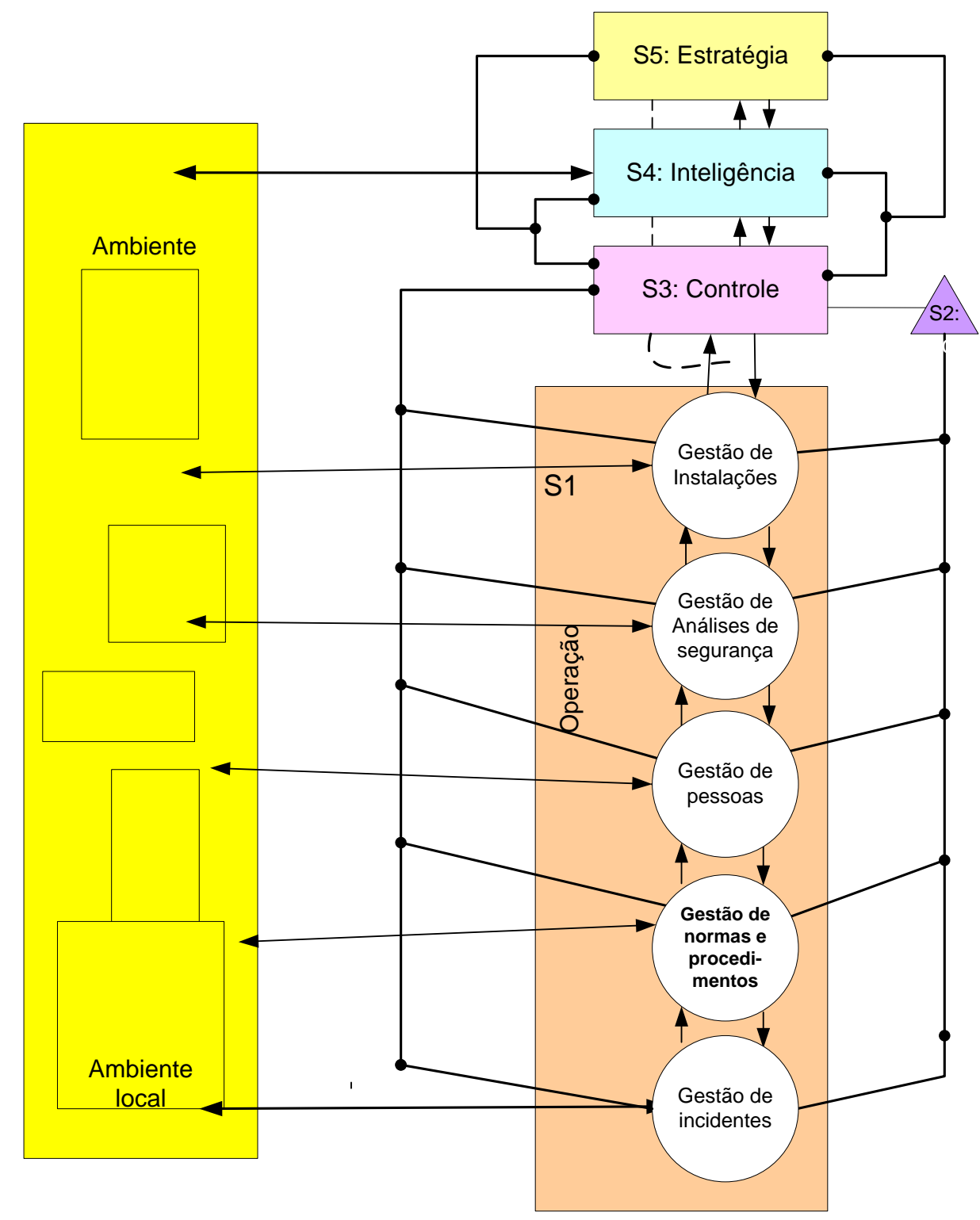

Figura 32 - Segundo cenário - SI de incidentes nucleares visto como um sistema viável

\subsubsection{Descrição constitutiva das partes do SI de incidentes}

A descrição constitutiva com relação aos sistemas de nível superior, paralelos e inferior é a mesma do primeiro cenário, uma vez que o sistema de interesse é o mesmo. 
A sua descrição é detalhada a seguir a partir dos seus objetivos e identificação das unidades operacionais.

\subsubsection{Objetivos do SI de incidentes}

Armazenar todos os incidentes nucleares ocorridos na instalação;

Prover informações para evitar novos acidentes ou orientar mitigações;

Prover insumos para entidades reguladoras estabelecerem diretrizes; e

Identificar vulnerabilidades e periculosidades nos sistemas em paralelo e em nível superior ao do sistema de interesse.

\subsubsection{Definição de incidentes no contexto deste trabalho}

Incidentes são todos os eventos indesejáveis à segurança. Isto engloba acidentes, quase-acidentes, atos e condições inseguras.

Acidente é um desvio inesperado e significativo das condições normais de operação de uma instalação que possa resultar em danos à propriedade ou ao meio ambiente ou em exposições de trabalhadores ou de indivíduos do público acima dos limites de dose estabelecidos pela CNEM.

Quase-acidente são aquelas situações relativamente freqüentes e que poderiam ter gerado um acidente sob circunstâncias levemente diferentes.

\subsubsection{Unidades operacionais identificadas}

\section{Gestão de instalações}

Esta unidade organizacional é responsável por manter:

Cadastros de materiais críticos, ou seja, materiais que podem causar incidentes nucleares utilizados nas instalações de uma maneira geral. Neste cadastro é importante ser registradas também a referência da norma que rege sobre segurança deste material, e a referência dos procedimentos em caso de incidentes. $O$ modelo de dados é um artefato que será detalhado na fase do projeto lógico no ciclo de 
desenvolvimento de software. No presente trabalho não é de interesse detalhá-lo.

Cadastros das quantidades de materiais críticos em cada instalação.

Cadastro dos equipamentos críticos por instalação.

Cadastro de pessoas que trabalham em cada instalação.

\section{Gestão de análise de segurança}

Esta unidade organizacional é responsável por classificar as análises de segurança, isto é, sistematizar os dados de cada análise de segurança. O objetivo é possibilitar verificações de possíveis melhorias das condições de segurança, através de lições aprendidas com a análise dos incidentes.

A responsabilidade da elaboração das análises de segurança é do sistema "Engenharia de análise de segurança", um sistema paralelo ao sistema de interesse. As análises de segurança são constituídas análises de cenários pré-estabelecidos considerados potencialmente perigosos. Também são identificados os equipamentos críticos além de ser realizada uma análise dos riscos.

\section{Gestão de pessoas}

Esta unidade organizacional além de ser responsável pelo cadastro de dados pessoais dos trabalhadores, também é responsável pelo controle da execução dos procedimentos exigidos pelas normas de segurança em trabalhadores que são sujeitos a exposição de rotina. Um exemplo são os tipos de exames de saúde periódicos e a sua freqüência.

Neste contexto, trabalhador Sujeito a Radiações ou simplesmente trabalhador é a pessoa que, em conseqüência do seu trabalho a serviço da instalação, possa vir a receber, por ano, doses superiores aos limites para indivíduos do público, estabelecidos na Norma CNEM-NE-3.01.

Indivíduos do Público refere-se a qualquer membro da população não exposto à radiação ocupacionalmente, inclusive trabalhadores, estudantes e estagiários quando ausentes das áreas da instalação. 
O termo "exposição de Rotina" é a exposição de trabalhadores em condições normais de trabalho.

\section{Gestão de normas e procedimentos}

Esta unidade organizacional é responsável por armazenar as normas e procedimentos relativos à radioproteção e segurança nuclear. Além disto, é responsável por classificar as normas e procedimentos de segurança, isto é, sistematizar os dados de cada norma ou procedimento de segurança. O objetivo é possibilitar verificações quantitativas na avaliação dos incidentes no que diz respeito a trabalhadores, indivíduos do público e contaminação do meio ambiente por exemplo.

O termo meio ambiente externo ou simplesmente meio ambiente, neste contexto, é referente a qualquer área, não pertencente à instalação, as quais indivíduos do público têm acesso irrestrito.

\section{Gestão de incidentes}

Esta unidade organizacional é responsável por registrar os dados dos incidentes, classificados de acordo com estudos pré-estabelecidos para facilitar a sua análise. Também é responsável por gerar relatórios padronizados para entidades reguladoras.

É objeto de registro a causa do incidente, a contaminação de trabalhadores ou indivíduos do público, bem como do meio ambiente no caso de existir.

As conseqüências, as ações recomendadas também devem ser registradas. É importante registrar quando e como as ações recomendadas foram executadas. Todos os incidentes devem ter classificação de "acidente", ou "quase-acidente".

\subsubsection{Descrição funcional: Interface entre as unidades operacionais e o sistema imediatamente superior}

Sistema imediatamente superior às unidades operacionais é o sistema de gestão de 
radioproteção e da segurança (safety) relativa à saúde humana e ambiental. Sua função é desenvolver e coordenar as atividades de radioproteção, segurança nuclear, monitoração ambiental e de segurança industrial.

O quadro 11 identifica os fluxos de informação entre o SIN e o Sistema de Radioproteção e Segurança (SRG).

\begin{tabular}{|l|l|}
\hline Fluxo informação SIN $\rightarrow$ SRS & Fluxo informação SRG $\rightarrow$ SIN \\
\hline $\begin{array}{l}\text { Informações sobre incidentes onde os limites } \\
\text { estabelecidos por norma foram alcançados ou } \\
\text { ultrapassados }\end{array}$ & Solicitação de relatórios de incidentes \\
\hline $\begin{array}{l}\text { Relatório para a CNEN padronizado sobre o } \\
\text { incidente }\end{array}$ & $\begin{array}{l}\text { Dados metereológicos no momento de } \\
\text { incidente caso seja relevante para o evento }\end{array}$ \\
\hline $\begin{array}{l}\text { Possíveis pontos de mitigação de futuros } \\
\text { incidentes }\end{array}$ & \\
\hline
\end{tabular}

Quadro 11 - Interface entre o SIN e o Sistema de radioproteção e segurança (SRG)

O quadro 12 identifica os fluxos de informação entre o Sistema de gestão de instalação (GInst) e o Sistema de Radioproteção e Segurança (SRG).

\begin{tabular}{|l|l|}
\hline Fluxo informação Glnst $\rightarrow$ SRS & Fluxo informação SRG $\rightarrow$ GInst \\
\hline Informações sobre as instalações & $\begin{array}{l}\text { Solicitações de informação sobre as } \\
\text { instalações }\end{array}$ \\
\hline
\end{tabular}

\section{Quadro 12 - Interface entre o Ginst e o SRG}

O quadro 13 identifica os fluxos de informação entre o Sistema de Gestão de análise de Segurança (SGAS) e o Sistema de Radioproteção e Segurança (SRG).

\begin{tabular}{|l|l|}
\hline Fluxo informação SGAS $\rightarrow$ SGR & Fluxo informação SGR $\rightarrow$ SGAS \\
\hline $\begin{array}{l}\text { Possíveis pontos de mitigação de futuros } \\
\text { incidentes }\end{array}$ & $\begin{array}{l}\text { Cenários de incidentes postulados na análise } \\
\text { de risco / probabilística de segurança / } \\
\text { análise de confiabilidade }\end{array}$ \\
\hline
\end{tabular}

Quadro 13 - Interface entre o SGAS e o SGR

O quadro 14 identifica os fluxos de informação entre o Sistema de Gestão de pessoas (SGP) e o Sistema de gestão de Radioproteção e segurança (SGR) 


\begin{tabular}{|l|l|}
\hline Fluxo informação SP $\rightarrow$ SGR & Fluxo informação SGR $\rightarrow$ SP \\
\hline $\begin{array}{l}\text { Informações sobre pessoas sob o aspecto da } \\
\text { Radioproteção }\end{array}$ & $\begin{array}{l}\text { Informações de pessoas sob o ponto de vista } \\
\text { cadastral }\end{array}$ \\
\hline & $\begin{array}{l}\text { Solicitação de informações sobre pessoas } \\
\text { sob o aspecto da Radioproteção }\end{array}$ \\
\hline
\end{tabular}

Quadro 14 - Interface entre o SGP e o SGR

\subsubsection{Descrição funcional: Interface entre as unidades operacionais}

O quadro 15 identifica os fluxos de informação entre o Sistema de Gestão de normas (GN) e as demais unidades organizacionais.

\begin{tabular}{|l|l|}
\hline Fluxo informação GN $\rightarrow$ outras & Fluxo informação outras $\rightarrow$ GN \\
\hline $\begin{array}{l}\text { Informações sobre padrões estabelecidos } \\
\text { pelas normas e procedimentos }\end{array}$ & Normas e procedimentos classificados \\
\hline
\end{tabular}

Quadro 15 - Interface entre o GN e as outras unidades organizacionais

O quadro 16 identifica os fluxos de informação entre o SIN e as demais unidades organizacionais.

\begin{tabular}{|l|l|}
\hline Fluxo informação SIN $\rightarrow$ outras & Fluxo informação outras $\rightarrow$ SIN \\
\hline Solicitação informações instalações & Ginst -> Dados sobre as instalações \\
\hline Solicitação informações Pessoas & GP $->$ Dados sobre as pessoas \\
\hline Solicitação informações Normas e & GN $->$ Dados sobre as Normas e \\
procedimentos & Procedimentos \\
\hline $\begin{array}{l}\text { GI -> GP: Normas a cumprir devido a } \\
\text { acidentes, registro de doses. }\end{array}$ & \\
\hline
\end{tabular}

Quadro 16 - Interface entre o SIN e as outras unidades organizacionais 


\subsection{Correlação de níveis do sistema de interesse e o VSM}

Os Quadros 17 a 21, representam os cenários definidos no modelo para este estudo de caso, correlacionados através dos cinco sistemas do VSM, que são tratados como S-1 a S-5.

\subsubsection{Aplicação do VSM - Nível 1:}

\begin{tabular}{|c|c|c|}
\hline \multirow[b]{2}{*}{ Cenários } & Primeiro cenário & Segundo cenário \\
\hline & $\begin{array}{l}\text { SI de incidentes } \\
\text { nucleares contido no } \\
\text { Sistema de gestão } \\
\text { de radioproteção e } \\
\text { da segurança }\end{array}$ & $\begin{array}{l}\text { Possível estruturação do } \\
\text { pensamento de um } \\
\text { engenheiro de software na } \\
\text { definição da arquitetura de } \\
\text { um SI que se enquadre em } \\
\text { um sistema viável }\end{array}$ \\
\hline $\begin{array}{l}\text { S-1 do VSM: } \\
\text { Operação } \\
\text { As unidades } \\
\text { organizacionais } \\
\text { correspondem a } \\
\text { partes da } \\
\text { organização } \\
\text { destinada à } \\
\text { execução das } \\
\text { tarefas para a qual é } \\
\text { constituída. } \\
\text { Cada parte do S-1 é } \\
\text { autônoma no que } \\
\text { lhe diz respeito, e } \\
\text { assim, interage com } \\
\text { o seu ambiente } \\
\text { local. Ela pode e } \\
\text { deve assumir a } \\
\text { variedade } \\
\text { encontrada no seu } \\
\text { ambiente. } \\
\text { Cada unidade de um } \\
\text { sistema viável } \\
\text { possui todas as } \\
\text { características de } \\
\text { qualquer sistema } \\
\text { viável. }\end{array}$ & $\begin{array}{l}\text { Identificação das } \\
\text { partes do Sistema de } \\
\text { gestão de } \\
\text { radioproteção e da } \\
\text { segurança } \\
\text { destinadas à } \\
\text { execução das tarefas } \\
\text { para a qual o } \\
\text { sistema é } \\
\text { constituído. } \\
\text { Com este } \\
\text { procedimento são } \\
\text { identificados os } \\
\text { sistemas paralelos } \\
\text { ao Sistema de } \\
\text { Interesse e suas } \\
\text { interações com o } \\
\text { Sistema de } \\
\text { interesse. } \\
\text {. }\end{array}$ & $\begin{array}{l}\text { Levantamento dos } \\
\text { requisitos funcionais tanto } \\
\text { para atender às demandas } \\
\text { internas do sistema de } \\
\text { interesse, como para } \\
\text { atender às demandas das } \\
\text { interações com os sistemas } \\
\text { paralelos. } \\
\text { Assim são identificadas as } \\
\text { partes do Sistema de } \\
\text { interesse destinadas à } \\
\text { execução das tarefas para } \\
\text { a qual o sistema é } \\
\text { constituído. } \\
\text { Aqui são descritas as } \\
\text { premissas, as restrições e } \\
\text { o escopo do Sistema de } \\
\text { informação no que diz } \\
\text { respeito a requisitos } \\
\text { funcionais que serão } \\
\text { utilizadas no projeto. }\end{array}$ \\
\hline
\end{tabular}

Quadro 17 - Correlação dos cenários com S-1 do VSM

O nível 1 representa as unidades organizacionais que correspondem às partes da organização destinada à execução das tarefas para a qual é constituída. Sendo 
assim, este levantamento de requisitos se aproxima do levantamento tradicional onde o foco são os processos e suas interações. O esperado é uma especificação do projeto dos componentes de acordo com os Requisitos funcionais do Sistema de Informação.

Porém, neste caso foram identificadas as possíveis interações entre os sistemas paralelos. Desta forma, mesmo que estas informações não forem utilizadas

\subsubsection{Aplicação do VSM - Nível 2}

\begin{tabular}{|c|c|c|}
\hline & Primeiro cenário & Segundo cenário \\
\hline $\begin{array}{l}\text { Sistemas } \\
\text { do VSM }\end{array}$ & $\begin{array}{l}\text { SI de incidentes } \\
\text { nucleares contido no } \\
\text { Sistema de gestão de } \\
\text { radioproteção e da } \\
\text { segurança }\end{array}$ & $\begin{array}{l}\text { Possível estruturação do } \\
\text { pensamento de um } \\
\text { engenheiro de software na } \\
\text { definição da arquitetura de } \\
\text { um SI que se enquadre em } \\
\text { um sistema viável }\end{array}$ \\
\hline $\begin{array}{l}\text { S-2 do VSM: } \\
\text { Coordenação } \\
\text { É constituído pelas } \\
\text { regras e } \\
\text { regulamentos que } \\
\text { atuam nas unidades } \\
\text { do S-1. } \\
\text { Seu objetivo principal } \\
\text { é assegurar que os } \\
\text { vários elementos que } \\
\text { constituem o S-1, } \\
\text { sua coordenação e a } \\
\text { regulação própria } \\
\text { local, atuem em } \\
\text { harmonia. } \\
\text { É responsável pelo } \\
\text { controle das suas } \\
\text { oscilações e das } \\
\text { monitorações } \\
\text { esporádicas } \\
\text { efetivadas pelo S-3. }\end{array}$ & $\begin{array}{l}\text { Identificação das } \\
\text { regras e } \\
\text { regulamentos do } \\
\text { sistema de gestão de } \\
\text { radioproteção e da } \\
\text { segurança que atuam } \\
\text { sobre o sistema de } \\
\text { interesse (Sistema de } \\
\text { Informação de } \\
\text { incidentes - uma das } \\
\text { unidades } \\
\text { operacionais ) }\end{array}$ & $\begin{array}{l}\text { Identificação, no sistema de } \\
\text { interesse, quais são as } \\
\text { regras e regulamentos que } \\
\text { atuam nas suas unidades } \\
\text { operacionais. } \\
\text { De acordo com o } \\
\text { levantamento das regras e } \\
\text { regulamentos que atuam } \\
\text { nas unidades operacionais, } \\
\text { estabelecer critérios de } \\
\text { intensa classificação na } \\
\text { entrada de dados para } \\
\text { facilitar outros } \\
\text { processamentos; } \\
\\
\text { São avaliadas as } \\
\text { metodologias, as teorias e } \\
\text { as técnicas para descrição } \\
\text { e armazenamento de } \\
\text { dados, especificação de } \\
\text { equipamentos e infra- } \\
\text { estrutura, ferramentas para } \\
\text { o desenvolvimento do Sl. }\end{array}$ \\
\hline
\end{tabular}


Projeto de componentes que classifiquem as entradas e assim facilitem a harmonia do funcionamento dos componentes que implementam os requisitos funcionais respeitando as regras que atuam sobre eles.

Projeto dos componentes que armazenam as regras que atuam nas unidades operacionais.

Projeto de componentes que ao detectarem comportamentos pré-estabelecidos diferentes do esperado, acionem componentes capazes de gerar um novo comportamento dentro de padrões pré-estabelecidos.

Projeto de componentes que iniciem os componentes de auditoria.

\subsubsection{Aplicação do VSM - Nível 3}

\begin{tabular}{|c|c|c|}
\hline & Primeiro cenário & Segundo cenário \\
\hline $\begin{array}{c}\text { Sistemas } \\
\text { do VSM }\end{array}$ & $\begin{array}{l}\text { SI de incidentes } \\
\text { nucleares contido no } \\
\text { Sistema de gestão de } \\
\text { radioproteção e da } \\
\text { segurança }\end{array}$ & $\begin{array}{l}\text { Possível estruturação do } \\
\text { pensamento de um engenheiro de } \\
\text { software na definição da } \\
\text { arquitetura de um SI que se } \\
\text { enquadre em um sistema viável }\end{array}$ \\
\hline $\begin{array}{l}\text { S-3 do VSM: Controle e } \\
\text { Monitoria (Auditoria) } \\
\text { Controla a auto-organização e a } \\
\text { regulação do S-1. Assim } \\
\text { assegura o efetivo cumprimento } \\
\text { das políticas. } \\
\text { Controle: Intercalação de um } \\
\text { agente corretivo no fluxo do } \\
\text { processo de modo a balizar seu } \\
\text { comportamento para que se } \\
\text { processe dentro dos padrões pré- } \\
\text { determinados. } \\
\text { Um sistema controlado tem } \\
\text { ciência de si mesmo, isto é, é } \\
\text { ciente quando, ao reagir a um } \\
\text { estímulo, é capaz de } \\
\text { reconhecer a alteração em si } \\
\text { mesmo e alterar sua } \\
\text { representação.onitora o S-1 e o } \\
\text { S-2. }\end{array}$ & $\begin{array}{l}\text { Devem ser } \\
\text { especificadas neste } \\
\text { cenário quais são as } \\
\text { informações trocadas } \\
\text { entre o sistema de } \\
\text { interesse e o sistema } \\
\text { de gestão de } \\
\text { radioproteção e da } \\
\text { segurança que } \\
\text { devem ser garantidas } \\
\text { como confiáveis. }\end{array}$ & $\begin{array}{l}\text { Levantamento das funções } \\
\text { operacionais que possam } \\
\text { apresentar desvios que devam ser } \\
\text { corrigidos através de um agente } \\
\text { corretivo de fluxo para retornar aos } \\
\text { padrões pré-determinados. } \\
\text { Levantamento dos tipos de } \\
\text { variedades existentes no sistema } \\
\text { de interesse que possam ser } \\
\text { validados para garantir o } \\
\text { cumprimento das políticas } \\
\text { estabelecidas pelo S-5. } \\
\text { Definição das inspeções } \\
\text { necessárias, e freqüência de } \\
\text { realização. }\end{array}$ \\
\hline
\end{tabular}


Projeto de componentes que validem as variedades estabelecidas pelo S-5 para as funcionalidades do SI e reajam de acordo com o pré-determinado.

Projeto de componentes que auditem componentes pré-estabelecidos no sistema de interesse.

Projeto de componentes que registrem e apresentem os resultados das auditorias.

\subsubsection{Aplicação do VSM - Nível 4}

\begin{tabular}{|c|c|c|}
\hline \multirow{2}{*}{ Cenários } & Primeiro cenário & Segundo cenário \\
\hline & $\begin{array}{l}\text { SI de incidentes nucleares } \\
\text { contido no Sistema de } \\
\text { gestão de radioproteção e } \\
\text { da segurança }\end{array}$ & $\begin{array}{l}\text { Possível estruturação do } \\
\text { pensamento de um } \\
\text { engenheiro de software na } \\
\text { definição da arquitetura de } \\
\text { um SI que se enquadre } \\
\text { em um sistema viável }\end{array}$ \\
\hline $\begin{array}{l}\text { S-4 do VSM: Inteligência } \\
\text { Local onde as decisões superiores } \\
\text { são viabilizadas. } \\
\text { Neste sistema é o ponto na } \\
\text { organização onde é possível ter um } \\
\text { retrato do estado das informações } \\
\text { externas e internas. Com este } \\
\text { quadro abrangente permite } \\
\text { tentativas de possíveis previsões } \\
\text { acerca o seu estado futuro. } \\
\text { Possui duas tarefas principais: a } \\
\text { primeira, de fazer a troca de } \\
\text { informações entre o S-5 e os níveis } \\
\text { inferiores da organização; e a } \\
\text { segunda, capturar para a } \\
\text { organização, toda a informação } \\
\text { relevante acerca do ambiente. } \\
\text { Aqui se posicionam as atividades } \\
\text { como planejamento, pesquisa de } \\
\text { mercado, pesquisa operacional, } \\
\text { pesquisa e desenvolvimento e } \\
\text { relações com algum sistema maior. }\end{array}$ & $\begin{array}{l}\text { Levantamento dos } \\
\text { protocolos de ação } \\
\text { referentes a: } \\
\text { pessoas (rotinas, } \\
\text { procedimentos, treinamento, } \\
\text { etc); } \\
\text { equipamentos e instalações } \\
\text { (manuais de operação e } \\
\text { manutenção, normas, etc); } \\
\text { organização } \\
\text { (regulamentação, normas, } \\
\text { legislação, etc), e } \\
\text { informação: (classificação, } \\
\text { intercâmbio de informação: } \\
\text { enquadramento segundo } \\
\text { regras de intercomunicação } \\
\text { eficazes). }\end{array}$ & $\begin{array}{l}\text { Decisões superiores são } \\
\text { entendidas aqui como as } \\
\text { políticas que determinam } \\
\text { o propósito do sistema, } \\
\text { além de intervenções que } \\
\text { o S-5 possa incorporar } \\
\text { como regras devidas } \\
\text { mudança de estratégia. } \\
\text { Assim, a partir do } \\
\text { conhecimento das } \\
\text { políticas atuais e } \\
\text { possíveis intervenções do } \\
\text { S-5 são projetados } \\
\text { componentes do SI de } \\
\text { interface com o ambiente } \\
\text { externo, contemplando } \\
\text { inclusive as suas } \\
\text { necessidades de } \\
\text { customização. } \\
\text { Além disto, é necessário } \\
\text { reunir as informações } \\
\text { relevantes para o } \\
\text { sistema de interesse e } \\
\text { prover mecanismos que } \\
\text { possibilitem a troca de } \\
\text { informação entre seus } \\
\text { diversos componentes. }\end{array}$ \\
\hline
\end{tabular}

Quadro 20 - Correlação dos cenários com S-4 do VSM

Projeto dos componentes de interface entre o $\mathrm{SI}$ e o ambiente externo. (Inclui 
projeto de componentes destinados à aquisição de dados obtidos por monitoração).

Encaminhamento das informações externas para o sistema de interesse. Pode ser para armazenamento ou para outros componentes que irão tratá-los.

Projeto de componentes que possuam características de Polimorfismo, ou seja, capazes de identificar pelo tipo de entrada diferentes comportamentos a serem seguidos.

Projeto dos componentes de encaminhamento de informações entre os componentes internos do SI.

Projeto de componentes de armazenamento de dados.

Projeto de componentes para módulo de $\mathrm{Bl}$ que possibilitem a extração de informações para o ambiente externo ou para tomadas de decisão pelo S-5. 


\subsubsection{Aplicação do VSM - Nível 5}

\begin{tabular}{|c|c|c|}
\hline Cenários & $\begin{array}{l}\text { Primeiro } \\
\text { cenário }\end{array}$ & Segundo cenário \\
\hline $\begin{array}{c}\text { Sistemas } \\
\text { do VSM }\end{array}$ & $\begin{array}{l}\text { SI de incidentes } \\
\text { nucleares } \\
\text { contido no } \\
\text { Sistema de } \\
\text { gestão de } \\
\text { radioproteção e } \\
\text { da segurança }\end{array}$ & $\begin{array}{l}\text { Possível estruturação do pensamento } \\
\text { de um engenheiro de software na } \\
\text { definição da arquitetura de um SI que } \\
\text { se enquadre em um sistema viável }\end{array}$ \\
\hline $\begin{array}{l}\text { S-5 do VSM: Estratégia } \\
\text { Determina os propósitos } \\
\text { do sistema. É o } \\
\text { responsável pela política. } \\
\text { A sua principal função é } \\
\text { fazer o balanceamento } \\
\text { das demandas internas e } \\
\text { externas (as vezes } \\
\text { antagônicas) que se } \\
\text { apresentam nos S-3 e S- } \\
4 . \\
\text { Este sistema também } \\
\text { representa as qualidades } \\
\text { essenciais do sistema } \\
\text { todo, para um sistema } \\
\text { mais amplo do qual é } \\
\text { parte integrante. } \\
\text { Através do conhecimento } \\
\text { do "estado" do ambiente } \\
\text { externo e das unidades } \\
\text { operacionais (S-1), este } \\
\text { sistema definine as } \\
\text { políticas internas do } \\
\text { sistema. } \\
\text { Deve ser capaz de prover } \\
\text { respostas para tomadas } \\
\text { de decisão que não } \\
\text { puderam ser tratadas } \\
\text { pelos S-1, } \\
\text { S-2, S-3 e S-4. }\end{array}$ & $\begin{array}{l}\text { Identificação do } \\
\text { propósito do } \\
\text { sistema de } \\
\text { gestão de } \\
\text { radioproteção e } \\
\text { da segurança. } \\
\\
\text { Levantamento } \\
\text { das ações que } \\
\text { ocorrem nas } \\
\text { fronteiras entre o } \\
\text { sistema de } \\
\text { interesse e os } \\
\text { sistemas } \\
\text { paralelos e o } \\
\text { sistema no nível } \\
\text { superior. } \\
\text { Além disto, é } \\
\text { importante } \\
\text { levantar } \\
\text { informações } \\
\text { sobre o } \\
\text { ambiente físico } \\
\text { como medição } \\
\text { por } \\
\text { instrumentos. }\end{array}$ & $\begin{array}{l}\text { Identificação do propósito do sistema } \\
\text { de informação de incidentes. } \\
\text { Identificação dos tipos de variações } \\
\text { externas que passam influenciar no } \\
\text { sistema de interesse. } \\
\text { Conhecer as interações com as } \\
\text { entidades reguladoras, interações } \\
\text { entre pessoas e sistema de interesse } \\
\text { com relação à cultura organizacional. } \\
\text { Além disto, é importante levantar } \\
\text { informações sobre o ambiente físico } \\
\text { como medição por instrumentos. } \\
\text { Esta atividade corresponde à fase de } \\
\text { levantamento e análise de requisitos } \\
\text { do sistema de informação referente às } \\
\text { ações que ocorrem nas fronteiras entre } \\
\text { o sistema de interesse, sistemas } \\
\text { paralelos e sistema no nível superior. } \\
\text { Assim, é necessário considerar no } \\
\text { projeto do SI, além dos requisitos } \\
\text { funcionais para a atividade fim, } \\
\text { requisitos que definam mecanismos } \\
\text { que permitam uma intervenção no } \\
\text { sistema que possam alterar a } \\
\text { variedade caso necessário. } \\
\text { No caso de um SI pode representar } \\
\text { mudanças de limites, alteração de } \\
\text { formatos de entradas e saídas, } \\
\text { emissões de alerta, comunicação } \\
\text { interna ou externa. }\end{array}$ \\
\hline
\end{tabular}

Quadro 21 - Correlação dos cenários com S-5 do VSM

Projeto de componentes que permitam a customização do sistema de interesse, ou seja, componentes que permitam a Parametrização que definam as políticas do sistema de interesse bem como viabilizem o equilíbrio da variedade do SI. 


\section{RESULTADOS}

O trabalho verifica a aplicabilidade do VSM no projeto de uma arquitetura de um SI voltado à área naval nuclear. A estratégia desta pesquisa baseia-se em uma revisão bibliográfica e correspondente avaliação da potencialidade de aplicação do VSM ao projeto de $\mathrm{SI}$, em comparação a modelos clássicos, com vistas à viabilidade organizacional. A aplicação do VSM no estudo de caso do SIN leva a um melhor entendimento da conjuntura em que está inserido, com relação ao que é praticado com os modelos usuais, isto levando a um projeto mais eficaz e eficiente quanto ao atendimento de requisitos e restrições.

A pesquisa bibliográfica realizada mostra o VSM como uma ferramenta de gestão organizacional, que possui um conjunto de funcionalidades, e que permite à organização uma maior flexibilidade e adaptabilidade. Não foram encontrados na Literatura informações referentes à aplicação do VSM na definição de uma arquitetura de um SI; até onde se identifica, tal aplicação aqui realizada é inovadora.

Desta forma, o estudo de caso é desenvolvido de uma maneira exploratória, baseado em elementos teóricos do VSM e de modelagem de arquitetura de SI, visando avaliar a aplicação do VSM na elaboração de uma modelagem alternativa de arquitetura do SIN mais próxima da realidade e das necessidades da organização.

O desenvolvimento da modelagem da arquitetura do SIN utiliza instrumentos tradicionais como entrevistas com usuários e levantamento documental e, ao mesmo tempo, explora o uso do VSM como instrumento adicional. O enfoque durante toda a elaboração é levar em consideração as propriedades dos sistemas viáveis e as cinco funcionalidades do VSM que se relacionam homeostaticamente entre si e também com o ambiente.

O expediente de adoção do princípio da recursividade como instrumento de identificação do foco e de um cenário de a consideração de um contexto para o SIN, representado no VSM por um nível imediatamente superior, mostra-se eficaz, pois estabelece claramente os limites do SIN e suas interações com o ambiente. 
É relevante o fato de que se tenha identificado a conveniência da aplicação do VSM, segundo a proposta aqui desenvolvida, na fase inicial do projeto. Nesta fase, a correta identificação dos limites, do contexto onde o SIN está inserido dos sistemas que interagem com o sistema de interesse e dos fluxos de informação entre eles contribuem para o aumento da qualidade e da eficiência da arquitetura, diminuindo o risco do retrabalho.

Esta abordagem foi determinante para dar suporte à modelagem alternativa e ao relacionamento das cinco funcionalidades de VSM (S1 a S5) com os elementos do SIN. Os resultados são descritos abaixo.

O S1 representa as unidades organizacionais que correspondem às partes da organização destinadas à execução das tarefas para a qual são constituídas. O SIN corresponde a uma unidade organizacional destinada ao registro de incidentes nucleares. Ele possui suas próprias relações com o ambiente externo e pode interagir com as outras unidades organizacionais. O SIN tem seu próprio gerenciamento e é autônomo no que lhe diz respeito, e assim, interage com o seu ambiente local.

Como o S1 trata da execução de tarefas, ou seja, a parte operacional do SIN, os elementos encontrados se confundem com a modelagem tradicional. em que o foco é o entendimento dos processos e suas interações. O esperado é uma especificação dos componentes de acordo com os Requisitos funcionais do Sistema de Informação tal qual um modelo tradicional.

O S2 é constituído pelas regras e regulamentos que atuam nas unidades do S1 do SIN, ou seja, as unidades organizacionais "gestão de instalação", "gestão de análise de segurança", "gestão de pessoas", "gestão de normas e procedimentos" e "gestão de incidentes". O seu objetivo principal é assegurar que estas unidades organizacionais, sua coordenação e a regulação própria local atuem em harmonia. É também responsável pelo controle das suas oscilações e das monitorações esporádicas efetivadas pelo S3.

Esta visão distingue-se da visão original, onde as regras que atuam são levantadas junto com os requisitos funcionais executados no S1. A abordagem dada no estudo de caso engloba uma ampla pesquisa das normas e procedimentos que se aplicam 
às diversas unidades organizacionais. Com tal levantamento fica possível ter uma visão mais próxima da realidade sobre quais regras devem ser aplicadas. Um ponto forte desta abordagem é a verificação de todas as regras e procedimentos que devem atuar no SIN estarem sendo usadas no processo manual. Este é um ponto de melhoria agregado à modelagem e ao negócio com relação à abordagem tradicional.

Com esta abordagem fica ainda evidenciada a necessidade de maciça classificação dos dados, uma vez que normas e procedimentos são textuais. Assim estabelece-se um novo requisito, a saber, a classificação dos dados e seu registro, para ser possível a implementação das funcionalidades respeitando as regras que atuam sobre elas e dentro dos limites estabelecidos. Desta forma, funcionamento harmônico do sistema em seu contexto fica fortalecido.

A partir da classificação das regras, é possível projetar componentes que, ao serem detetados comportamentos pré-estabelecidos diferentes do esperado, acionem outros dispositivos capazes de gerar um novo comportamento dentro de padrões pré-estabelecidos. Este é mais um diferencial que agrega valor no produto.

De acordo com esta visão de modelagem, todo sistema deve passar por auditorias para garantir sua qualidade. O nível S2 é responsável por monitorar sua execução. Sob este enfoque, são especificados componentes que disparam outros dispositivos responsáveis pela auditoria. Neste modelo aqui proposto, os componentes de segurança são inseridos por obrigatoriedade, e assim elevam mais ainda a qualidade da especificação da arquitetura e do SIN.

O S3 tem a função de controlar a auto-organização e regulação das unidades organizacionais do SIN e de executar auditorias nas funcionalidades S1 e S2.

O resultado obtido através desta visão é o projeto de componentes que validam as variedades dos dados classificados de acordo com a especificação do S2, para que as funcionalidades das unidades organizacionais reajam de acordo com o prédeterminado. Apesar desta qualidade ser efetivada com uma modelagem de arquitetura de SI qualquer, espera-se, como conseqüência de S2, que, por suportar uma variedade mais próxima da realidade, este processo torne o SIN mais aderente às necessidades da organização. 
A exigência de ter auditorias registradas nos processos funcionais, seus resultados tornados explícitos, requer a especificação de componentes que auditem, registrem e apresentem os resultados, resultando em melhor definição e confiabilidade para a especificação da arquitetura e do SIN.

O S4 possui duas tarefas principais: a primeira, de fazer a troca de informações entre o S5 e os níveis inferiores da organização; a segunda, de capturar para a organização toda a informação relevante acerca do ambiente.

Para atender ao primeiro objetivo, os componentes de interface entre o SIN e o ambiente externo e seu encaminhamento são configurados, o que inclui o projeto de componentes destinados à aquisição de dados obtidos por monitoração. Este produto é esperado na modelagem tradicional. Porém, como um sistema viável deve ser adaptável e flexível, sua aplicação resulta no projeto de componentes que possuam características de polimorfismo e de componentes que possibilitem a extração de informações para o ambiente externo ou para tomadas de decisão pelo S5.

No nível S4 também são projetados os componentes de armazenamento de dados com capacidade evolutiva.

O S5 determina os propósitos do sistema. É o responsável pela política. A sua principal função é fazer o balanceamento das demandas internas e externas. Esta funcionalidade do VSM é determinante para a execução do projeto de componentes, os quais permitam a customização do SIN, ou seja, componentes que permitam a parametrização que leve às políticas do sistema de interesse, bem como viabilizem o equilíbrio da variedade do SI.

O nível S5 leva, para atendimento ao modelo do VSM, à especificação da arquitetura do SIN de forma flexível, por meio da parametrização de dados e funcionalidades, bem como adaptável, por meio do controle da variedade. 


\subsection{Visão geral dos resultados}

Os Quadros 22 e 23 apresentam um resumo dos resultados agrupados pelos níveis de funcionalidades do VSM e pela aplicação da recursividade.

Legenda:

Modelagem utilizando o VSM trouxe vantagens sobre as tradicionais

Modelagem utilizando o VSM não trouxe vantagens sobre as tradicionais

Modelagem utilizando o VSM pior do que as tradicionais

Alto valor agregado

Baixo valor agregado

\begin{tabular}{|c|c|c|}
\hline Nível VSM & $\begin{array}{l}\text { Resultado da } \\
\text { aplicação }\end{array}$ & Motivo \\
\hline S1 - operação & $\odot$ & $\begin{array}{l}\text { O resultado obtido é muito próximo do } \\
\text { resultado da modelagem tradicional. }\end{array}$ \\
\hline S2 - Coordenação & & $\begin{array}{l}\text { Visão mais aproximada da realidade com } \\
\text { relação às regras que atuam no sistema } \\
\text { Elementos projetados para gerar maior } \\
\text { harmonia no funcionamento do SIS. } \\
\text { Elementos projetados para prover auto- } \\
\text { regulação. } \\
\text { Melhoria da qualidade da especificação da } \\
\text { arquitetura e do SIS, por ser mandatória a } \\
\text { realização de processos de auditoria. }\end{array}$ \\
\hline $\begin{array}{l}\mathrm{S} 3-\text { Controle e } \\
\text { monitoria }\end{array}$ & $\dot{ن}$ & $\begin{array}{l}\text { Apesar de ser esperado o mesmo resultado } \\
\text { que seria obtido na análise tradicional, não há } \\
\text { a dependência de uma ação do arquiteto. } \\
\text { Com a aplicação do VSM na definição da } \\
\text { arquitetura, passa a ser garantido que os } \\
\text { elementos de auditoria sejam projetados. }\end{array}$ \\
\hline S4 - Inteligência & 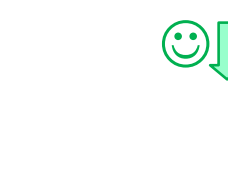 & $\begin{array}{l}\text { É esperado este resultado na definição } \\
\text { tradicional de arquitetura, entretanto com a } \\
\text { aplicação do VSM passa a ser cobrado um } \\
\text { sistema mais flexível e adaptável. }\end{array}$ \\
\hline S5 - Estratégia & $(\bullet$ & $\begin{array}{l}\text { É esperado este resultado na definição } \\
\text { tradicional de arquitetura, entretanto com a } \\
\text { aplicação do VSM passa a ser cobrado um } \\
\text { sistema mais flexível e adaptado. }\end{array}$ \\
\hline
\end{tabular}

Quadro 22 - Resumo dos resultados numa visão por funcionalidades do VSM 


\begin{tabular}{|l|l|l|}
\hline Conceito VSM & $\begin{array}{l}\text { Resultado da } \\
\text { aplicação }\end{array}$ & Motivo \\
\hline $\begin{array}{l}\text { Uso da recursividade } \\
\text { para estabelecer o } \\
\text { foco do sistema de } \\
\text { interesse }\end{array}$ & \multicolumn{1}{|c}{$\begin{array}{l}\text { O resultado obtido foi diferenciado uma vez } \\
\text { que naturalmente o limite foi estabelecido e em } \\
\text { uma fase inicial do projeto. }\end{array}$} \\
\hline $\begin{array}{l}\text { Uso da recursividade } \\
\text { para estabelecer os } \\
\text { cenários }\end{array}$ & $\begin{array}{l}\text { O resultado obtido foi construtivo uma vez que } \\
\text { permitiu um conhecimento do SIN e do } \\
\text { contexto que ele está inserido. }\end{array}$ \\
\hline
\end{tabular}

Quadro 23 - Resumo dos resultados numa visão por aplicação da recursividade 


\section{CONCLUSÕES}

O desafio deste trabalho é utilizar uma ferramenta concebida para aprimorar a gestão das organizações para ajudar a especificar a arquitetura de um SI. O objetivo é fortalecer a arquitetura do SI, incorporando o conjunto de funcionalidades especificadas pelo VSM.

Este contexto envolve um conhecimento interdisciplinar o que demandou uma extensiva pesquisa bibliográfica envolvendo as áreas de administração, tecnologia da informação, sistemas de informação e cibernética aplicada à administração. Como suporte também foi pesquisado metodologias científicas.

A escolha do sistema a testado foi decorrente de uma necessidade real identificada no projeto de pesquisa e desenvolvimento de tecnologia naval nuclear. Pelas características peculiares deste projeto, ele requer um alto nível de gestão de qualidade e de segurança nuclear que envolve segurança industrial, ambiental e normativa. Neste contexto, existia a necessidade de um SI de incidentes nucleares e a aplicação deste estudo aí se encontra.

O objetivo deste SI de incidentes é armazenar dados sobre incidentes ocorridos nas instalações do projeto, tornando-se uma importante fonte de conhecimento a ser aplicada na prevenção ou mitigação de novos incidentes.

As entidades reguladoras exigem relatórios padronizados sobre os incidentes nucleares ocorridos em instalações deste tipo e assim, também esta necessidade é suprida.

Para o SIN atingir seus objetivos, foi necessário o levantamento informal de subsídios de campo com engenheiros, físicos, técnicos. Além deste esforço, foi executada uma pesquisa documental do histórico dos incidentes, planos de emergência, procedimentos internos de segurança, materiais armazenados ou manipulados, instalações, análises de segurança, levantamento de normas e procedimentos. 
Como instrumento para identificar claramente o foco, ou seja, o sistema de interesse foi aplicado o conceito de recursividade onde foi traçado um esboço da organização entendida como sistemas aninhados sob o ponto de vista do sistema de interesse. Além disto, foi utilizado no modelo proposto o conceito de recursividade para escolher os dois cenários.

Através do estudo para a identificação dos sistemas de nível imediatamente superior, de nível imediatamente inferior e os de nível paralelo, foi possível um aprimoramento da identificação dos componentes pertencentes ao SI de incidentes.

A descrição constitutiva do sistema de interesse, dos sistemas paralelos e dos níveis imediatamente superior e inferior foi realizada. Por meio desta atividade, tanto o próprio sistema de interesse como o ambiente onde está inserido ficou melhor caracterizado.

O identificação e descrição constitutiva dos sistemas de nível imediatamente superior, de nível imediatamente inferior e de nível paralelo, permitem um mapeamento do fluxo de dados entre os sistemas.

O levantamento de requisitos apresentou situações onde são identificadas as variedades inerentes ao SI de incidentes. A definição da arquitetura prevê mecanismos de polimorfismo, customização e parametrização e assim, além da implementação do conceito de variedade requerida, projeta um sistema adaptável.

Foram constatadas necessidades de elementos que funcionem como agentes corretivos do fluxo do processo. Este caso é explícito quando são detectadas situações de melhoria de segurança ou mitigação de riscos através da análise dos incidentes cadastrados.

A aplicação do modelo proposto mapeou os componentes de software nos cinco sistemas do VSM permitindo uma visualização da associação entre os elementos e o VSM.

O mapeamento realizado mostrou vantagens de se usar o VSM como instrumento adicional para a modelagem da arquitetura do SIN. Como demonstrado nos 
resultados, utilizadas as cinco funcionalidades do VSM como norte para a definição da arquitetura, obteve-se em quatro destas funcionalidades valores agregados na identificação de elementos da arquitetura e, em uma funcionalidade não se obteve um valor agregado visível. Em nenhum caso foi verificado uma situação pior do que na especificação da arquitetura tradicional.

Diante dos resultados obtidos, verificou-se a aplicabilidade do Modelo do Sistema Viável (VSM - Viable System Model) no projeto da arquitetura de um SI voltado à área naval nuclear. 


\section{REFERÊNCIAS BIBLIOGRÁFICAS}

ALLENA, L. (1999). A Viable System Model:Consideration of Knowledge Management . Journal of Knowledge Management Practice .

ANSOFF, H. (1993). Implantando a administração estratégica. São Paulo: Atlas.

ASHBY, W. R. (1970). Uma introdução à Cibernética. São Paulo, SP, Brasil: PERSPECTIVA.

BASIL, D., \& COOK, C. (1974). The management of change. New York:: McGrawHill.

BASS, L., \& CLEMENTS, P. (1998). Software architecture in practice. (s. HOMEM, Ed.) Addison-Wesley.

BATTAGLIA, M. D. (1999). A Inteligência Competitiva modelando o Sistema de Informação de Clientes - Finep. Ciência da Informação , 28 (2).

BECHLER, R. (2002). Stafford Beer: the man who could have run the world. Acesso em outubro de 2007, disponível em www.openDemocracy.net

BEER, S. (1994). Brain of the firm (2a ed.). Chichester: John Wiley.

BEER, S. (1969). Cibernética e administração industrial. (E. Rottenberg, Trad.) Rio de Janeiro, RJ, Brasil: Zahar Editores.

BEER, S. (1996). Diagnosing the System for Organizations (8 Edição ed.). Baffins Lane, Chichester, England: Jonh Wiley \& Sons Ltd.

BEER, S. (1995). The Heart of Enterprise (4 edição ed.). Baffins Lane, Chichester, England: John Wiley \& Sons. 
BERTALANFFY, L. V. (1975). Teoria geral dos sistemas (2 ed.). Petrópolis: Vozes.

BOH, W. B., YELLIN, D., DILL, B., \& HERBSLEB, J. (jANEIRO de 1994). EFFECTIVELY MANAGING INFORMATION SYSTEMS ARCHITECTURE STANDARDS:AN INTRA-ORGANIZATION PERSPECTIVE. Information \& Management , 26, pp. 1-11.

BOH, W. F., YELLIN, D., DILL, B., \& HERBSLEB, J. D. (2003). Effectively Managing Information Systems Architecture Standards: An Intra-Organization Perspective. (J. L. Lyytinen, Ed.) in Proceedings of the Workshop on Standard Making: A Critical Research Frontier for Information, pp. 171-187.

BORGES, M. G. (set/dez de 2000). A compreensão da sociedade da informação. Ci. Inf. , 29, pp. 25-32.

BRITO, M. J. (1996). Tecnologia da Informação e Mercado Futuro - O caso da BM\&F. São Paulo.

CAPRA, F. (1996). A Teia da Vida - Uma Nova Compreensão Científica dos Sistemas Vivos. São Paulo: Cultrix/Amana-key.

CERVO, A. L., \& BERVIAN, P. A. (1996). Metodologia científica (4a Edição ed.). São Paulo: Makron Books.

ch. (1999). Journal Cybernetics \& Human Knowing, Vol.6, no.3, . 6, pp. 91-95. CHIAVENATO, I. (2004). Introdução à teoria geral da Administração. Rio de Janeiro, RJ, Brasil: Elsevier.

COOPER, D. R., \& SCHINDLEN, P. S. (2002). Métodos de Pesquisa em Administração (7a ed.). Bookman.

CORNING, P. A. (1996). Synergy, Cybernetics, and the Evolution of Politics. Journal INTERNATIONAL POLITICAL SCIENCE REVIEW, 17.

CURVELLO, J. J. (1996). Caos e ordem na cena organizacional. Anais do III 
Congresso Internacional Latino-Americano de Semiótica . São Paulo.

DANIELS, J., \& DANIELS, N. (1996). Visão global. São Paulo: Makron Books. DAVENPORT, T. H., \& SHORT, J. E. (1990). The new industrial engineering: information technology and business process redesign. Sloan Management Review , 31 (4), pp. 11-27.

DIAS, T. (1998). Modelo de sistemas viáveis em organizações públicas. BELO hORIZONTE.

DRUCKER, P. (1997). Introdução: Rumo à nova organização. A Organização do futuro: como preparar hoje as empresas de amanhã. São Paulo: Futura.

EARL, M. J. (1981). Strategies for information Technology. Grã-Bretanha: Prentice Hall.

ENSSLIN, L., SOUZA, E., SPÍNDOLA F., A., \& FERREIRA, M. (1996). O uso Estratégico da Tecnologia da informação. Angra dos Reis: Anais 20. ENANPAD.

ESPEJO, R. (2000, Aug). Giving Requisite Variety to Strategic and Implementation Process:Theory and Practice.

ESPEJO, R. The viable System Model.

Espejo, R. (2003). The viable System Model - A briefing about organisational structure.

ESPEJO, R. (2003). The Viable System model - A briefing about organiztional structure. (SYNCHO Limited) Retrieved OCT 12, 2007, from www.syncho.com: http://www.syncho.com/pages/pdf2.php

ESPEJO, R. (1994, February). What is Systemic thinking? 10 (2-3), pp. 199-212.

ESPEJO, R., \& GILL, A. (1997). The viable System Model as a Framework for Understanding Organizations. 
FAIRLEY, R. (1987). Software Engineering Concepts. New York: McGraw-Hil.

FERNADES, L. A., \& GOMES, J. M. (2003). Relatórios de pesquisa nas ciências sociais: características e modalidades de investigação. Contexto (4).

Fernandes, A. M. (2005). Inteligência artificial - noções gerais (2 ed.). Florianópolis: VisualBooks.

Florentino, A. M. (1988). Auditoria contábil (5 ed.). Rio de Janeiro: FGV. Fowler, M., Beck, k., Brant, J., Opdyke, W., \& Roberts, D. (1999). Refactoring improving the design of existing code.

FOX, C., \& FRAKES, W. (junho de 1997). The quality approach is it delivering? Communication of theACM , $40,25-52$.

Freeman, P. W. (1980). The context of design. Software Design Techniques , pp. 24.

Furlan, J. (1991). Como elaborar e implementar Planejamento estratégico de SI. São Paulo.

GIL, A. C. (1991). Como elaborar projetos de pesquisa (3a Edição ed.). São Paulo: Atlas.

Grosshans, W., \& Chelimsky, E. (Nov de 1990). Case study evaluations. Program evaluation and methodology division, 91.10.1.9.

HERRING, C. (2001, Dezembro). Adaptable and Adaptive Systems:The Intelligent Control Paradigm for Software Architecture. Working Conference on Complex and Dynamic Systems .

HERRING, C., \& KAPLAN, S. (1998). Cybernetic Components: A Theoretical Basis for Component Software Systems . Component Oriented Software Engineering Workshop (COSE'98). Adelaide, Austrália. 
HERRING, C., \& Kaplan, S. (2000). The Viable System Model for Software. in 4th World Multiconference on Systemics, Cybernetics and Informatics (SCl'2000) . Orlando, Florida.

HERRING, C., \& Kaplan, S. (s.d.). Viable Components: A Cybernetic Organization for Computing. Queensland.

HERRING, C., \& KAPLAN, S. (1999). Viable Components: A Cybernetic Organization for Computing , in . 1999. , Australia. International Conference on Technology of Object-Oriented Languages and Systems, TOOLS Pacific: 2nd Australian Workshop on Software Architectures. Melbourne.

HERRING, C., \& KAPLN, S. (October de 2000). Component-based Software Systems for Smart Environments. pp. 6-8.

HERRING, C., \& KAPLN, S. (2001). Groove: A Case Study in Adaptive Architecture . 5th World Multiconference on Systemics, Cybernetics and Informatics (SCl'2001) . Orlando, Florida.

HERRMANN, D. S. (1999). Software safety and reliability. Los Alamitos, California: IEEE Computer society.

IM-AGIMB. (2004). teoria do controle. (Instituto Virtual de Excelência - o Instituto do Milênio "Avanço Global e Integrado da Matemática Brasileira) Acesso em 17 de novembro de 2007, disponível em Instituto do Milênio "Avanço Global e Integrado da Matemática Brasileira: http://milenio.impa.br/pt/2004/relcontrol-pt.pdf

JANTZEN, L. C. ( March-April de 2001). Taking Charge of Technology. Journal Military Review, 81, pp. 65-71.

KATZ, D., \& KAHN, R. (1987). Psicologia das organizações (3a Edição ed.). São Paulo: Atlas.

KOCHAN, T., \& USEM, M. (1992). Transforming organizations. New York: Oxford 
University Press.

KOVACHEVA, T. (2005). Viable model of the enterprise - A cybernetic approach for implementing the information technologies in management. 13, pp. 337-340.

KOVACHEVA, T. (2005). Viable model of the enterprise - A cybernetic approach for implementing the information technologies in management. 13, pp. 337-340.

W. R. (2000). Tecnologia de Informação - O uso de TI pelas empresas que obtêm vantagem competitiva. São Paulo: Atlas.

GUIMARÃES, L. (2003). Gerenciamento de riscos e segurança de sistemas. São Paulo: leditora.

GUIMARÃES, L. S. (1999). Síntese de doutrina de segurança para projeto e operação de submarinos NUCLEARES. São Paulo: Tese de Mestrado - USP.

LAKATUS, E. M., \& MARCONI, M. A. (2001). Metodologia do trabalho científico: procedimentos básicos, pesquisa bibliográfica, projeto e relatório, publicações e trabalhos científicos (5a Edição ed.). São Paulo: Atlas.

LAUDON, K. C., \& LAUDON, J. P. (2002). Management information Systems (7 edição ed.). Upper Saddler River, New jersey: Prentice Hall.

LEVESON, N. G. (1995). Safeware - System Safety and Computers (5 ed.). Washington: Addison-Wesley.

MADUREIRA, C., \& RODRIGUES, M. (2006). A Administração Pública do século XXI: Aprendizagem organizacional, mudança comportamental e reforma administrativa. Revista Comportamento Organizacional e Gestão , 12 (2), pp. 153171.

MINDELL, D., SEGAL, J., \& GEROVITCH, S. (2003). Cybernetics and Information Theory in the United States, France and the Soviet Union. (M. Walker, Ed.) Science 
and Ideology: A Comparative History, 66-95.

MULLER, P.-A. (1997). Instant UML. Parir: Wrox Press.

NBR ISO/IEC 17799. (2001). Tenologia da informação: código de prática para gestão da segurança da informação. Rio de Janeiro.

ORTOLANI, L. F. (1997). Produtividade da tecnologia da informação: evidência e indicadores da administração pública no Paraná. São Paulo.

PACHECO, R. C., \& TAIT, T. F. (maio de 2000). Tecnologia de informação:evolução e aplicações. Teor. Evid. Econ , 8, n. 14, pp. 97-113.

PORTER, M. (1999). Competição: Estratégias Competitivas Essencias. Rio de Janeiro: Campus.

POZZEBON, M., FREITAS, H. M., \& PETRINI, M. (1997). Pela integração da inteligência competitiva nos Enterprise Information Systems (EIS). 26 (No 3).

PRESSMAN, R. S. (2002). Engenharia de Software. Rio de Janeiro: McGraw-Hill.

PROJECT MANAGEMENT INSTITUTE. (2000). PMBOK Guide. Newtown Square: Project Management Institute, Inc.

RAPOPORT, A., \& HOVARTH, W. (1976). Aspectos Matemáticos da Análise Geral dos Sistemas. Getúlio Vargas.

RASKIN, S. (1997). Uma arquitetura de tecnologia de informação. Bahia. REINHARD, N. (1996). Evolução das ênfases gerenciais e de pesquisa na área de tecnologia de informática e de telecomunicações aplicada nas empresas. RAUSPRevista de Administração , 31, pp. 5-6.

REINHARD, N., \& ZWICKER, R. (1993). Informatização no Governo Federal. RAUSP-Revista de Administração, 28. 
SANTOS, A. F., \& PAIM, I. (Jan de 2000). A informação nos modelos organizacionais. Revista Perspectivas em ciências da Informação , 5 (n. 1), pp. 9-21.

SCHEIN, E. H. (1982). Psicologia Organizacional (3a edição ed.). Rio de Janeiro: Prentice Hall.

SCHWANINGER, M. (2005). System Dynamics and the Evolution of the Systems Movement - A Historical Perspective. 52.

SCHWANINGER, M. (Jul/Set de 1998). Vencendo a complexidade: Um conceito de Fitness Organizacional. RAE - Revista de Administração de Empresas , 38 (3), pp. 6-15.

SEMOLA, M. (2003). Gestão da segurança da informação: uma visão executiva. Rio de Janeiro: Campus.

SENGE, P. M. (1990). A quinta disciplina. Arte, teoria e prática da organização de aprendizagem. (4 ed.). São Paulo: Best Seller.

SERVA, M. (Abr/Jun de 1992). O Paradigma da complexidade e a análise organizacional. RAE - Revista de Administração de Empresas , 32 (2), pp. 26-35.

SHANNON, C. (1948, July, October). A Mathematical Theory of Communication. The Bell System Technical Journal , 27, pp. 379-423, 623-656.

SHANNON, C. (1949, oct). Communication Theory of Secrecy Systems. Bell System technical Journal , 28, pp. 656-715.

SHAW, M. (1995). Beyond objects: A software design paradigm based on process control. ACM Software Engineering Notes .

Tait, T. F. (2000). Um Modelo de Arquitetura de Sistemas de Sistemas para o setor público: estudo em empresas estatais prestadoras de serviço de Informática. 
Florianópolis.

TAIT, T., BARCIA, R., \& PACHECO, R. (2001). Modelo de arquitetura de sistemas de informação para integrar aspéctos técnicos e organizacionais nos sistemas de informação. Proposição de um Modelo de Arquitetura de Sistemas de Informação para o Setor Público , 23, 1449-1458. Maringá: Acta Scientiarum.

VASCONCELOS, I., MASCARENHAS, A. O., \& VASCONCELOS, F. C. (Jul/Dez de 2004). Paradoxos organizacionais, gestão de pessoas e tecnologia na Souza Cruz. Revista Administração de Empresas , 3 (no 2).

VENKATRAMAN, N. (1994). IT-Enabled Business Transformation: From Automation to Business Scope Redefinition. Sloan Management Review , 35 (2), pp. 73-87.

VERGARA, S. C. (2007). Projetos e relatórios de pesquisa em administração (9a Edição ed.). São Paulo: Atlas.

VERGARA, S. C. (2004). Resenha - Métodos de pesquisa em administração. Revista eletônica de Gestão organizacional , 2 (2).

WALKER, J. (2001). The Viable Systems Model Pack. SMSE Strategic Management in the Social Economy training programme with the financial assistance of Directorate General XXIII of the Commission of the European Communities . Inglaterra.

WOOD JR., T. (1997). Mais leve que o ar: gestão empresarial na era de gurus, curandeiros e modismos gerenciais. São Paulo: Atlas.

YIN, R. K. (2005). Estudo de caso. (Artmed, Ed., \& D. Grassi, Trad.) São Paulo: Bookmam.

ZACHMAN, J. (1987). A framework for Information Systems Architecture. IBM System Journal , 26, pp. 276-285.

ZANELA, A. C., MACADAR, M. A., \& SOARES, R. O. (1999). Mudança organizacional provocada pela utilização de sistemas integrados de gestão 
empresarial: uma proposta de estudo. Anais do 23ํㅡㄹ 